\title{
A NOVEL MEMBRANE REACTOR FOR DIRECT HYDROGEN PRODUCTION FROM COAL
}

\author{
Final Technical Report
}

Reporting Period Start Date: 9/9/2003

Reporting Period End Date: 9/30/2005

\author{
Principal Authors: \\ Shain Doong \\ Estela Ong \\ Mike Atroshenko \\ Francis Lau \\ and Mike Roberts
}

Date Report Issued: 1/20/2006

DOE Award Number: DE-FC26-03NT41851

\section{Submitting Organization:}

Gas Technology Institute

1700 South Mount Prospect Road

Des Plaines, IL 60018 


\section{DISCLAIMER}

This report was prepared as an account of work sponsored by an agency of the United States Government. Neither the United States Government nor any agency thereof, nor any of their employees, makes any warranty, express or implied, or assumes any legal liability or responsibility for the accuracy, completeness, or usefulness of any information, apparatus, product, or process disclosed, or represents that its use would not infringe privately owned rights. Reference herein to any specific commercial product, process, or service by trade name, trademark, manufacturer, or otherwise does not necessarily constitute or imply its endorsement, recommendation, or favoring by the United States Government or any agency thereof. The views and opinions of authors expressed herein do not necessarily state or reflect those of the United States Government or any agency thereof. 


\begin{abstract}
Gas Technology Institute has developed a novel concept of a membrane reactor closely coupled with a coal gasifier for direct extraction of hydrogen from coal-derived syngas. The objective of this project is to determine the technical and economic feasibility of this concept by screening, testing and identifying potential candidate membranes under the coal gasification conditions. The best performing membranes were selected for preliminary reactor design and cost estimate. The overall economics of hydrogen production from this new process was assessed and compared with conventional hydrogen production technologies from coal.
\end{abstract}

Several proton-conducting perovskite membranes based on the formulations of BCN $\left(\mathrm{BaCe}_{0.8} \mathrm{Nd}_{0.2} \mathrm{O}_{3-\mathrm{x}}\right)$, BCY $\left(\mathrm{BaCe}_{0.8} \mathrm{Y}_{0.2} \mathrm{O}_{3-\mathrm{x}}\right)$, SCE (Eu-doped $\left.\mathrm{SrCeO}_{3}\right)$ and SCTm $\left(\mathrm{SrCe}_{0.95} \mathrm{Tm}_{0.05} \mathrm{O}_{3}\right)$ were successfully tested in a new permeation unit at temperatures between 800 and $1040^{\circ} \mathrm{C}$ and pressures from 1 to 12 bars. The experimental data confirm that the hydrogen flux increases with increasing hydrogen partial pressure at the feed side. The highest hydrogen flux measured was $1.0 \mathrm{cc} / \mathrm{min} / \mathrm{cm}^{2}$ (STP) for the SCTm membrane at 3 bars and $1040^{\circ} \mathrm{C}$. The chemical stability of the perovskite membranes with respect to $\mathrm{CO}_{2}$ and $\mathrm{H}_{2} \mathrm{~S}$ can be improved by doping with $\mathrm{Zr}$, as demonstrated from the TGA (Thermal Gravimetric Analysis) tests in this project.

A conceptual design, using the measured hydrogen flux data and a modeling approach, for a 1000 tons-per-day (TPD) coal gasifier shows that a membrane module can be configured within a fluidized bed gasifier without a substantial increase of the gasifier dimensions. Flowsheet simulations show that the coal to hydrogen process employing the proposed membrane reactor concept can increase the hydrogen production efficiency by more than $50 \%$ compared to the conventional process. Preliminary economic analysis also shows a $30 \%$ cost reduction for the proposed membrane reactor process, assuming membrane materials meeting DOE's flux and cost target.

Although this study shows that a membrane module can be configured within a fluidized bed gasifier, placing the membrane module outside the gasifier in a closely coupled way in terms of temperature and pressure can still offer the same performance advantage. This could also avoid the complicated fluid dynamics and heat transfer issues when the membrane module is installed inside the gasifier.

Future work should be focused on improving the permeability and stability for the proton-conducting membranes, testing the membranes with real syngas from a gasifier and scaling up the membrane size. 


\section{TABLE OF CONTENTS}

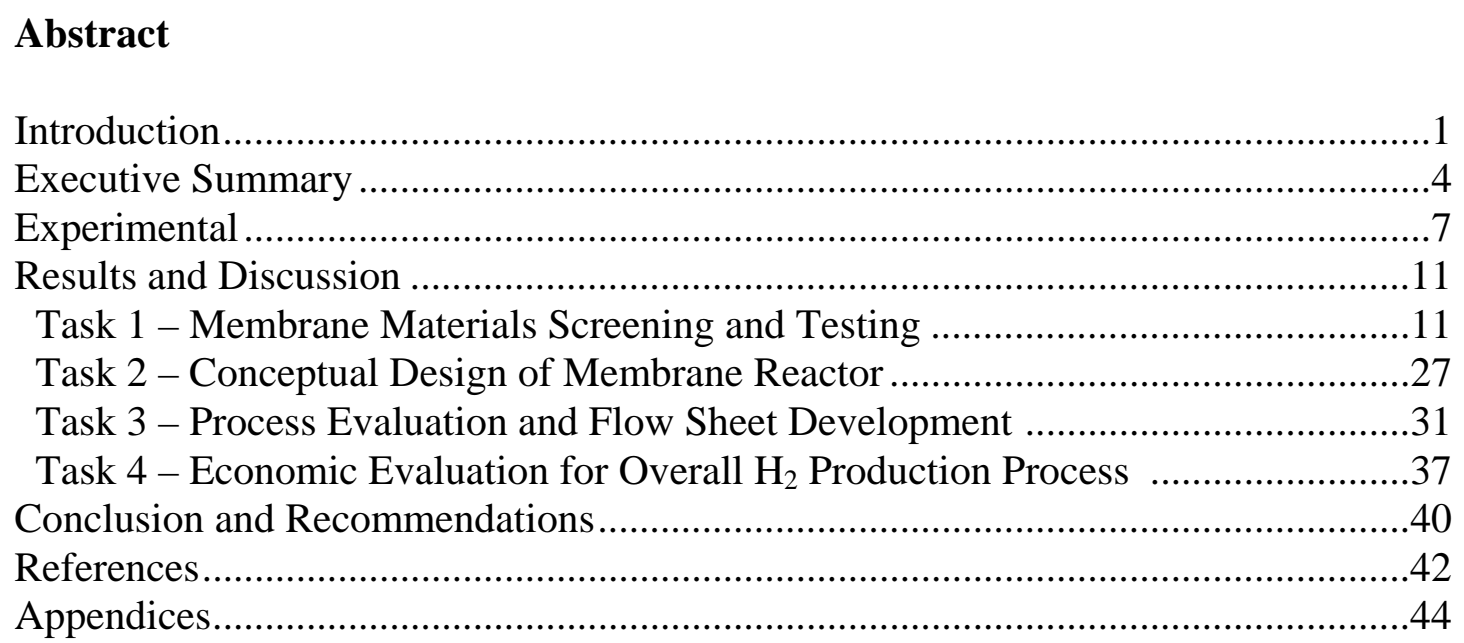




\section{LIST OF GRAPHICAL MATERIALS}

Figure 1. Hydrogen production from coal gasification based on the conventional gasifier and the novel membrane gasification reactor concept.......................2

Figure 2. A schematic showing the permeation cell of the high temperature/high pressure membrane permeation unit.....

Figure 3. Photo of high temperature/high pressure membrane permeation unit ...........8

Figure 4. Flow diagram for the high temperature/high pressure permeation unit .........9

Figure 5. Hydrogen flux measured from the high pressure permeation unit for the unsupported BCN membrane

Figure 6. Hydrogen flux measured from the high pressure permeation unit for the supported BCN membrane

Figure 7. Hydrogen permeation data for the unsupported BCN and the SCTm at different temperatures

Figure 8. Hydrogen permeation flux for SCE-10 membrane measured from high-pressure permeation unit

Figure 9. Hydrogen permeation flux for SCE-20 membrane measured from high-pressure permeation unit

Figure 10. Hydrogen flux for the SCTm membrane at different $\mathrm{H}_{2}$ partial pressures.15

Figure 11. Hydrogen permeation testing for the SCTm membrane at 1 bar with pure hydrogen in the feed and nitrogen sweep in the permeate side..16

Figure 12. Polished cross section of the tested SCTm membrane with the feed side at the top and the permeate side at the bottom

Figure 13. Two connecting areas for the feed side of the SCTm membrane magnified at 500X

Figure 14. 2000X Magnification of SCTm membrane near the feed side showing light colored grain boundaries under a slight back scattered mode.

Figure 15. EDX pattern of (a) the light colored region, and (b) the background region, from the SEM micrograph shown in Figure 14

Figure 16. Two connecting areas for the permeate side of the SCTm membrane 
magnified at $500 \mathrm{X}$

Figure 17. 2000X Magnification of SCTm membrane near the permeate side showing little presence of light colored areas......

Figure 18. EDS pattern of the bulk region near the permeate side. .21

Figure 19. Microstructure of the fresh SCTm membrane at magnification of 2000X 22

Figure 20. Thermo gravimetric results for the reaction of $\mathrm{CO}_{2}$ with $\mathrm{BCN}$ powder and disk

Figure 21. Thermo gravimetric results for the reaction of $\mathrm{H}_{2} \mathrm{~S}$ with $\mathrm{BCN}$ powder and disk

Figure 22. Thermo gravimetric results for the reaction of $\mathrm{CO}_{2}$ with Zr-doped BCZY, BCN and SCE membrane disks.

Figure 23. Dense membrane of $\mathrm{Zr}$ doped perovskite shows stronger resistance to $\mathrm{H}_{2} \mathrm{~S}$ than $\mathrm{BCN}$ membrane or powder 25

Figure 24. Comparison of simulation results with the literature data 26

Figure 25. Concentration profiles for the four defect species, proton, vacancy, electron and electron hole inside a SCY membrane

Figure 26. Schematic diagram of a tubular membrane module within a fluidized bed gasifier

Figure 27. Enlarged cross section of a membrane tube .28

Figure 28. Modeling of a tubular membrane reactor within a gasifier 29

Figure 29. Hydrogen flux and calculated ambipolar conductivity for the SCTm membrane 30

Figure 30. Comparison of Process Options for Hydrogen from Coal Gasification.....32

Figure 31. Block flow diagram for the coal to hydrogen process based on the conventional technologies, Process A

Figure 32. Block flow diagram for the coal to hydrogen process using a low temperature membrane shift reactor, Process B

Figure 33. Modeling of membrane shift reactor 
Figure 34. Block flow diagram for the coal to hydrogen process using a high temperature membrane reactor, Process C....................................................35

Figure 35. Block flow diagram for the coal to hydrogen process using a high temperature and a low temperature membrane reactors, Process D ............36

Figure 36. Roadmap for successful membrane reactor development ............................41 


\section{LIST OF TABLES}

Table 1 Equilibrium and diffusivity parameters used in the simulation.....................26

Table 2. Summary of design parameters for the conceptual membrane gasification

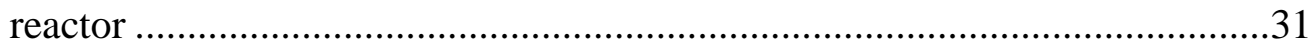

Table 3. Summary of performance for different coal to hydrogen processes...............37

Table 4. Itemized capital cost and corresponding equipment size ...........................38

Table 5. Summary of equipment size and capital cost for the four hydrogen production processes from coal gasification ............................................................39 


\section{INTRODUCTION}

As the US has begun the transformation process from a reliance on petroleum to the use of clean-burning hydrogen, hydrogen is expected to be the major energy carrier in the future hydrogen economy. With abundant coal reserve in the US, coal to hydrogen will play a crucial role as a source of hydrogen supply. However, the cost of hydrogen produced from coal is currently not competitive to hydrogen from natural gas. The US department of Energy has set a long-range goal to develop coal-based hydrogen systems that will be capable of producing hydrogen at 25 percent lower costs than current coalbased commercial systems by 2015 [1]. Production of low-cost hydrogen from coal will provide a reliable, domestic and cost-effective hydrogen source for fuel cell vehicles and other stationery fuel cell applications.

Gasification is a promising technology for the production of hydrogen from coal. Gasification combines coal, steam and oxygen to produce synthesis gas, mainly hydrogen and carbon monoxide. After cleaned of impurities such as sulfur or mercury, the synthesis gas is shifted using water-gas shift reactor technology to generate additional hydrogen and convert carbon monoxide to carbon dioxide. Hydrogen is subsequently separated from the gas stream, typically through the use of Pressure Swing Adsorption (PSA) technology. Currently no coal to hydrogen plant in the world today is configured to optimize hydrogen production. Gasification, shift reaction, and PSA operation are all relatively mature technologies. Continuing improving on these technologies may result in only incremental reduction in the overall cost of hydrogen from coal. To achieve significant reduction of costs, novel, advanced and breakthrough technologies must be developed.

One of the active research areas in reducing the hydrogen cost from coal gasification processes is the development of high temperature membranes that can be designed to separate hydrogen from the coal-derived syngas. This type of membrane system is primarily targeted as a membrane reactor at $250-500^{\circ} \mathrm{C}$ for the water-gas-shift reaction to convert the syngas to hydrogen. While pure hydrogen is generated directly from the membrane shift reactor, the remaining gas containing mostly $\mathrm{CO}_{2}$ and some $\mathrm{CO}$ and $\mathrm{H}_{2}$ is sent to a gas turbine to combust with oxygen for power generation. Recent studies performed by Parsons [2] and Mitretek [3] showed that the hydrogen plant employing this type of membrane system could achieve a significant reduction of hydrogen cost, compared with the conventional hydrogen plant for coal gasification.

GTI has developed a novel concept of a membrane reactor by incorporating a hydrogenselective membrane near or within a gasifier for direct extraction of hydrogen from the coal-derived syngas. As more than $50 \sim 60 \%$ of the final hydrogen product is generated in the gasification stage, there is great potential of maximizing hydrogen production by separating hydrogen directly from the gasifier. This concept has the potential of significantly increasing the efficiency of producing hydrogen and simplifying the processing steps by reducing/eliminating the downstream shift reactor, separation and purification operations for the conventional gasification technologies. Figure 1 shows a 
simplified process diagram for the novel membrane gasification reactor, in comparison with the conventional gasification process for hydrogen production from coal.

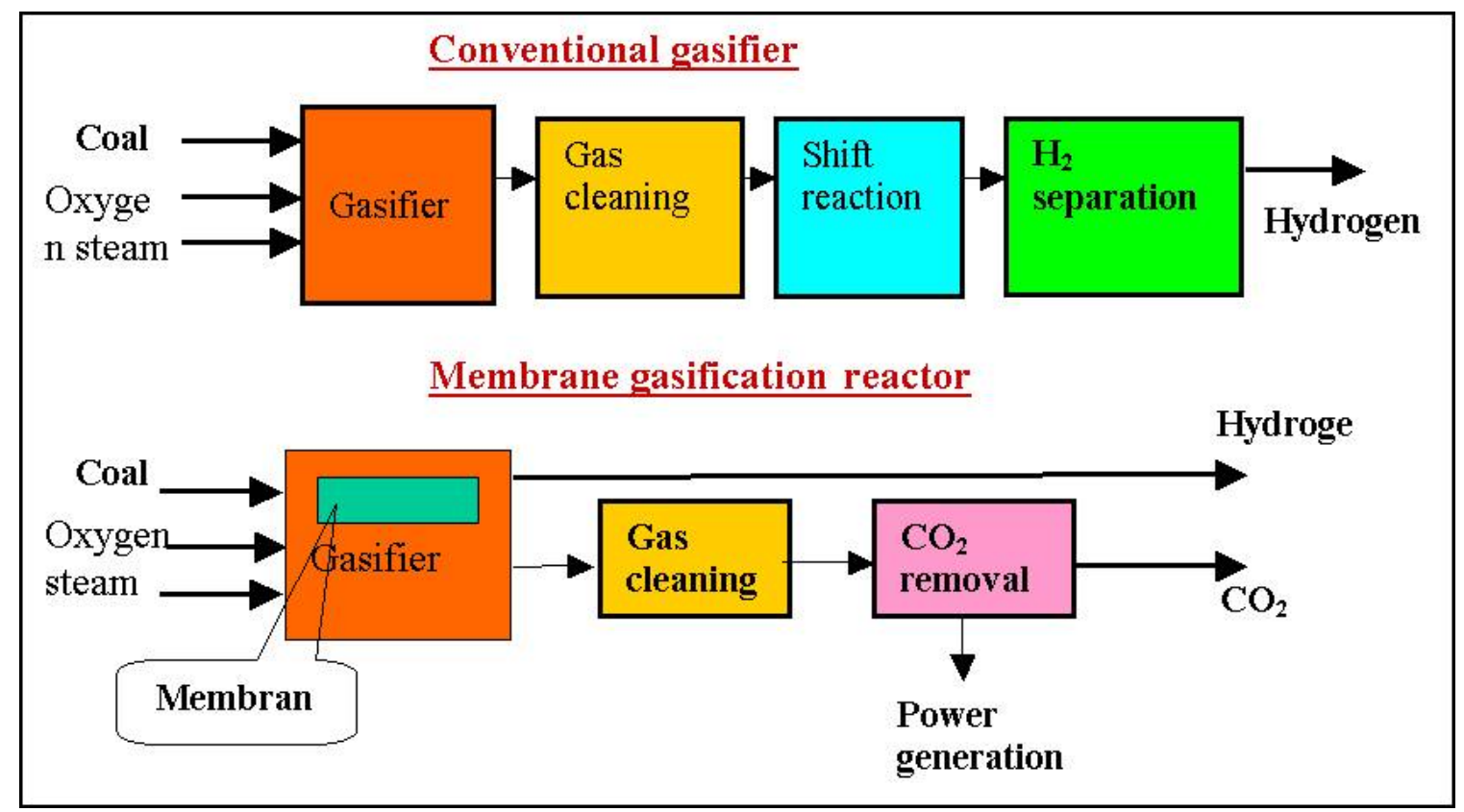

Figure 1. Hydrogen production from coal gasification based on the conventional gasifier and the novel membrane gasification reactor concept

Due to high temperature operation in the gasifier, only inorganic materials can be considered for this application. Dense ceramic membranes of perovskite type, which possess a unique property of conducting both proton and electron, represent one group of promising inorganic membranes for the use in the high temperature membrane reactors. Under a pressure gradient of hydrogen across the membrane, only hydrogen can permeate through it, resulting in a pure and clean hydrogen product. The perovskite membranes may not be suitable for low temperature $\left(<500^{\circ} \mathrm{C}\right)$ membrane shift reactor applications. The best working temperature range, $700 \sim 1200^{\circ} \mathrm{C}$ of this type of material is ideal for the membrane gasification reactor applications proposed in this project.

Under the sponsorships of DOE/NETL, Illinois Clean Coal Institute, and American Electric Power, a GTI-led team has been conducting the research to determine the technical and economic feasibility of this novel concept. The project team has screened, tested and identified several potential candidate membranes at the temperature and pressure conditions of coal gasification. In addition to experimental testing, a modeling approach was also used to examine the expected performances of the membrane gasification reactor for hydrogen production from coal. The best performing membranes were selected for preliminary reactor design and cost estimate. The feasibility of configuring a membrane module within a gasifier was investigated. Based on the performance of the membrane reactor, several hydrogen from coal gasification processes with and without the membrane reactors were developed and evaluated by flowsheet 
simulation. Economic analysis was also conducted for the different coal to hydrogen processes. The advantages of using the membrane reactors for the hydrogen from coal gasification processes were demonstrated in terms of the thermal efficiency of the process as well as the hydrogen product cost. The project includes the following four tasks:

\section{Task 1 - Membrane Materials Screening and Testing}

The objective of this task is to determine the hydrogen separation performance for selected membranes under the temperature and pressure conditions of coal gasification. This task involves design and construction of a high pressure permeation unit and testing of the candidate membranes.

\section{Task 2 - Conceptual Design of Membrane Reactor Membrane Reactor}

This task is to investigate how a membrane reactor can be configured with a coal gasifier. The conceptual design is based on the membrane testing results from Task 1 and a modeling approach.

\section{Task 3 - Process Evaluation and Flow Sheet Development}

The objective of this task is to compare the performances for several hydrogen from coal gasification processes with and without the membrane reactors. The advantages of using the membrane reactors in the hydrogen from coal gasification processes are demonstrated in terms of the hydrogen cold gas efficiency and the thermal efficiency.

\section{Task 4 - Economic Evaluation for Overall $\mathrm{H}_{2}$ Production Process}

The hydrogen costs from various process schemes incorporating the membrane reactor concept are compared with the current technologies from coal gasification without the use of the membranes. This task would demonstrate the ultimate benefit of the proposed membrane reactor concept. 


\section{EXECUTIVE SUMMARY}

The overall objective of this project is to develop a novel membrane reactor process for high efficiency, clean and low cost production of hydrogen from coal. The concept incorporates a hydrogen-selective membrane closely coupled with a gasification reactor for direct extraction of hydrogen from coal-derived syngas. As more than $50 \sim 60 \%$ of the final hydrogen product is generated in the gasification stage, there is great potential of maximizing hydrogen production by separating hydrogen directly from the gasifier. By configuring a hydrogen-selective membrane with a gasification reactor in a closely coupled way, both gasification reactions and hydrogen separation can be accomplished simultaneously. This concept has the potential of significantly increasing the thermal efficiency of producing hydrogen, simplifying the processing steps and reducing the cost of hydrogen production from coal. In addition, this concept can also reduce the cost of $\mathrm{CO}_{2}$ capture for the hydrogen from coal gasification processes.

Under the sponsorships of DOE/NETL, Illinois Clean Coal Institute, and American Electric Power, a GTI-led team has been conducting the research to determine the technical and economic feasibility of this novel concept. The project team has screened, tested and identified several potential candidate membranes at the temperature and pressure conditions of coal gasification. The best performing membranes were selected for preliminary reactor design and cost estimate. The overall economics of hydrogen production from this new process was assessed and compared with conventional hydrogen production technologies from coal. The project included the following four tasks:

\section{Task 1 - Membrane Materials Screening and Testing}

The objective of this task is to determine the hydrogen separation performance for selected membranes under the temperature and pressure conditions of coal gasification.

Due to high temperature operation in the gasifier, only inorganic materials can be considered for this application. Dense ceramic membranes of perovskite type, which possess a unique property of conducting both protons and electrons, represent one group of promising inorganic membranes for use in high temperature membrane reactors. Under a pressure gradient of hydrogen across the membrane, only hydrogen can permeate through it, resulting in a pure and clean hydrogen product.

To evaluate the performances of the candidate membranes at the gasification conditions, a high temperature/high pressure hydrogen permeation unit was constructed. The unit was designed to operate at temperatures up to $1100^{\circ} \mathrm{C}$ and pressures to 60 bars for evaluation of ceramic membranes such as mixed protonic-electronic conducting membrane.

Several proton-conducting perovskite membranes based on the formulations of BCN $\left(\mathrm{BaCe}_{0.8} \mathrm{Nd}_{0.2} \mathrm{O}_{3-\mathrm{x}}\right), \quad \mathrm{BCY} \quad\left(\mathrm{BaCe}_{0.8} \mathrm{Y}_{0.2} \mathrm{O}_{3-\mathrm{x}}\right)$, Eu-doped $\mathrm{SrCeO}_{3} \quad$ (SCE) and $\mathrm{SrCe}_{0.95} \mathrm{Tm}_{0.05} \mathrm{O}_{3}$ (SCTm) were successfully tested in a new permeation unit at 
temperatures between 800 and $1040^{\circ} \mathrm{C}$ and pressures from 1 to 12 bars. These membranes were made by either tape casting or uniaxial pressing methods. The experimental data confirm that the hydrogen flux increases with increasing hydrogen partial pressure at the feed side. The hydrogen flux, however, declines with increasing hydrogen pressure beyond about 6 bars, presumably due to the limited equilibrium solubility of hydrogen in the membrane. The highest hydrogen flux measured was $1.0 \mathrm{cc} / \mathrm{min} / \mathrm{cm}^{2}$ (STP) for the SCTm membrane at 3 bars and $1040^{\circ} \mathrm{C}$. The flux of the SCTm membrane appears to be adequate for the membrane module design.

The chemical stability of the perovskite membranes was also evaluated by testing the reactions of a $\mathrm{Zr}$-doped perovskite with respect to $\mathrm{CO}_{2}$ and $\mathrm{H}_{2} \mathrm{~S}$ in a TGA (Thermal Gravimetric Analysis) unit. The $\mathrm{Zr}$-doped perovskite showed better resistance to $\mathrm{CO}_{2}$ and $\mathrm{H}_{2} \mathrm{~S}$ than the BCN or SCE membrane.

\section{Task 2 - Conceptual Design of Membrane Reactor}

This task is to investigate how a membrane reactor can be configured with a coal gasifier. The conceptual design is based on the membrane testing results from Task 1 and a modeling approach.

A conceptual design of the membrane reactor configuration for a 1000 tons-per-day (TPD) coal gasifier was conducted. The design considered a tubular membrane module located within the freeboard area of a fluidized bed gasifier. The membrane ambipolar conductivity was based on the value calculated from the measured permeation data. A membrane thickness of 25 micron was assumed in the calculation. GTI's gasification model combined with a membrane reactor model was used to determine the dimensions of the membrane module. It appears that a membrane module can be configured within a fluidized bed gasifier without substantial increase of the gasifier dimensions.

\section{Task 3 - Process Evaluation and Flow Sheet Development}

The objective of this task is to compare the performances for several hydrogen from coal gasification processes with and without the membrane reactors.

The commercial flowsheet simulator HYSYS was used to calculate material and energy balances based on four hydrogen production processes from coal using high temperature membrane reactor $\left(1000^{\circ} \mathrm{C}\right)$, low temperature membrane reactor $\left(250^{\circ} \mathrm{C}\right)$, or conventional technologies. The results show that the coal to hydrogen process employing both the high temperature and the low temperature membrane reactors can increase the hydrogen production efficiency (cold gas efficiency) by more than $50 \%$ compared to the conventional process. Using either high temperature or low temperature membrane reactor processes also result in an increase of the cold gas efficiencies as well as the thermal efficiencies of the overall process.

Although this study shows that a membrane module can be configured within a fluidized bed gasifier, placing the membrane module outside the gasifier in a closely coupled way 
in terms of temperature and pressure can still offer the same performance advantage, according to the results of process simulation. This could also avoid the complicated fluid dynamics and heat transfer issues when the membrane module is installed inside the gasifier.

\section{Task 4 - Economic Evaluation for Overall $\mathrm{H}_{2}$ Production Process}

Based on the flowsheet results, a preliminary economic analysis was conducted to estimate the hydrogen product cost for various process schemes with and without the membrane reactor. Capital costs for process equipment were adopted from those reported in the literature. The membrane cost was assumed to meet the DOE's cost target of $\$ 100 / \mathrm{ft}^{2}$. The results show that the coal to hydrogen process employing both the high temperature and the low temperature membrane reactors can reduce the hydrogen cost by about $30 \%$ compared to the conventional process.

At a scoping level, the project demonstrated the technical feasibility and the economic benefit of the proposed membrane reactor concept for hydrogen production from coal gasification. However, significant technical challenges still need to be overcome in order for the technology to be successful. The following are recommendation for future work:

- Improve the hydrogen permeability by minimizing the membrane thickness and increasing the material conductivity.

- Improve the chemical and mechanical stability of the membrane materials.

- Conduct permeation testing with simulated syngas

- Conduct permeation testing with real syngas from a coal gasifier

- Scale up the size of the membrane disks. Samples as large as 1.25 " diameter disks have been routinely prepared in this program. Much bigger sizes will be needed for future commercial applications. 


\section{EXPERIMENTAL}

Our approach to membrane material screening and testing is to first identify the materials that have good thermal stability under the conditions of gasification temperatures. The candidate membranes were evaluated for their hydrogen flux in a laboratory permeation unit. The acquired data provided the basis for a preliminary membrane gasifier design, process development and economic analysis. In the next stage of material screening, chemical stability of the membranes with the syngas and its contaminants generated from coal gasification will be evaluated. The trade-off between the hydrogen permeability and chemical stability will be determined.

\section{$\underline{\text { Hydrogen Flux Measurement in High Pressure Permeation Unit }}$}

As coal gasification for hydrogen production occurs at temperatures above $900^{\circ} \mathrm{C}$ and pressures above 20 bars, it is critically important to evaluate the hydrogen flux of the candidate membrane materials under these operational conditions. To this end, a high pressure/high temperature permeation unit has been constructed. The unit is capable of operating at temperatures and pressures up to $1100^{\circ} \mathrm{C}$ and 60 bar respectively. The unit can allow screening and testing of the membrane materials at more realistic gasification temperature and pressure conditions. The permeation assembly consists of a permeation cell, a surrounding cylindrical heater, and an enclosing pressure vessel. A simplified schematic illustrating the concept of the permeation cell design is shown in Figure 2. The membrane to be tested, which is in a disc form of about $2 \mathrm{~cm}$ in diameter, is attached or cemented to a holding tube. A hydrogen gas flows through the upper inner tube and after in contact with the membrane, exits the system as a non-permeate gas diverted by an outer tube. An inert sweeping gas passing through the lower inner tube is used to sweep the hydrogen permeate from the membrane. Therefore, the pressures on both sides of the membrane can be adjusted to be equal, which would make the membrane sealing less difficult. A glass-based sealant material is used to seal the membrane along the edge of the metallic holding tube.

The inner tube, outer tube and the membrane holding tube are made of Inconel material for its good resistance to heat and easy machining and welding. The entire permeation cell assembly is heated by a cylindrical heater, which is enclosed in a pressure vessel purged with inert gas. Figure 3 is a photo of the new permeation unit.

Before testing the membranes in the high pressure unit, helium was introduced to the feed side of the membrane while nitrogen was used in the permeate side as a sweeping gas to check the leakage across the membrane or the sealing material. Absence of helium in the permeate stream indicated good quality of the membrane and the seal. Pure hydrogen or hydrogen/helium mixture was used in the feed with flow rates generally in the order of $1000 \mathrm{cc} / \mathrm{min}$. The flow rates of sweeping nitrogen varied from $80 \mathrm{cc} / \mathrm{min}$ to about 380 $\mathrm{cc} / \mathrm{min}$ to generate about $1 \%$ hydrogen compositions in the permeate stream. The data were obtained at pressures up to about 12 bar and temperatures to $950^{\circ} \mathrm{C}$. 


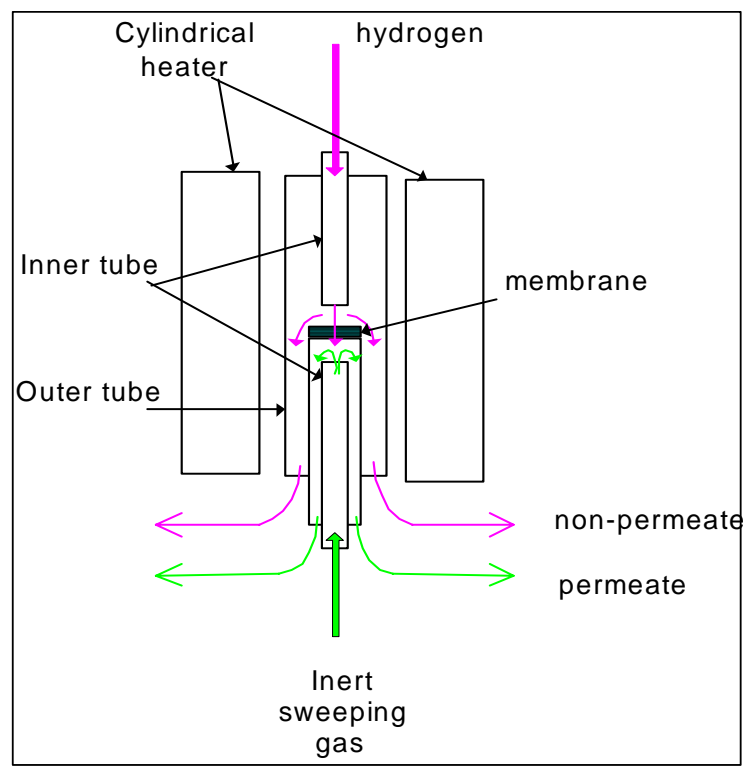

Figure 2. A schematic showing the permeation cell of the high temperature/high pressure membrane permeation unit

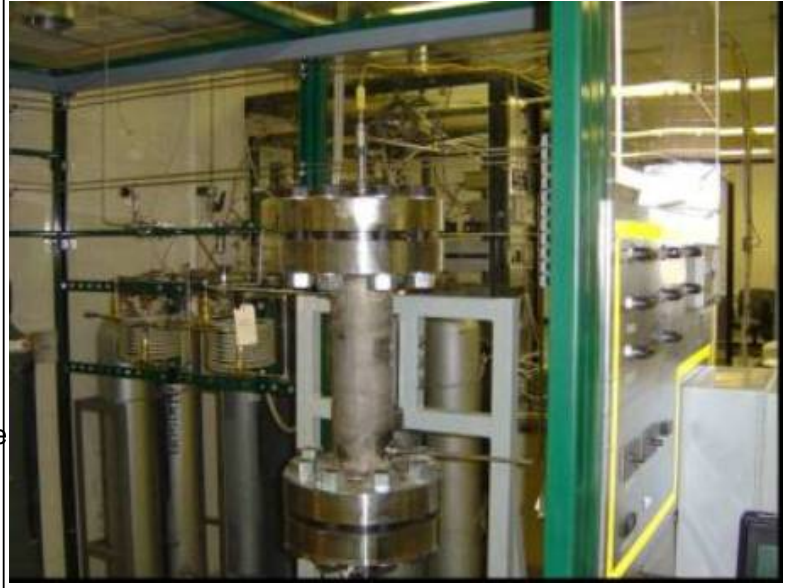

Figure 3. Photo of high temperature/high pressure membrane permeation unit

The entire flow diagram for the high temperature/high pressure permeation unit is shown in Figure 4. All gas flow rates were measured and controlled by the mass flow controllers from Brooks. Although there are three gas inlets into the vessel, feed, purge and sweep gases, all three gas streams eventually vent out of the system through a back pressure regulator, which controls the system pressure and maintains the same pressure for all the three gas streams. The hydrogen content of the permeate is analyzed by a by a HP 5890 gas chromatograph with a 30-m capillary column packed with molecular sieve 13X.

\section{$\underline{\text { Membrane Material Fabrication }}$}

\section{BCN Membrane}

Nd-doped $\mathrm{BaCeO}_{3}$ was selected as the candidate membrane for testing because $\mathrm{BCN}$ $\left(\mathrm{BaCe}_{0.9} \mathrm{Nd}_{0.1} \mathrm{O}_{3-\mathrm{x}}\right)$ was shown in the literature to be among the highest proton conductive materials of the perovskite [4]. The BCN powders, which were acquired from Praxair, possess the required high surface areas $\left(5-10 \mathrm{~m}^{2} / \mathrm{g}\right)$, purity, phase composition and the specified dopant level. Two BCN membranes, one unsupported and the other supported, were fabricated. The unsupported membranes ( $0.2 \mathrm{~mm}$ in thickness) was prepared by the tape casting method, followed by sintering at 1450 to $1550^{\circ} \mathrm{C}$ for $2 \sim 3$ hours. The supported membrane was prepared by a combination of the tape casting and the uniaxial pressing techniques. A thin $(0.25 \mathrm{~mm})$ membrane was first made by the tape casting process. Another thick ( 0.25 to $0.5 \mathrm{~mm}$ ) membrane tape with 20 volume percent of an organic pore former was then prepared as a membrane support. The two membrane tapes were pressed together to form a laminate. The laminate was then heated to $1450-1550^{\circ} \mathrm{C}$ to sinter and densify the thin membrane layer and create a porous support layer of about 
$0.33 \mathrm{~mm}$ with $31 \%$ porosity. The dense layer of the supported membrane sample was 0.2 $\mathrm{mm}$. Additional details about membrane fabrication can be avaiable in a previous project report sponsored by the Illinois Clean Coal Institute[5].

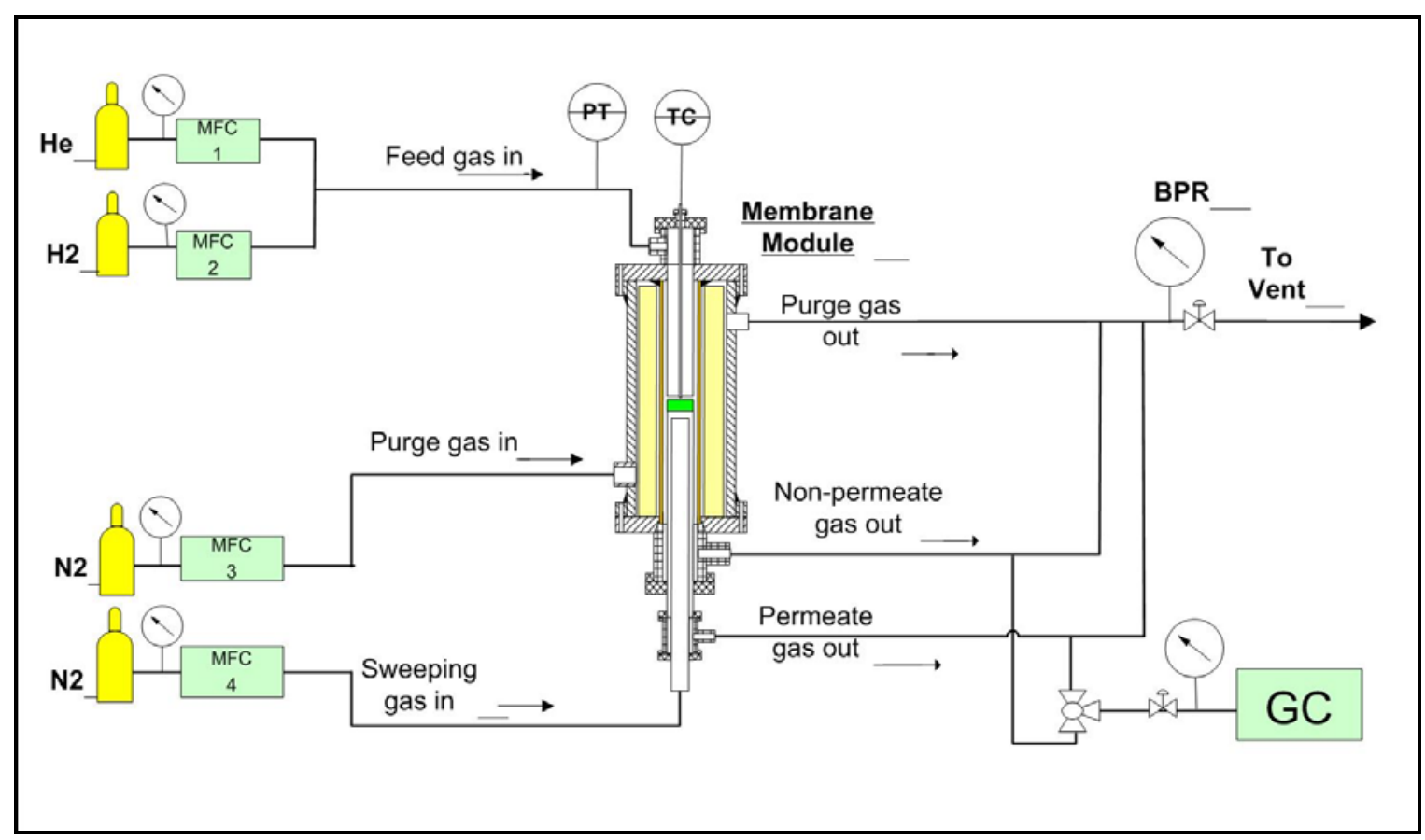

Figure 4. Flow diagram for the high temperature/high pressure permeation unit MFC: mass flow controller, PT: pressure transducer, TC: thermocouple BPR: back pressure regulator, GC: gas chromatograph

\section{SCE Membrane}

The SCE (Eu-doped $\mathrm{SrCeO}_{3}$ ) membranes were fabricated by the tape casting method using the powders supplied from the laboratory of Professor E. Wachsman of University of Florida. Two SCE membranes, one with 10\% Eu doping (SCE-10) and the other with 20\% Eu doping (SCE-20) were successfully made and tested in the high pressure permeation unit. The thickness of the membranes was about $0.3-0.4 \mathrm{~mm}$.

\section{SCTm membranes}

Three membrane disks of SCTm $\left(\mathrm{SrCe}_{0.95} \mathrm{Tm}_{0.05} \mathrm{O}_{3}\right)$ were prepared by the research group of Professor Jerry Lin of Arizona State University (formerly with University of Cincinnati). These are pressed membrane disks with a diameter of about $2 \mathrm{~cm}$ and a thickness of about $1.7 \mathrm{~mm}$. These disks have required perovskite structure for proton conduction based on XRD analysis. Two of the membrane samples were tested in the GTI’s high pressure permeation unit. 


\section{BCY membranes}

Y-doped $\mathrm{BaCeO}_{3}\left(\mathrm{BaCe}_{0.8} \mathrm{Y}_{0.2} \mathrm{O}_{3-\mathrm{x}}\right)$ was also fabricated into membrane disks similar to BCN, using the powders purchased from Praxair. Four supported BCY membranes and four unsupported ones were tested in the high pressure permeation unit. However, all BCY membranes except one did not pass the helium leak checking. The only BCY membrane that underwent hydrogen permeation testing did not show any detectable hydrogen flux. Therefore, no hydrogen flux will be reported for the BCN membrane. 


\title{
RESULTS AND DISCUSSION
}

\section{Task 1 - Membrane Materials Screening and Testing}

\author{
Hydrogen Permeation Data for Perovskite Membrane
}

\section{BCN membranes}

The hydrogen permeation testing results are shown in Figure 5 and 6 for the unsupported and the supported BCN membranes respectively. During the experiment, the dense layer of the supported membrane was facing the feed side and the porous support layer was on the permeate side. Despite the same thickness of the dense layer, the hydrogen fluxes for the unsupported membrane are slightly higher than the supported one probably due to the additional mass transfer resistance in the porous support layer. This is the first time that the hydrogen permeation data at high pressures ( $>1$ bar)for the mixed protonic-electronic conducting materials have been reported. Because of the higher operating pressures, the hydrogen flux generally is about one order of magnitude higher than those reported in the literature.

The hydrogen flux increases with the increasing hydrogen partial pressure in the feed and appears to reach a maximum at about 6 bar, after which the flux starts to drop. The pressure probably affects the hydrogen flux through two mechanisms: (1) providing the driving force of the permeation by the hydrogen partial pressure difference across the membrane and (2) affecting the conductivity by the different proton and electron concentrations or proton diffusivities inside the perovskite membrane due to the different hydrogen pressures. Further study looking into this peculiar phenomenon using a detailed membrane permeation model seems to indicate that the decreasing flux above 6 bars is due to the limitation that the hydrogen solubility within the membrane already reaches a maximum or saturation at a pressure above 6 bar [6].

Figure 6 also shows that the flux increases with the increasing hydrogen concentration in the feed side. This is simply due to the increasing hydrogen partial pressure difference across the membrane, which results in an increasing flux. The data were obtained at 7.8 bars with 20, 60 and 100\% hydrogen with balance of He in the feed side. 


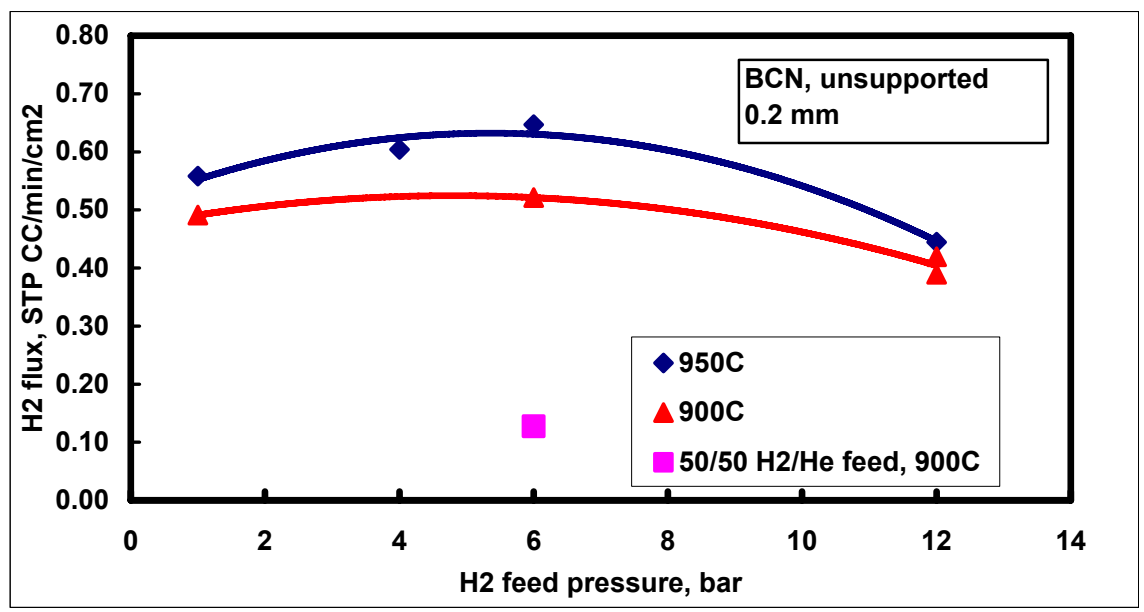

Figure 5. Hydrogen flux measured from the high pressure permeation unit for the unsupported BCN membrane

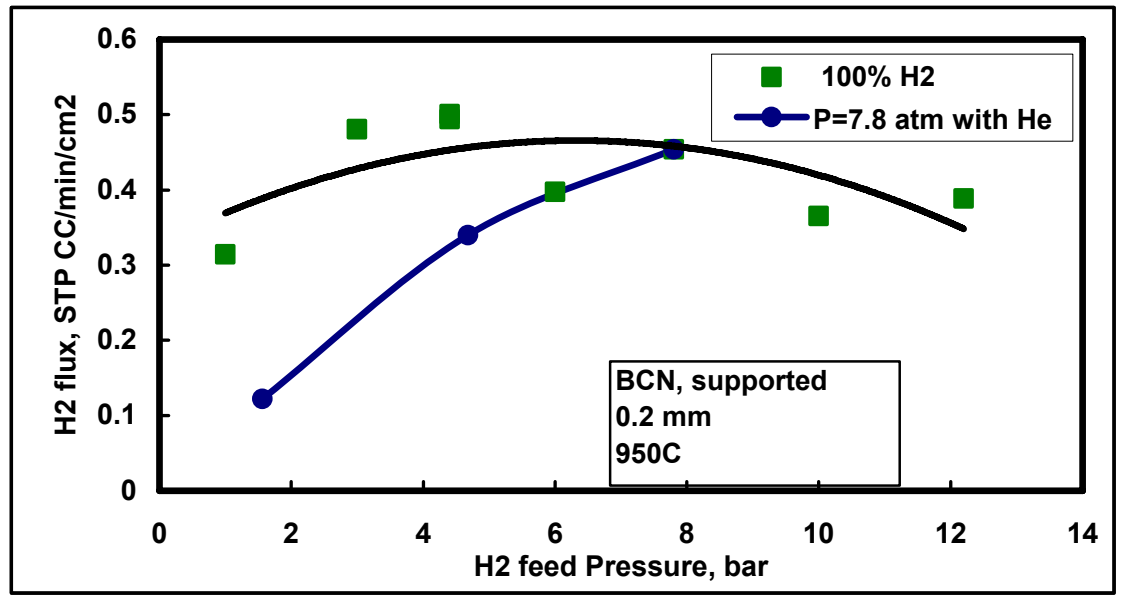

Figure 6. Hydrogen flux measured from the high pressure permeation unit for the supported BCN membrane

As expected, the hydrogen flux increases with the increasing temperature as shown in Figure 7 for the unsupported BCN membrane. The calculated activation energy is about $11.8 \mathrm{Kcal} / \mathrm{mole}$. Activation energy of $12 \mathrm{Kcal} / \mathrm{mole}$ for the proton conductivity of BCN material in the presence of steam was reported in the literature [7]. The data of the SCTm membrane in Figure 7 will be discussed later. 


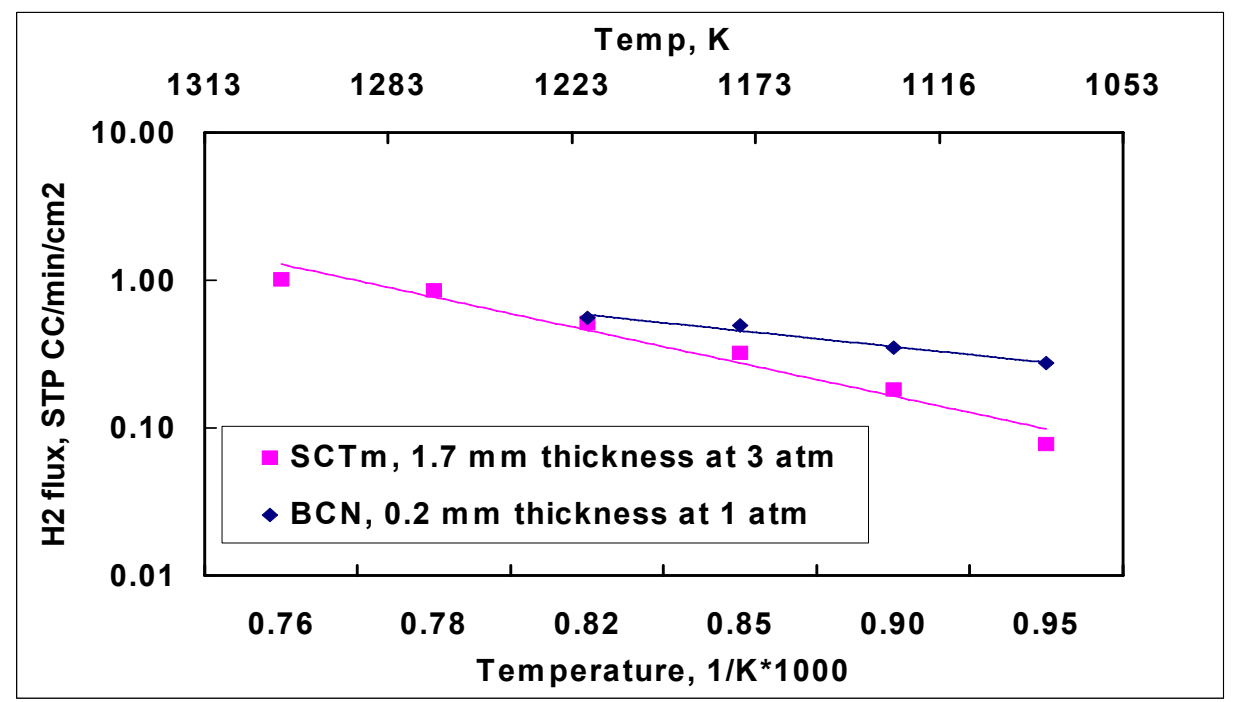

Figure 7. Hydrogen permeation data for the unsupported BCN and the SCTm at different temperatures

\section{SCE membrane}

The measured hydrogen fluxes for the SCE-10 (10\% Eu doping in $\mathrm{SrCeO}_{3}$ ) are shown in Figure 8 under different nitrogen sweeping flows. The hydrogen flux appears to increase with the increasing sweeping flow rate. A high sweeping flow can eliminate or reduce the mass transfer resistance in the gas phase of the permeate side. An insufficient sweeping gas flow would create a concentration gradient in the gas phase next to the permeate side of the membrane. Therefore, the measured flux increases with the flow rate of the sweeping gas and reaches a constant value eventually. The hydrogen flux for this membrane of $0.4 \mathrm{~mm}$ thickness is about $0.35 \mathrm{STP} \mathrm{cc} / \mathrm{min} / \mathrm{cm}^{2}$ at 6 bars and $900^{\circ} \mathrm{C}$ with $100 \%$ hydrogen in the feed. The hydrogen flux of the SCE-10 membrane at 12 bars and $900^{\circ} \mathrm{C}$ with $100 \%$ hydrogen in the feed was also measured at $0.22 \mathrm{cc} / \mathrm{min} / \mathrm{cm}^{2}$, which is lower than the flux at 6 bars. This pressure dependence is similar to the BCN membrane.

Figure 9 is the hydrogen flux for the SCE-20 membrane at three different pressures for a hydrogen feed of $100 \%$ at $950^{\circ} \mathrm{C}$. The hydrogen fluxes go through a maximum with the hydrogen feed pressure. Again, this is very similar to the data of the BCN membranes shown in Figure 5 and 6.

The hydrogen flux for the SCE-20 membrane is about $0.38 \mathrm{STP} \mathrm{cc} / \mathrm{min} / \mathrm{cm}^{2}$ at 6 bars and $950^{\circ} \mathrm{C}$ with $100 \%$ hydrogen in the feed. No significant difference in the flux was observed between the two membranes with the different Eu dopings. The fluxes generally are lower than the BCN membranes obtained in Figure 5 and 6. 


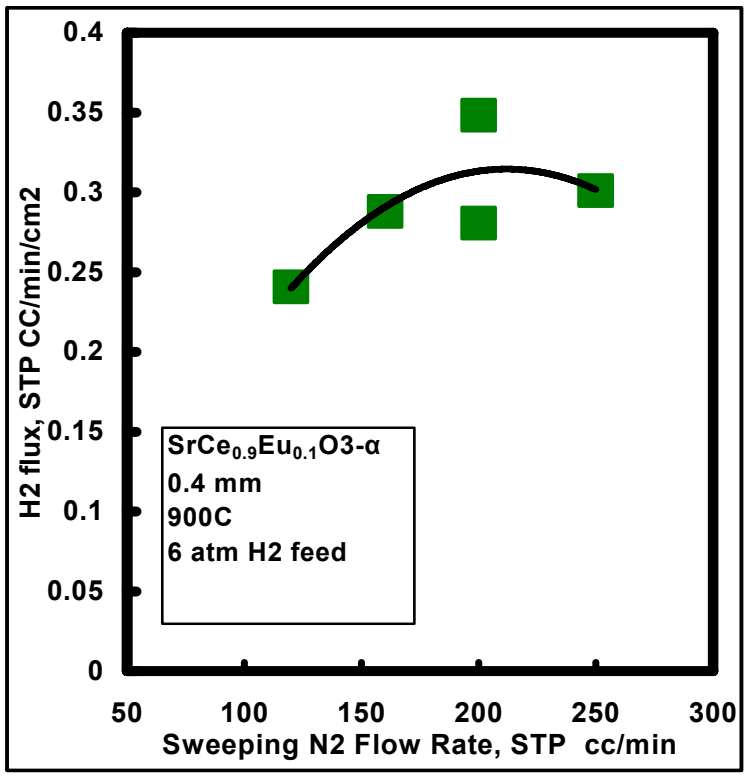

Figure 8. Hydrogen permeation flux for SCE10 membrane measured from high-pressure permeation unit

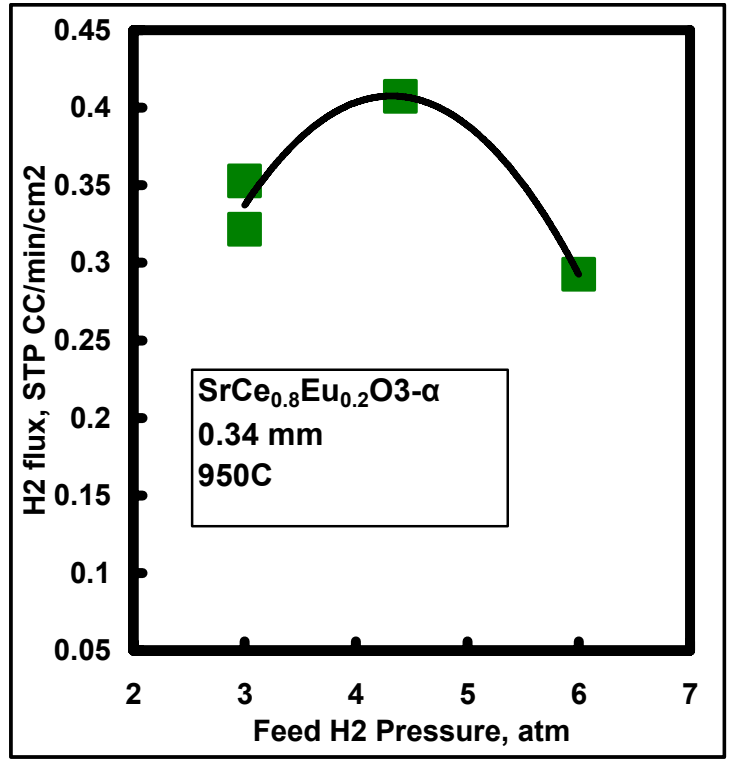

Figure 9. Hydrogen permeation flux for SCE-20 membrane measured from highpressure permeation unit

\section{SCTm membrane}

The hydrogen permeation results for the SCTm membrane at $950^{\circ} \mathrm{C}$ are summarized in Figure 10 for the different hydrogen feed partial pressures. The hydrogen flux increases with the increasing feed pressure up to about 5 bar and then decreases with the pressure, as shown in Figure 10 by the curve noted with $100 \% \mathrm{H}_{2}$. With $60 \%$ hydrogen in the feed (balance of helium), the hydrogen fluxes still go through a maximum with respect to the hydrogen partial pressure in the feed, as shown by the curve with $60 \% \mathrm{H} 2$ (triangle points). Also shown in the figure is the effect of the hydrogen compositions in the feed on the flux at 8.14 bars. The hydrogen compositions in the feed are 20, 40, 60, 80 and $100 \%$ for this curve with the diamond points. As expected, the flux increases with the increasing composition or the partial pressure of hydrogen in the feed. Similar effect of the hydrogen compositions at 1 bar pressure is shown in the same figure. The hydrogen compositions are $100 \%, 60 \%$ and $20 \%$ at 1 bar for the curve with the open circles. The measured hydrogen flux with $20 \%$ hydrogen in the feed at 1 bar is also close to the literature data reported by Qi and Lin [8].

The second SCTm membrane, which had the same composition and thickness as the first sample was tested with a pure hydrogen feed at $950^{\circ} \mathrm{C}$ and various pressures. The hydrogen fluxes measured from this membrane are also shown in Figure 10. As can be seen, some of the data from the first membrane can be reproduced by the second membrane. 


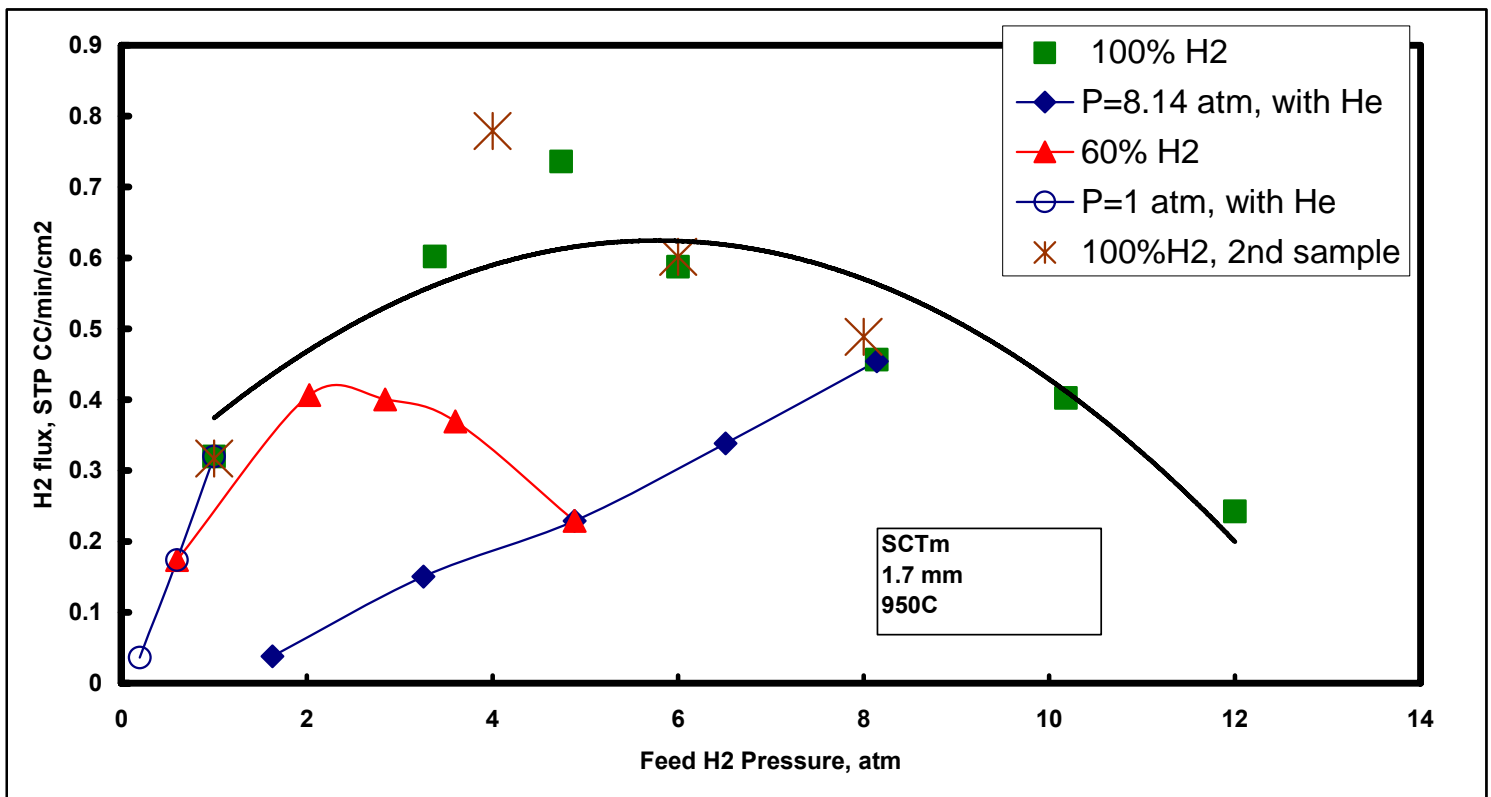

Figure 10. Hydrogen flux for the SCTm membrane at different $H_{2}$ partial pressures

If the membrane thickness is taken into consideration, the SCTm membrane (thickness $1.7 \mathrm{~mm}$ ) shows much higher flux than the SCE membranes (thickness 0.3-0.4 mm). The fluxes are also higher than the BCN membranes reported in Figure 5 and 6. The SCTm membrane needs to be investigated further.

Additional data for the temperature dependency of the hydrogen flux for the SCTm membrane are shown in Figure 7 with 100\% hydrogen in the feed at a pressure of 3 bars. The calculated activation energy for the SCTm membrane is about $27 \mathrm{Kcal} / \mathrm{mole}$, which is higher than the $\mathrm{BCN}$ membrane. At higher temperatures, above $1000^{\circ} \mathrm{C}$, the hydrogen flux of the SCTm membrane is higher. At temperatures below $1000^{\circ} \mathrm{C}$, the $\mathrm{BCN}$ membrane gives higher flux.

After the reproducibility runs, the 2'nd SCTm membrane was tested under continuous hydrogen feed at 1 bar for over 250 hours. The temperature was between 1010 and $1030^{\circ} \mathrm{C}$ and the permeate side was swept using nitrogen gas. The testing results are shown in Figure 11 for both the flux and the temperature. The hydrogen flux actually drifted upwards because the temperature was not exactly maintained at a constant value. After manually decreasing the temperature, the hydrogen flux returned back to about the same value as the beginning. A helium leak checking was also performed at the $120^{\text {th }}$ hour, with an interruption of hydrogen flow of about 2 hours, to verify no deterioration of the leakage. This long term test indicates that the perovskite membrane has good thermal stability under reducing conditions in the hydrogen atmosphere. The chemical stability of the perovskite membrane under the coal-derived syngas conditions, however, still needs to be tested. 


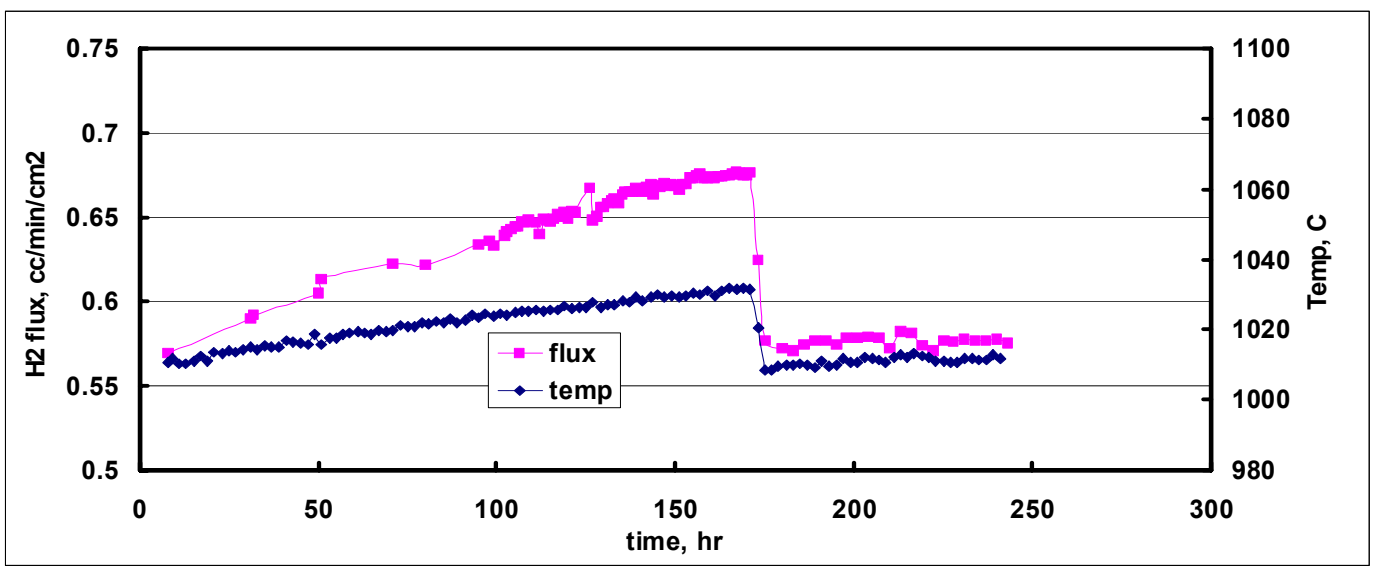

Figure 11. Hydrogen permeation testing for the SCTm membrane at 1 bar with pure hydrogen in the feed and nitrogen sweep in the permeate side

\section{$\underline{\text { SEM and EDS Analysis of SCTm Membrane }}$}

The SCTm membrane showed the highest hydrogen flux among the membranes tested in this project. One of the tested SCTm samples was characterized by SEM (Scanning Electron Microscope) and EDS (Energy Dispersive Spectra) to investigate the structure integrity after permeation. The SCTm membrane after the permeation testing was removed from the test fixture and analyzed by micrography. The sample was fractured near the center and one piece was polished in the area of the cross section. The polished cross section was examined under SEM. Figure 12 is a SEM micrograph showing the entire cross section. There is a significant population of black dots in the picture. They are identified as pores as will be shown later.

A representative area near the feed side of the sample was magnified to 500X. Two connecting pictures, shown in Figure 13, were taken to include different features. The pores do not appear to be connected together, but look more like isolated islands. However, some cracks are visible, especially in the picture of the right hand side. The cracks also propagate almost to the entire picture. Not all cracks initiates from the surface as there are also cracks running parallel to the surface (near the bottom of the right picture). The cracks may have been caused by the force applied to remove the disk from the membrane tube after the permeation testing. 


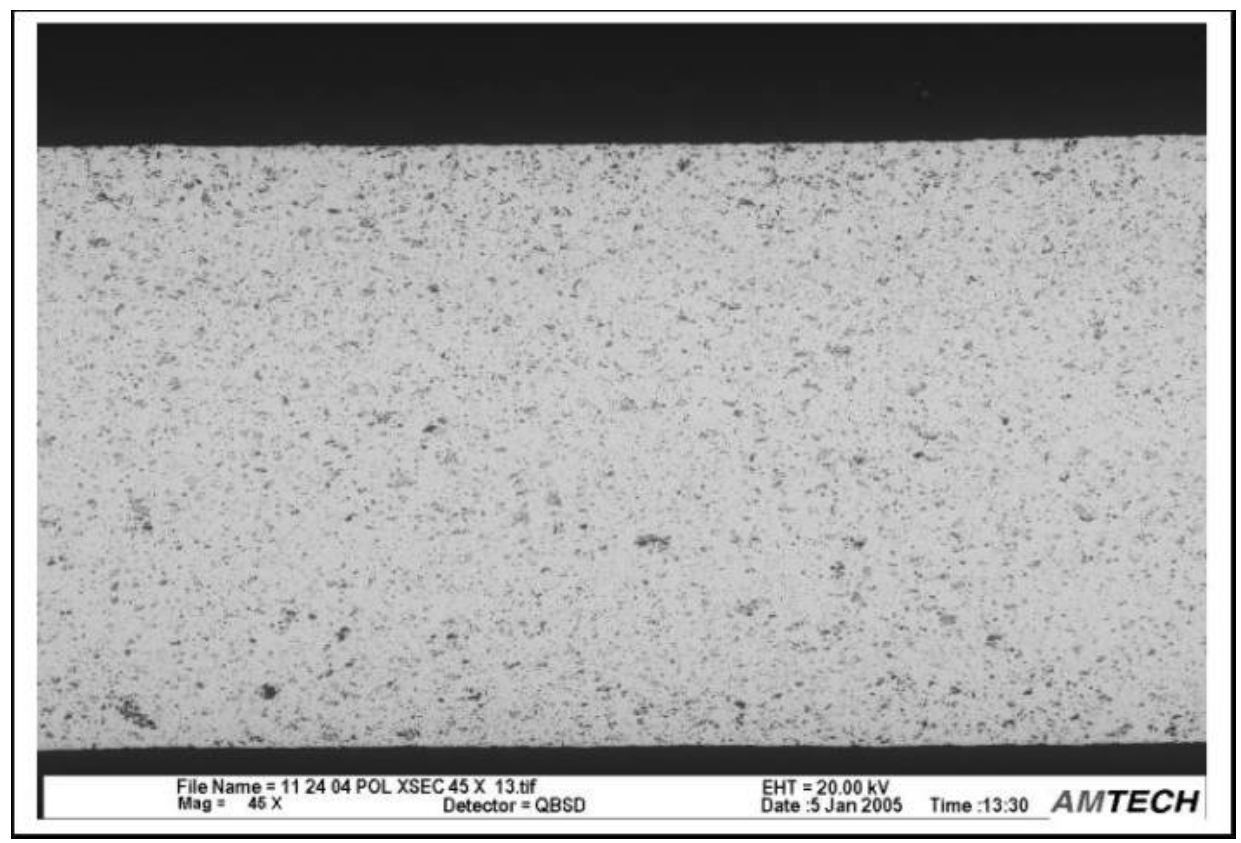

Figure 12. Polished cross section of the tested SCTm membrane with the feed side at the top and the permeate side at the bottom

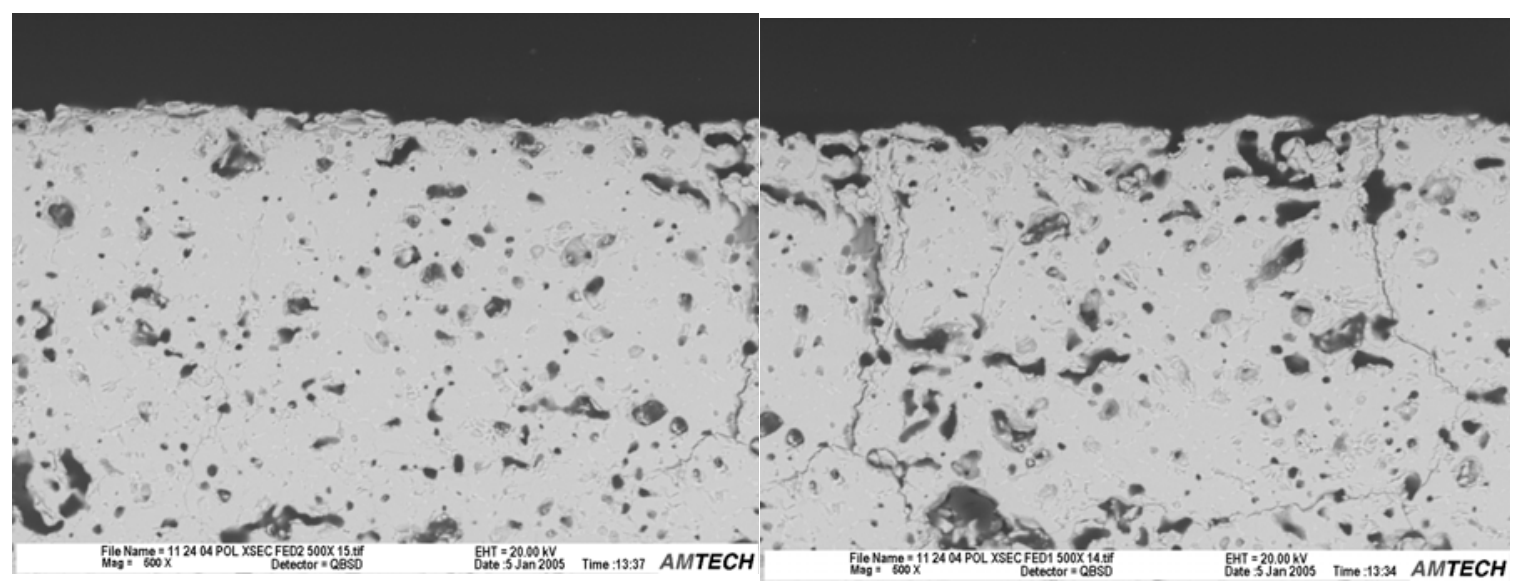

Figure 13. Two connecting areas for the feed side of the SCTm membrane magnified at $500 X$

A crack-free area was further examined at $2000 \mathrm{X}$ to visualize the features of the microstructure. It was observed that in addition to the empty pores, light colored material formed between grains (see Figure 14). To detect the elements present in the light colored areas, EDS was used with the electron beam pointed at the grain bulk and the grain boundary regions separately. The relative concentration of the elements between 
the grain bulk and the grain boundary areas could then be determined. The EDS spectra of the two areas are shown in Figure 15. As shown, the light colored material along the grain boundary is rich in Ce (Figure 15-a, top) while the bulk is richer in Sr (Figure 15-b, bottom). Presumably, cerium oxide could be separated from the perovskite structure and deposited along the grain boundaries.

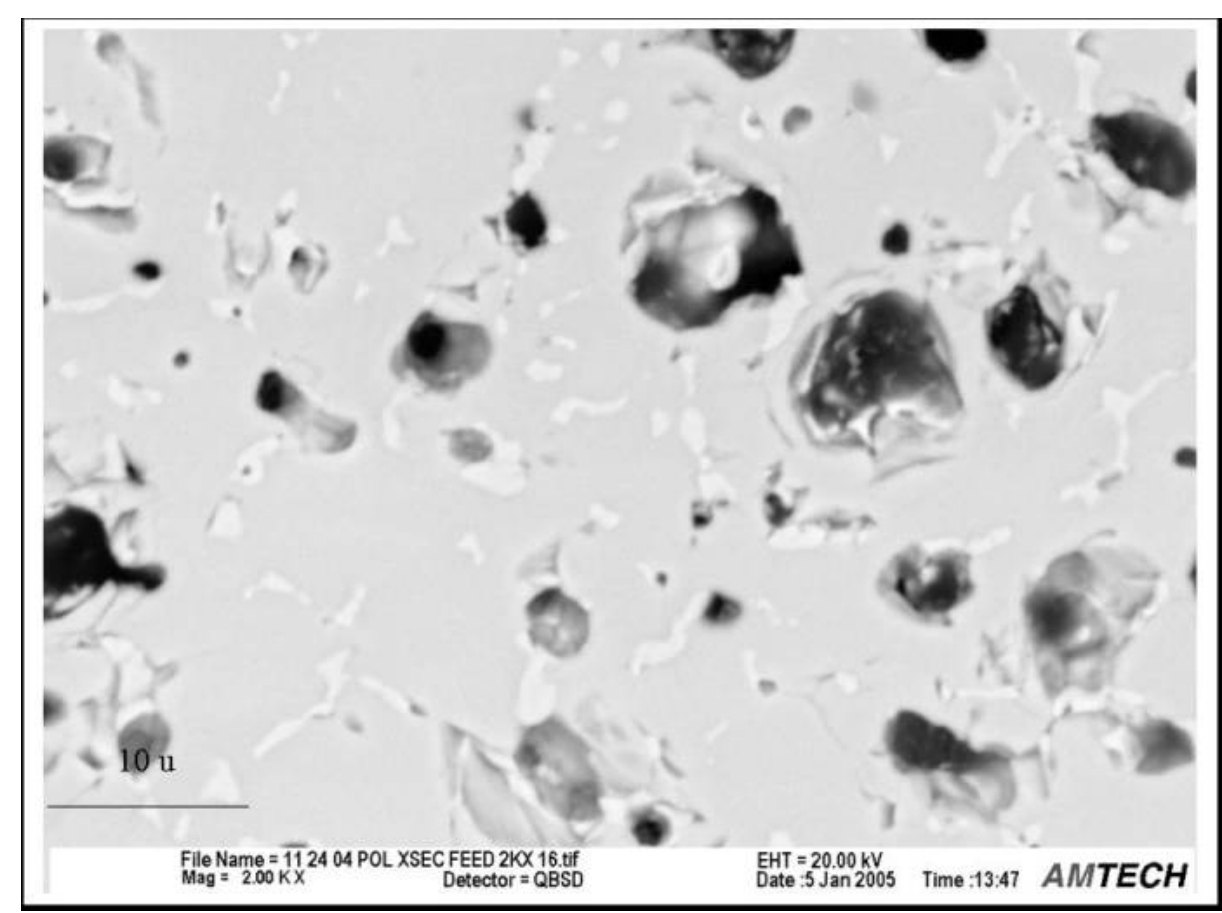

Figure 14. 2000X Magnification of SCTm membrane near the feed side showing light colored grain boundaries under a slight back scattered mode

The interior of the sample was also examined by SEM. The SEM graphs are similar to the Figures 13 and 14 and are not shown here. As in the feed side of the membrane, light colored materials appeared between the grains. No significant differences were observed between this interior area and the feed side of the membrane. 
(a)

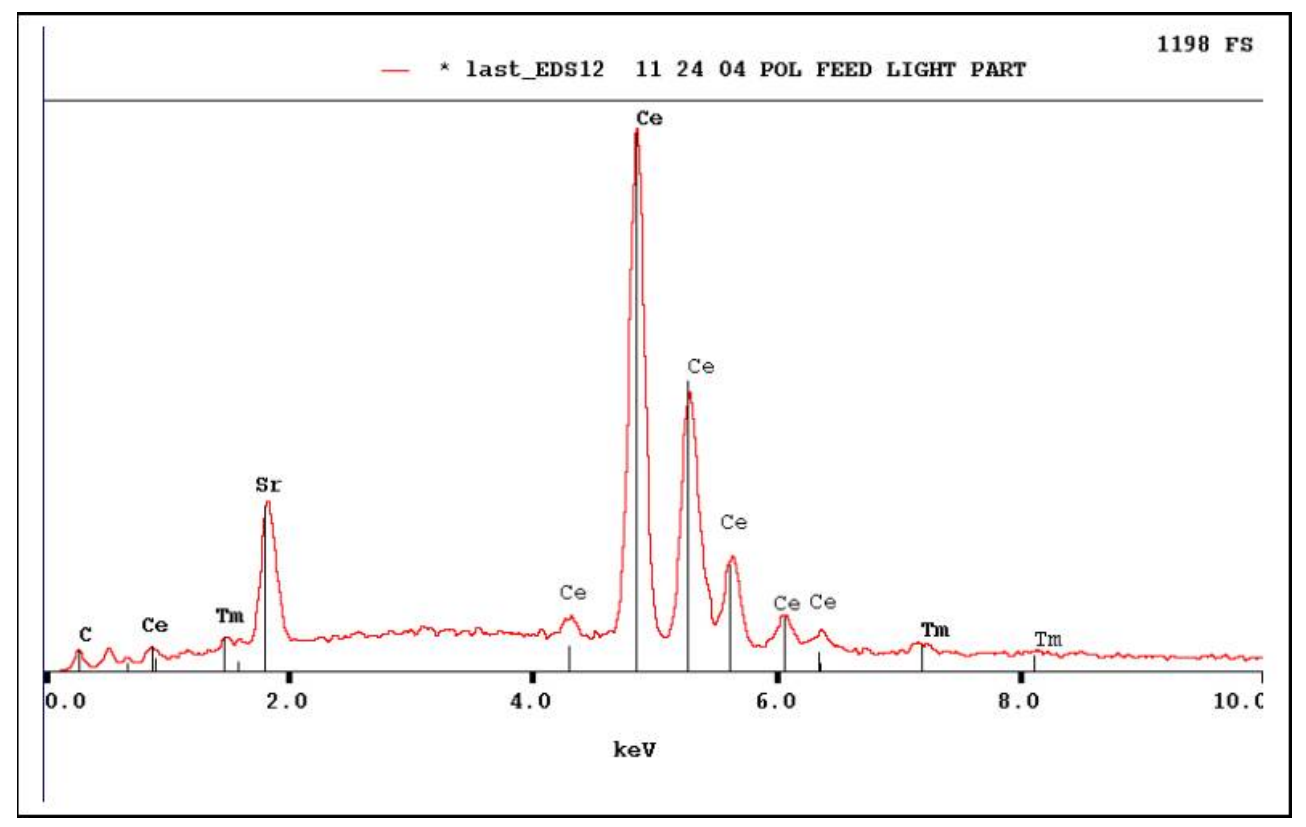

(b)

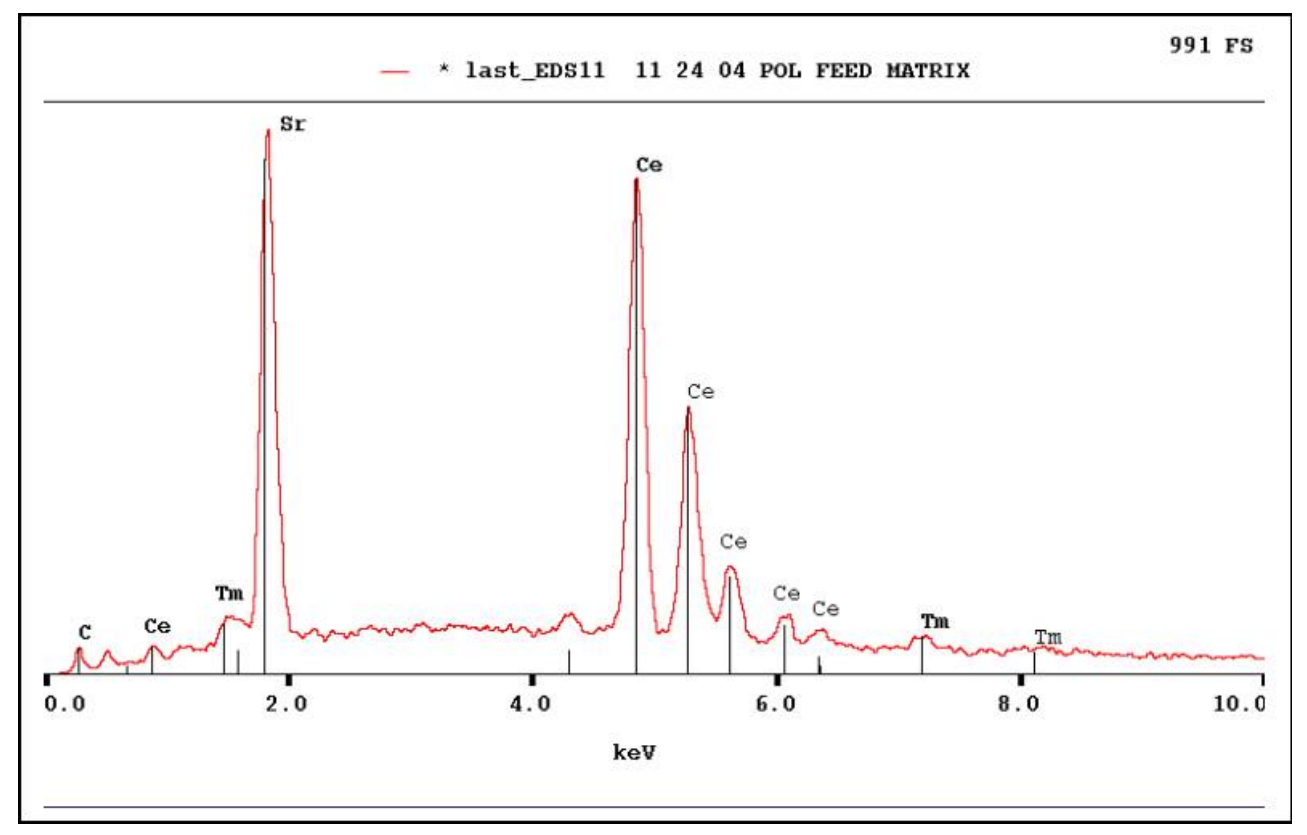

Figure 15. EDS pattern of (a) the light colored region, and (b) the background region, from the SEM micrograph shown in Figure 14

An area near the permeate surface was also examined. Micrographs at 500X are shown in Figure 16. It appears to have a larger population of the pores than the area near the feed surface (compare Figure 13 and 16). Micrograph at 2000X of two connecting areas is shown in Figure 17. In contrast to the area near the feed side in Figure 14, the solid material seems homogeneous and no phase separation is evident. An EDS spectrum of the material near the permeate side is shown Figure 18. It shows that the area is rich in 
Sr, similar to the bulk material of the preceding areas in the feed side and the interior of the membrane.

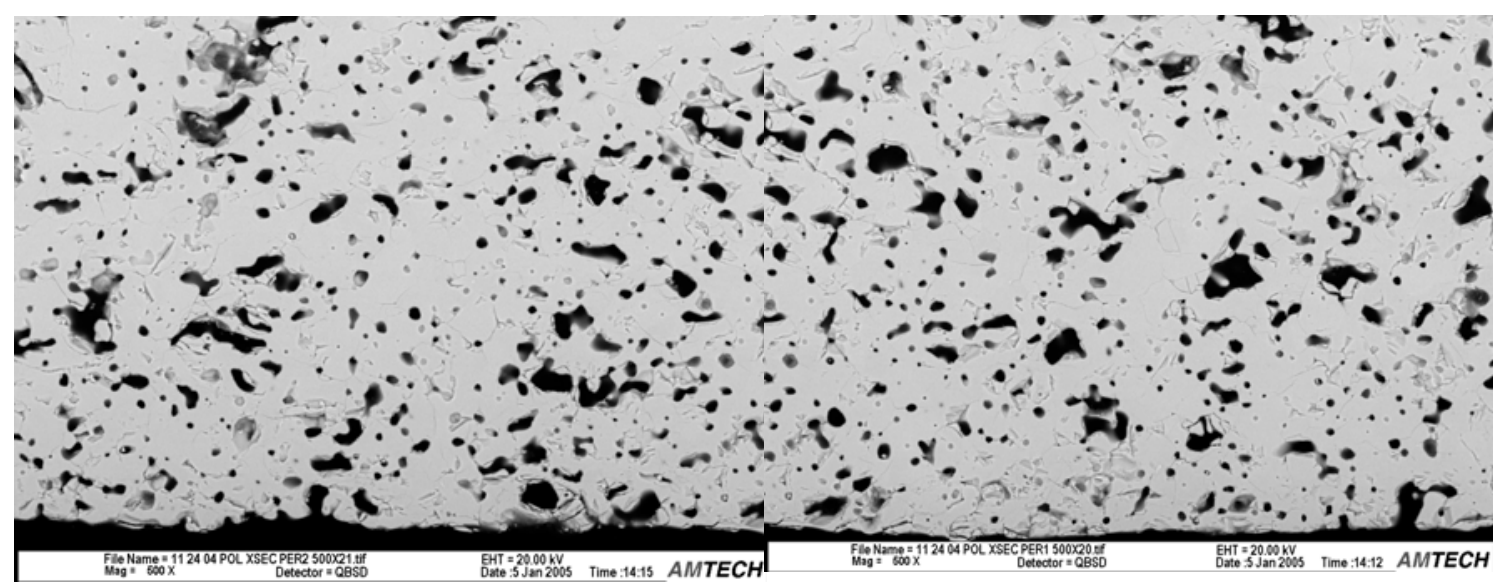

Figure 16. Two connecting areas for the permeate side of the SCTm membrane magnified at $500 \mathrm{X}$

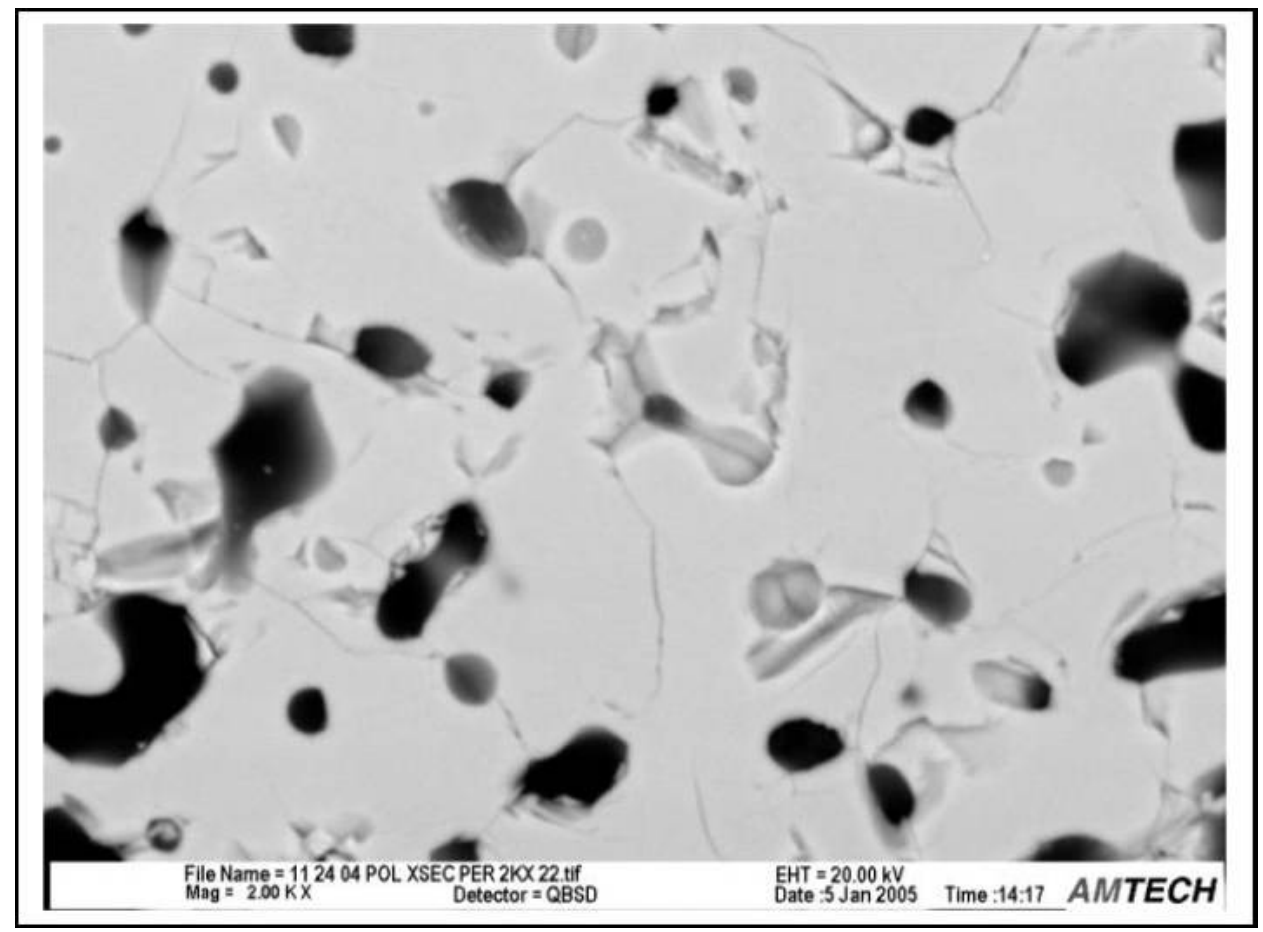

Figure 17. 2000X Magnification of SCTm membrane near the permeate side showing little presence of light colored areas 


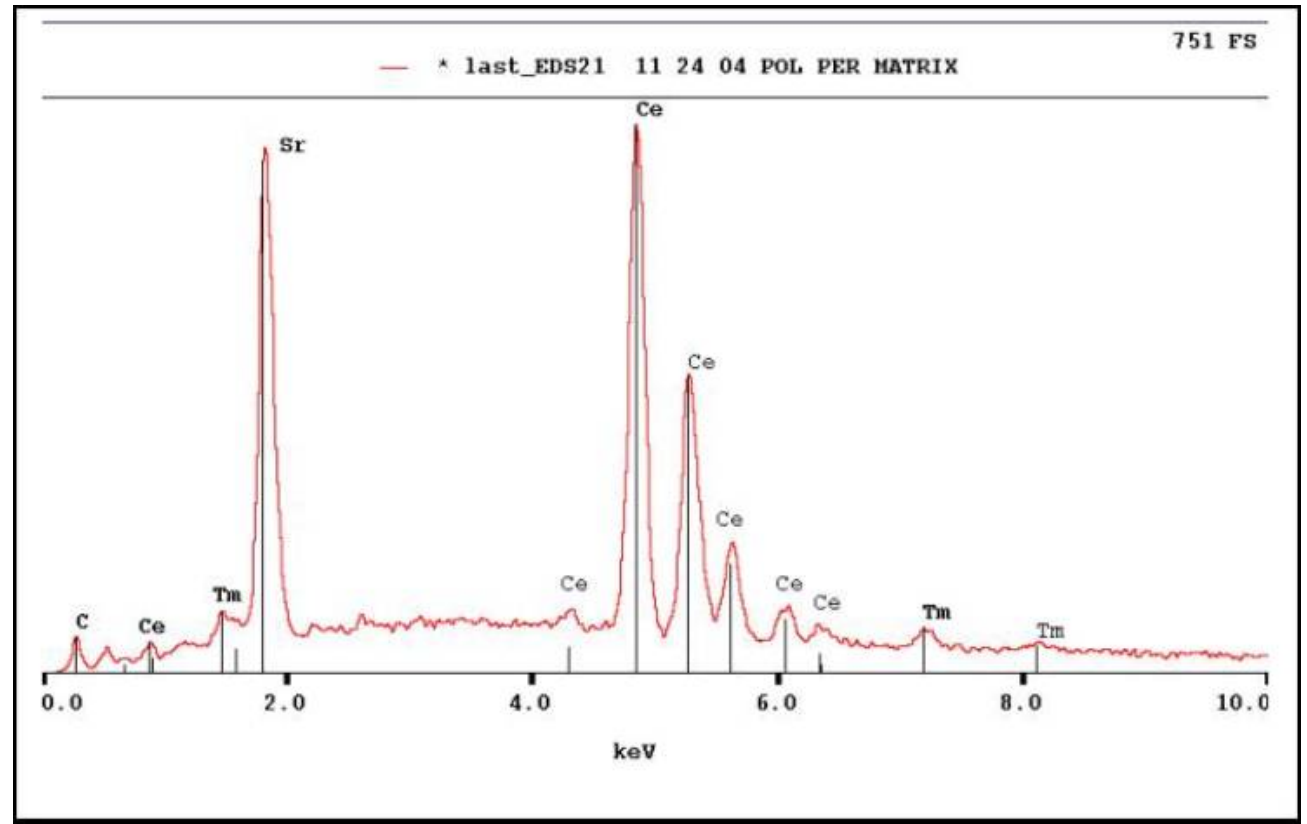

Figure 18. EDS pattern of the bulk region near the permeate side

From the above SEM and EDS analysis on the tested SCTm membrane, there appears to have a phase separation for the perovskite structure, especially in the feed side of the membrane. Because the feed side of the membrane had been encountered with pure hydrogen at pressures during the permeation testing, the perovskite could have been partially reduced by hydrogen to cause the phase separation. The phase separation was not clearly seen in the SEM graph for the permeate side of the membrane, perhaps due to the low hydrogen partial pressure in the permeate side. The stability issues of the perovskite membrane material will need to be addressed in the next phase of the development program.

A fresh sample of the SCTm membrane was examined by Professor J. Lin of Arizona State University. The SEM image of the membrane cross section for the fresh sample is shown in Figure 19. The fresh sample has much clearer grain boundary and more faceted grain surface than the permeation-tested sample, which has almost invisible grainboundary (see Figure 14). This difference could be caused by the additional sintering effects for the permeation-tested sample, which was subjected to elevated temperatures for the permeation test for an extended period of time. Although the permeation temperature (around $900^{\circ} \mathrm{C}$ ) may not be as high as the normal sintering temperature $\left(>1200^{\circ} \mathrm{C}\right)$, the actual sintering effects during permeation could be more pronounced due to the presence of hydrogen (more like a reactive sintering). This additional sintering may have resulted in a smaller pore population observed at the feed side than the permeate side (Figure 13 and 16) during hydrogen permeation testing. If the "reactive sintering" during permeation test actually occurs, the membrane can be further densified and its mechanical strength could be enhanced. This still needs to be verified. 


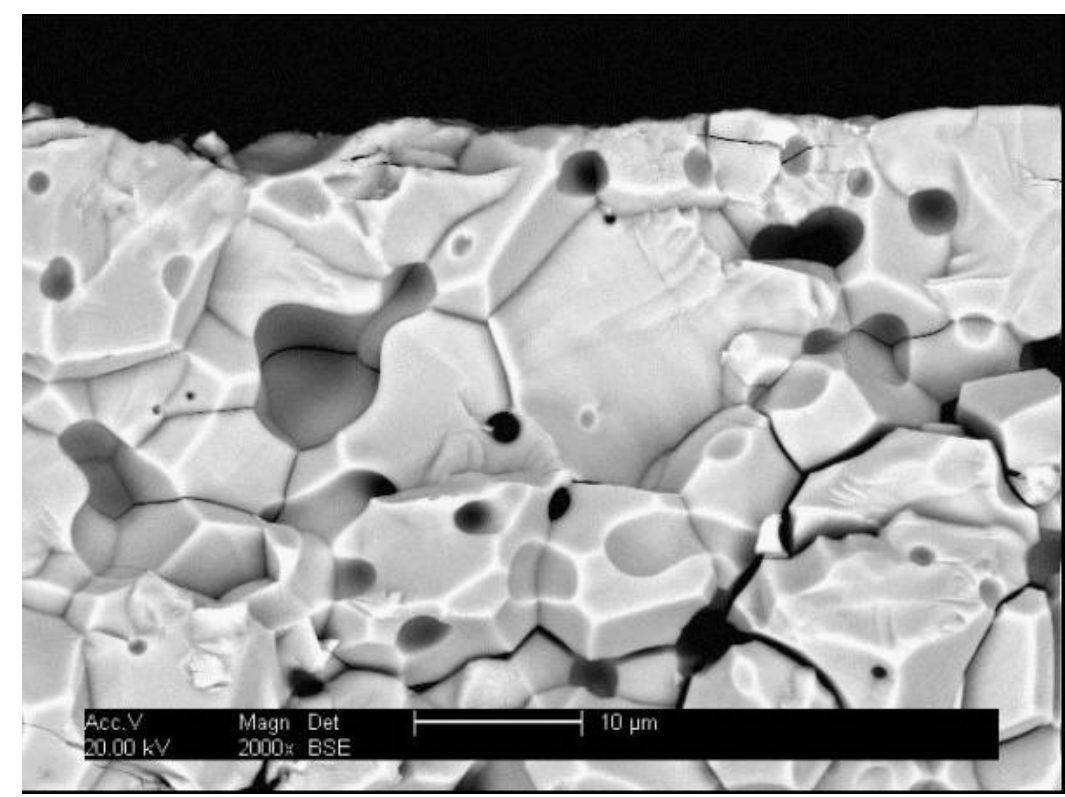

Figure 19. Microstructure of the fresh SCTm membrane at magnification of $2000 X$

\section{$\underline{\text { Reaction of Perovskite with } \mathrm{CO}_{2}} \underline{\text { and } \mathrm{H}_{2}} \underline{\underline{\mathrm{S}}}$}

A particularly notable issue with the proton conducting perovskites is their tendency to react with $\mathrm{CO}_{2}$ or $\mathrm{H}_{2} \mathrm{~S}$ in the syngas under the high temperature and pressure conditions of coal gasification. Therefore, Thermo Gravimetric Analyzer (TGA) unit was used to study the reactions of perovskite powders and membrane disks with $\mathrm{CO}_{2}$ and $\mathrm{H}_{2} \mathrm{~S}$.

The BCN powders were in the size range of 250 to 400 micron. The disk form of BCN was of irregular shape of 2-3 mm in dimensions and about $0.5 \mathrm{~mm}$ in thickness. The tests were conducted at $950 \mathrm{C}$ and $10 \mathrm{~atm}$ with $10 \% \mathrm{CO}_{2}$ in He. When the perovskite material encountered $\mathrm{CO}_{2}$, the weight of the sample increased due to the formation of carbonate compounds. The TGA results are shown in Figure 20 in terms of moles of $\mathrm{CO}_{2}$ per mole of BCN sample versus time. As can be seen, the powder form of BCN reacted with $\mathrm{CO}_{2}$ very quickly and reached complete conversion equilibrium. On the other hand, the disk form of BCN reacted with $\mathrm{CO}_{2}$ much slower. Only about $15 \%$ of $\mathrm{BCN}$ was converted in about 2 hours. The slow reaction of the membrane form of the perovskite material with $\mathrm{CO}_{2}$ could be due to the smaller areas available to the $\mathrm{CO}_{2}$ molecules in the membrane than in the powder. It is also possible that the sintered membrane disk has stronger structure than the powder.

The reaction of $\mathrm{BCN}$ with $\mathrm{CO}_{2}$ resulted in the formation of $\mathrm{BaCO}_{3}$, which was confirmed by the XRD analysis of the reacted membrane sample. 


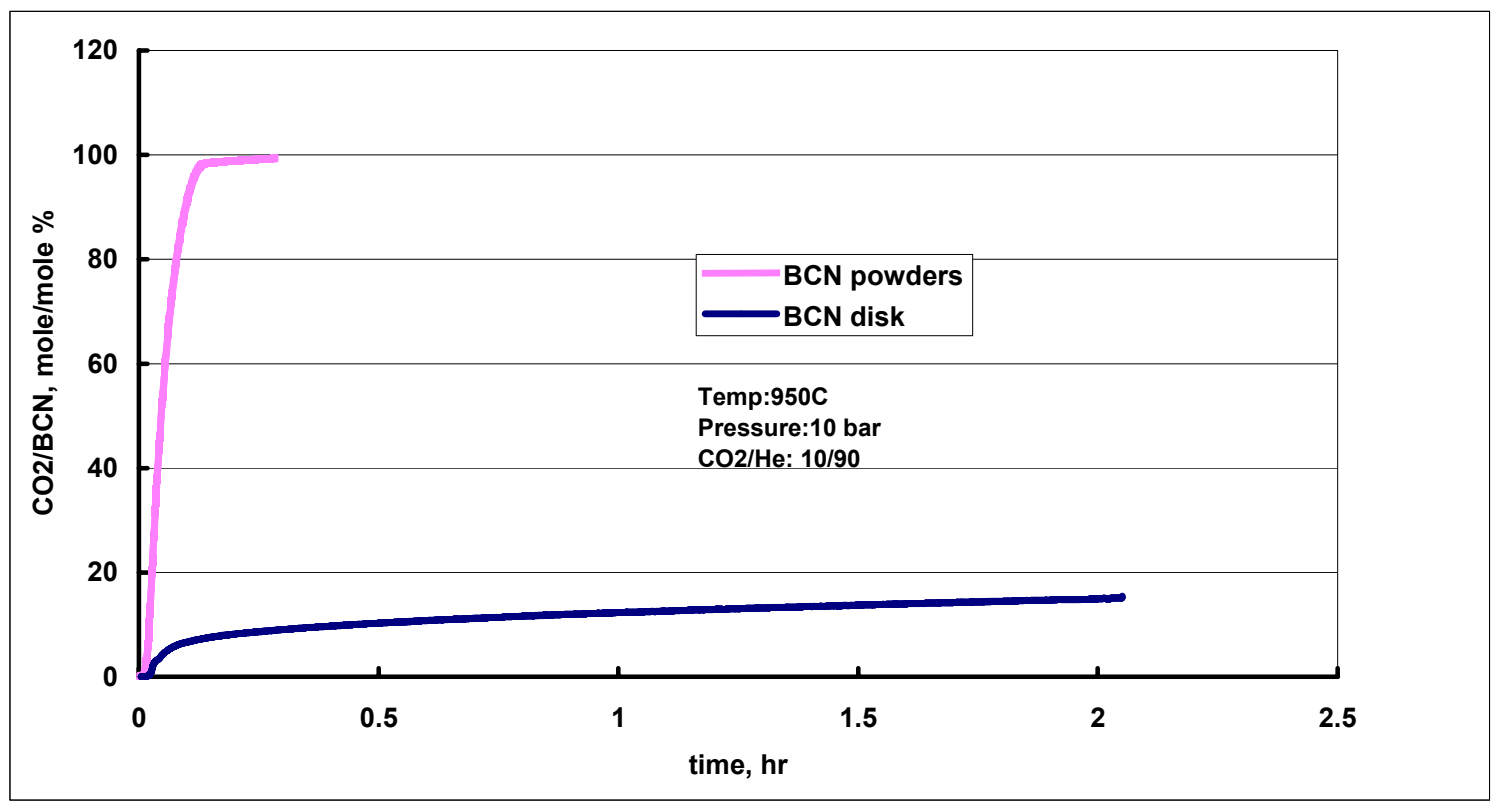

Figure 20. Thermo gravimetric results for the reaction of $\mathrm{CO}_{2}$ with $\mathrm{BCN}$ powder and disk

The tests for the reaction of perovskite with $\mathrm{H}_{2} \mathrm{~S}$ were conducted at $950^{\circ} \mathrm{C}$ and $10 \mathrm{~atm}$ with $0.1 \% \mathrm{H}_{2} \mathrm{~S}$ in $\mathrm{H}_{2}$. The TGA results are shown in Figure 21 in terms of the moles of $\mathrm{H}_{2} \mathrm{~S}$ per mole of the BCN sample versus time. As can be seen, the disk form of BCN reacted with $\mathrm{H}_{2} \mathrm{~S}$ much slower than the powder form, similar to the reaction with $\mathrm{CO}_{2}$. When the perovskite material encountered $\mathrm{H}_{2} \mathrm{~S}$, the weight of the sample increased, perhaps due to the adsorption of the $\mathrm{H}_{2} \mathrm{~S}$ molecules on the perovskite surface. XRD analysis of the reacted sample indicated the presence of the perovskite structure with the formation of neodymium oxide sulfide, $\mathrm{Nd}_{2} \mathrm{O}_{2} \mathrm{~S}$ and barium sulfide, BaS. Presumably, $\mathrm{H}_{2} \mathrm{~S}$ was adsorbed chemically on the surface of the membrane, forming the above sulfide compounds.

\section{Zr-doped Perovskite}

Literature survey indicates that the $\mathrm{Zr}$ doped perovskite materials have improved stability for $\mathrm{CO}_{2}[9,10,11]$. In particular, the Yb-doped perovskite shows little reduction of the conductivity by the introduction of $\mathrm{Zr}$ [9]. Therefore, the $\mathrm{Zr}$ and $\mathrm{Yb}$ doped barium cerate perovskite powder; $\mathrm{BaCe}_{0.5} \mathrm{Zr}_{0.4} \mathrm{Yb}_{0.1} \mathrm{O}_{3-\mathrm{x}}$ (BCZY) was fabricated into dense membrane disks and tested in the TGA unit for the chemical stability with respect to $\mathrm{CO}_{2}$ and $\mathrm{H}_{2} \mathrm{~S}$. The reaction of BCZY disk with $\mathrm{CO}_{2}$ is shown in Figure 22 in comparison with the BCN and SCE membranes. The tests were conducted at $950^{\circ} \mathrm{C}$ and 10 bar with $10 \% \mathrm{CO}_{2}$ in $\mathrm{He}$. As can be seen, the $\mathrm{Zr}$ doped perovskite or $\mathrm{BCZY}$ has better stability with $\mathrm{CO}_{2}$ than BCN or SCE. BCZY in the form of powders was also tested in the TGA and showed better $\mathrm{CO}_{2}$ stability than the powder form of the BCN or SCE (data not shown here). Further, the disk form of the material has better stability than the powder form. 


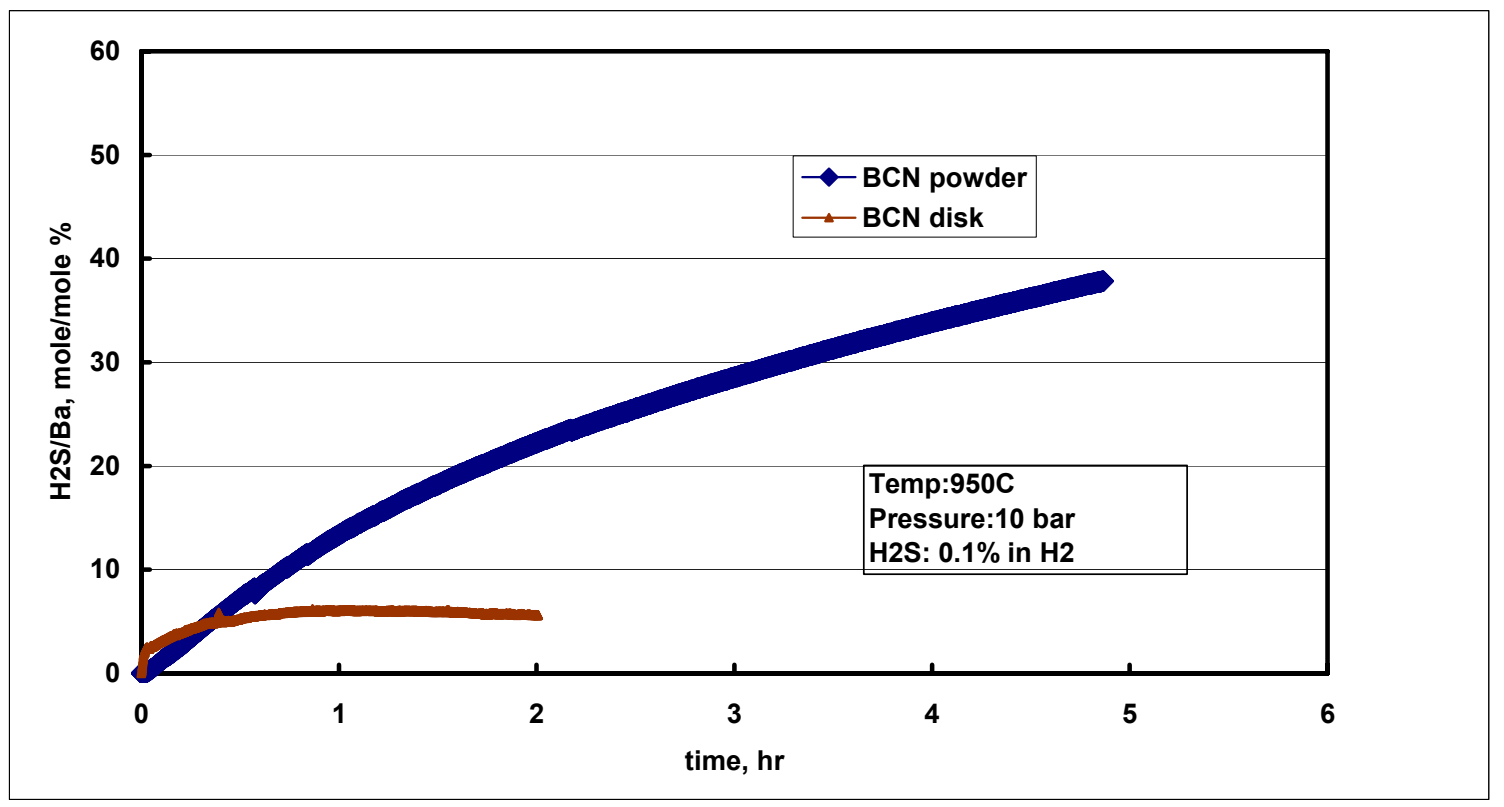

Figure 21. Thermo gravimetric results for the reaction of $\mathrm{H}_{2} \mathrm{~S}$ with $\mathrm{BCN}$ powder and disk

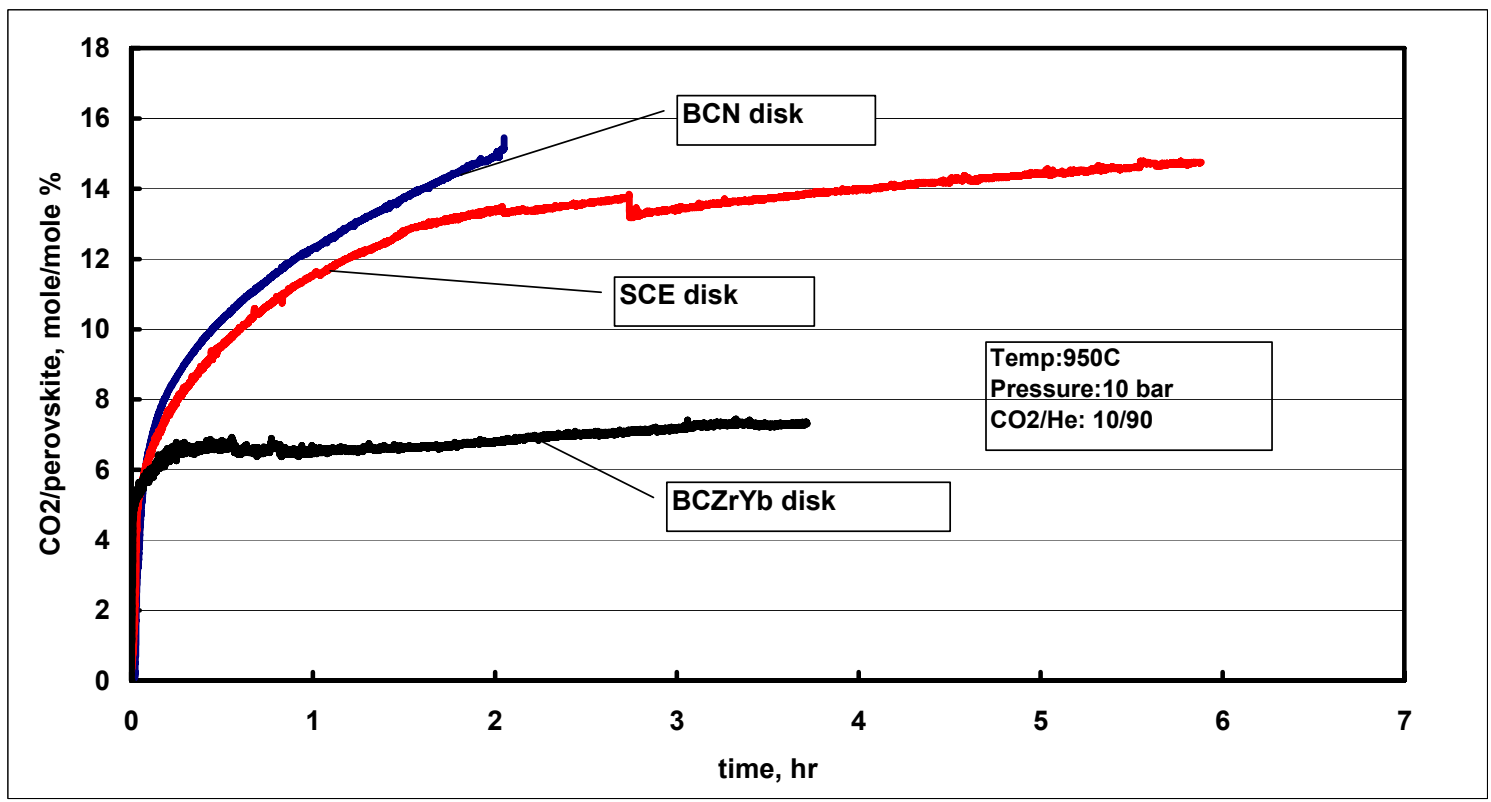

Figure 22. Thermo gravimetric results for the reaction of $\mathrm{CO}_{2}$ with $\mathrm{Zr}$-doped $\mathrm{BCZY}$, BCN and SCE membrane disks

The chemical stability of BCZY with respect $\mathrm{H}_{2} \mathrm{~S}$ is shown in Figure 23. The tests were conducted at $950^{\circ} \mathrm{C}$ and 10 bar with $0.1 \% \mathrm{H}_{2} \mathrm{~S}$ in $\mathrm{H}_{2}$. In comparison with the $\mathrm{BCN}$ powder and the BCN membrane disks, the BCZY shows improved resistance to $\mathrm{H}_{2} \mathrm{~S}$. 


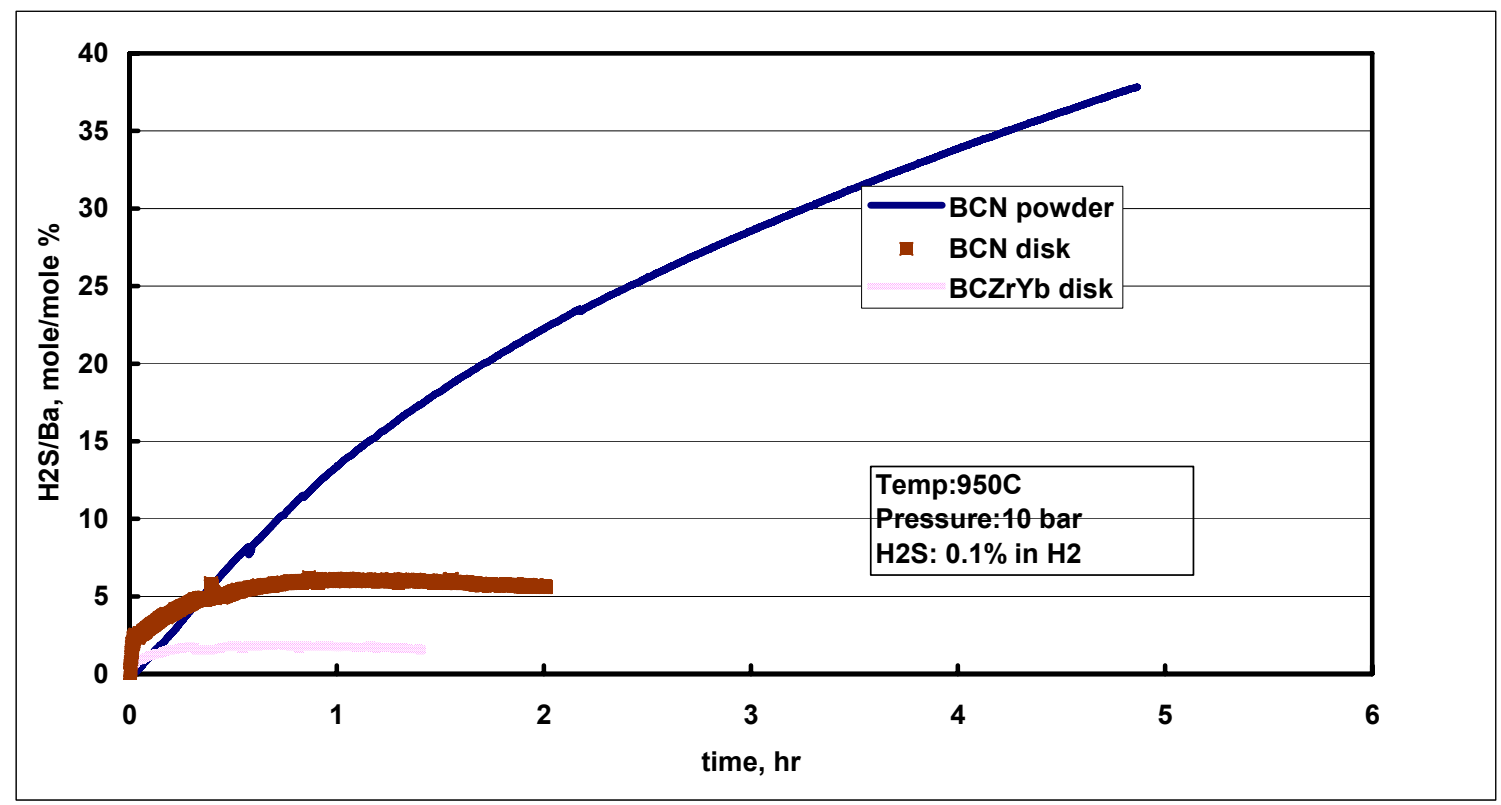

Figure 23. Dense membrane of $\mathrm{Zr}$ doped perovskite shows stronger resistance to $\mathrm{H}_{2} \mathrm{~S}$ than BCN membrane or powder

The $\mathrm{Zr}$ doped perovskites tend to have high tolerance factor to the distortion of the structure from the ideal cubic type [9]. The relatively low free energy of formation compared to other perovskites also contributes to the stability of the $\mathrm{Zr}$ doped perovskite [9]. The Zr-doped perovskite is expected to have lower conductivity, hence lower hydrogen flux. Material development in increasing the conductivity and reducing the membrane thickness will be required to raise the flux of the $\mathrm{Zr}$-doped materials. Long term evaluation of the material under the environment of CO2 and H2S is also necessary"

\section{Modeling of Mixed Proton-Electron Conducting Membrane}

To better understand the transport mechanism for the perovskite membranes, a rigorous model for hydrogen permeation through mixed proton-electron conducting ceramic membranes was also developed based on non-equilibrium thermodynamics. The transport of four charged species, proton, oxygen vacancy, electron, and electron hole are described by classical Fick's equation, i.e. flux is proportional to the concentration gradient and the transport coefficient of the species. The concentrations of the species are related to defect chemistry of the perovskite materials and its associated chemical equilibrium. The transport coefficients are determined from the diffusivity, conductivity or mobility measurement. The detailed derivation of the model was given in Appendix A. Essentially, a more general form of Wagner equation, (See Eq. (3) below), was derived by including contributions from two other defect species, vacancy and electron hole. Furthermore, the conductivities are expressed in terms of species concentrations and diffusivities in the perovskite material, as shown in Eq. (A7). 
Because the physical parameters such as the diffusivity and the equilibrium constants for the BCN membranes are not available in the literature, modeling analysis of hydrogen permeation through the mixed protonic-electronic conducting membrane was carried out for the $\mathrm{SrCe}_{0.95} \mathrm{Y}_{0.05} \mathrm{O}_{3-\mathrm{x}}$ (SCY) perovskite membrane. The required physical parameters are taken from the literature [12-16] and are listed in Table 1.

Table 1 Equilibrium and diffusivity parameters used in the simulation

\begin{tabular}{|c|c|c|c|}
\hline Equilibrium constant & Value, in mole/cc \& atm & diffusivity & Value, $\mathrm{cm}^{2} / \mathrm{sec}$ \\
\hline $\mathrm{K}_{1} \quad$ (Eq. A-9) & $5 \times 10^{-6}[12]$ & proton & $\begin{array}{l}2.19 \times 10^{-3} \exp (-5339 / \mathrm{T}) \\
{[14]}\end{array}$ \\
\hline $\mathrm{K}_{2}$ (Eq. A-10) & $\begin{array}{l}4.24 \times 10^{-6} \exp (14214 / \mathrm{T}) \\
{[16]}\end{array}$ & vacancy & $\begin{array}{l}24.24 \exp (-23467 / T) \\
{[15]}\end{array}$ \\
\hline $\mathrm{K}_{3} \quad$ (Eq. A-11) & $\begin{array}{l}1.31 \times 10^{-3} \exp (29809 / \mathrm{T}) \\
{[13]}\end{array}$ & $\begin{array}{l}\text { electron } \\
\text { hole }\end{array}$ & $\begin{array}{l}\text { 49.38exp(-12589/T) } \\
{[15]}\end{array}$ \\
\hline $\mathrm{K}_{\mathrm{e}} \quad$ (Eq. A-15) & $1 . x 10^{-11}[13]$ & electron & $\begin{array}{l}\text { 49.38exp(-12589/T) } \\
{[15]}\end{array}$ \\
\hline
\end{tabular}

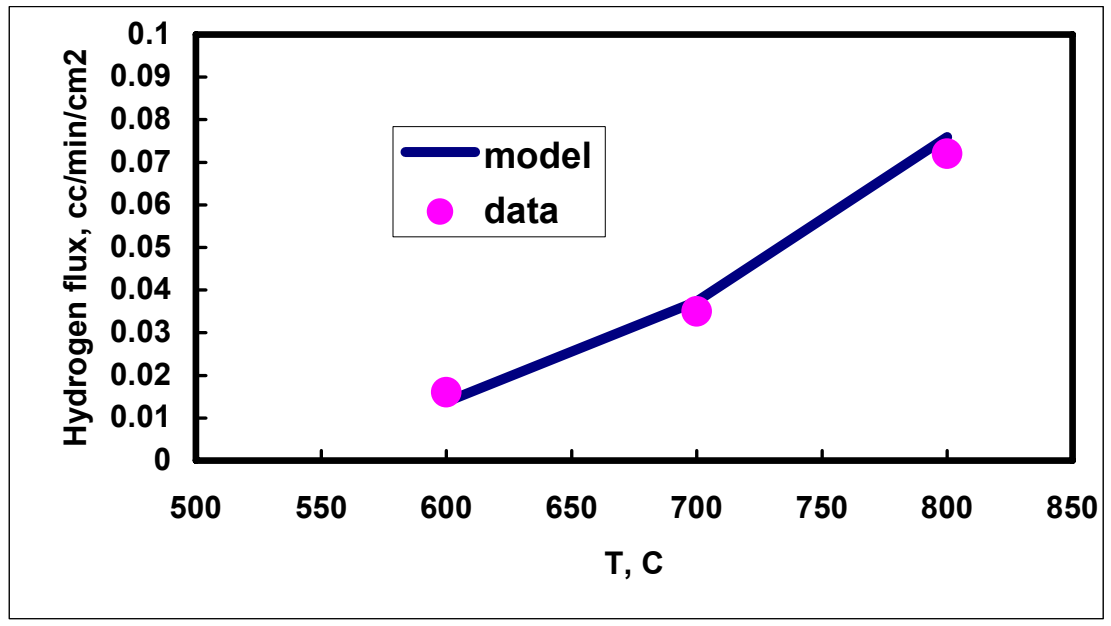

Figure 24. Comparison of simulation results with the literature data [17] 


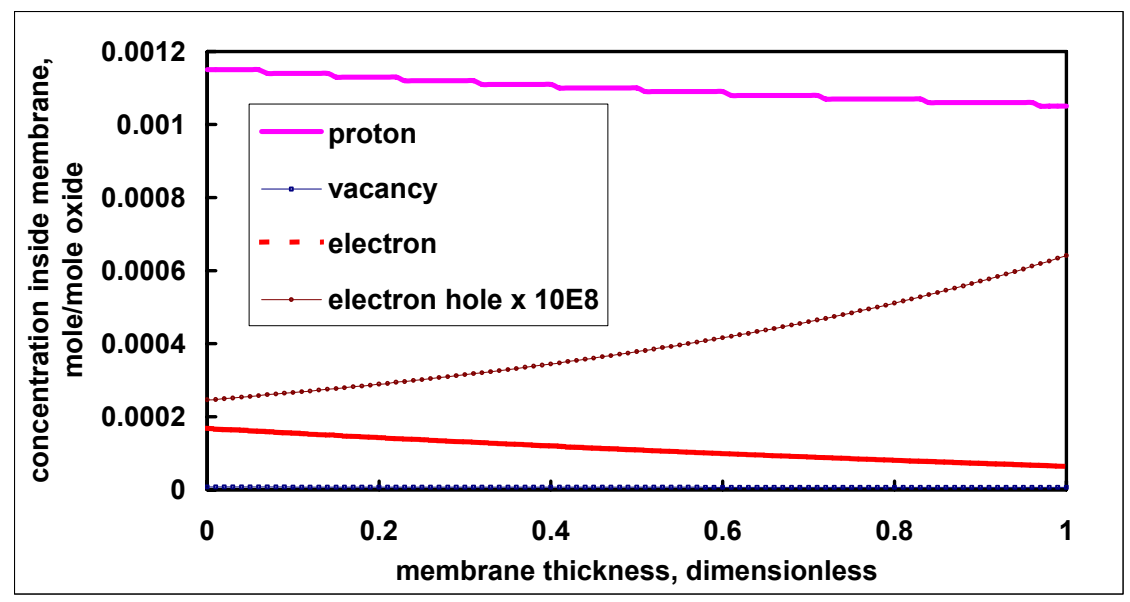

Figure 25. Concentration profiles for the four defect species, proton, vacancy, electron and electron hole inside a SCY membrane

The simulation results are first compared with the experimental hydrogen flux reported in [17] and are shown in Figure 24. The feed was 4\% hydrogen with balance of argon and the permeate side was maintained at $0.488 \%$ hydrogen with Ar. The SCY membrane was $0.11 \mathrm{~cm}$ in thickness. The model appears to match the data quite well, considering the uncertainties of the parameters.

The concentration profiles of the four major defect species predicted from the model at $700^{\circ} \mathrm{C}$ are shown in Figure 25. The feed is $4 \%$ hydrogen and the permeate is $0.488 \%$ hydrogen, the same conditions as in Figure 24. Both the proton and the electron species dominate in the SCY membrane and the concentrations of the vacancy and the electron hole are very low. The results are reasonable because hydrogen permeation is mainly carried by both the proton and the electron while the vacancy and the electron hole are responsible for the oxygen transport. The proton and the electron concentrations decrease from the feed side to the permeate side as expected. Due to the low pressure operation, the proton concentrations generally are low, below $1.2 \times 10^{-3}$ mole per mole of perovskite, or $2.4 \times 10^{-5} \mathrm{~mole} / \mathrm{cm}^{3}$, with a membrane density of $5.85 \mathrm{~g} / \mathrm{cm}^{3}$. However, the electron concentrations are even lower than the proton concentrations. The simulation shows that to increase the hydrogen flux for the SCY membrane, the electronic conductivity needs to be increased.

\section{Task 2 - Conceptual Design of Membrane Reactor}

A conceptual design of the membrane reactor configuration for a 1000 TPD coal gasifier was conducted to investigate the feasibility of placing a membrane reactor within a gasifier. The design considered a tubular membrane module located within the freeboard area of a fluidized bed gasifier as shown in Figure 26. The coal syngas generated in the gasification zone at the lower section of the fluidized bed enters the membrane reactor module. To further protect the membrane material from the solid particles, each 
membrane tube, as a provision, can be enclosed within a ceramic filter tube as shown in Figure 27. Thus, only gas species can enter the annual section of the tube. As the filter tubes are sealed at the bottom, the syngas will continue traveling upwards inside the annular part. Due to the selective property of the membrane material, hydrogen will permeate through the inner membrane tube and flow upwards to the top plenum chamber before exiting the gasifier. The non-permeate gas or retentate will be collected at another plenum chamber below the hydrogen chamber and exit through the side ports of the gasifier.

Alternatively, the membrane module can be located outside the gasifier, e.g. just after the cyclone of the gasifier to be closely coupled with the gasifier in terms of the syngas temperature and pressure. This arrangement would not affect the sizing of the membrane module. This could also avoid the complicated fluid dynamics and heat transfer issues when the membrane module is installed inside the gasifier.

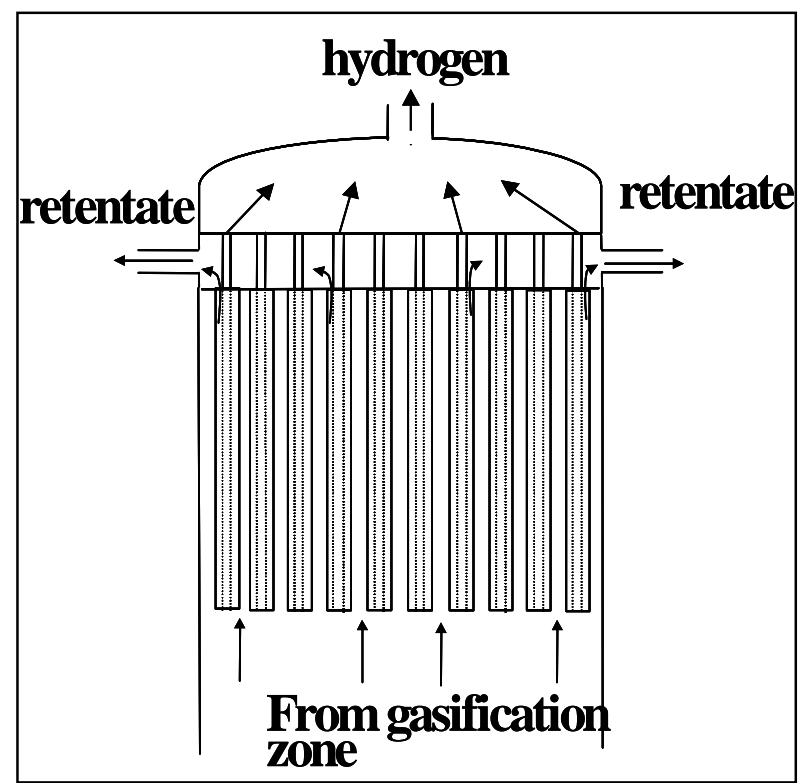

Figure 26. Schematic diagram of a tubular membrane module within a fluidized bed gasifier

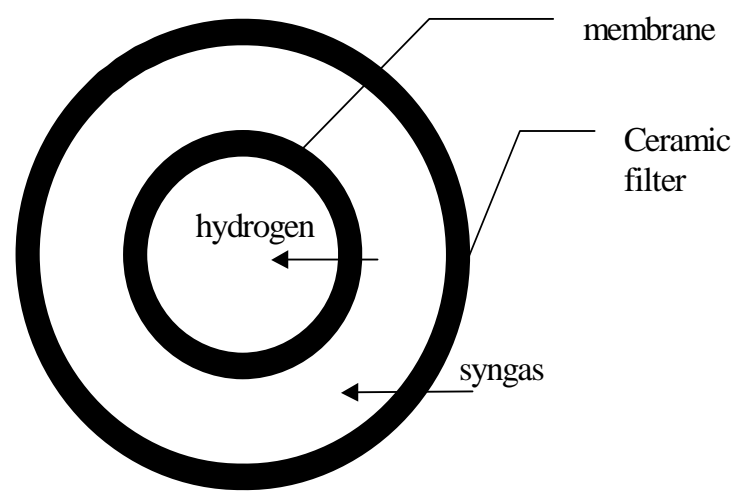

Figure 27. Enlarged cross section of a membrane tube

To support the conceptual design of the membrane gasification reactor, the required size or dimension of the membrane module for a given operating condition must be determined. A tubular membrane reactor module within a fluidized bed gasifier was used for this modeling study. The free board area or the disengaging zone of a fluidized bed gasifier provides a convenient location for the membrane reactor. Figure 28 is a schematic showing one of the membrane tubes within a fluidized bed gasifier. The coal syngas generated in the gasification zone at the lower section of the fluidized bed enters the membrane reactor module. The membrane tube is assumed to be made of mixed proton/electron conducting perovskite material. Hydrogen will be removed from the tube side of the membrane and the non-permeate will exit the gasifier from the shell side. In 
this preliminary study, contaminants generated from coal gasification are not considered. In reality, a stable, durable and robust membrane material and the reactor module must be developed.

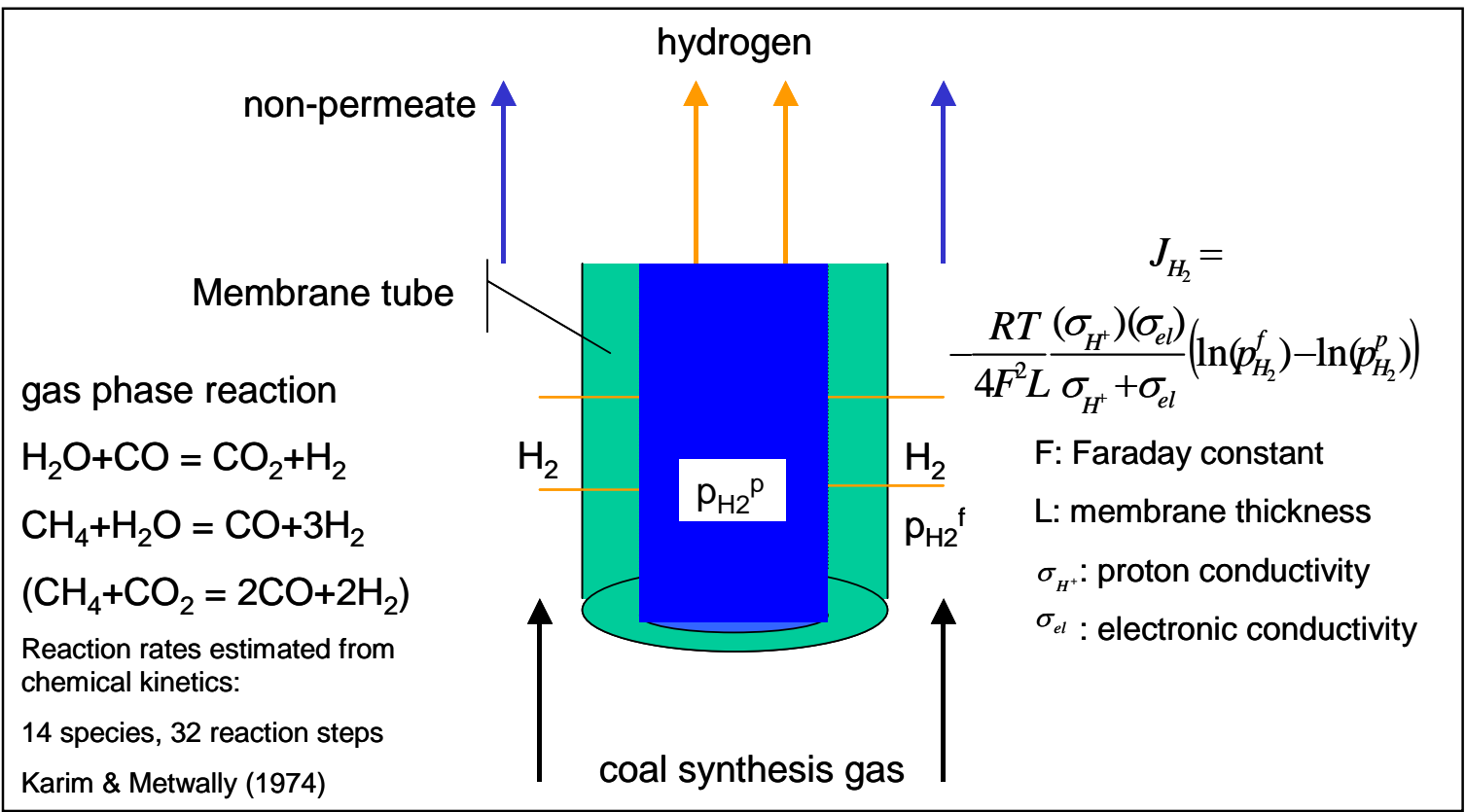

Figure 28. Modeling of a tubular membrane reactor within a gasifier

A mass balance for the feed side of the membrane tube yields

$\frac{\partial F_{i}}{\partial x}-R_{i}+J_{i}=0$

where $F_{i}$ is the molar flow rate of component $i, x$ is the length of the membrane tube, $R_{i}$ is the reaction rate for forming component $i$, and $J_{i}$ is the permeation rate of component $i$.

To evaluate $R_{i}$, chemical kinetics was employed to describe the rates of gas reactions in the feed side of the membrane. This approach was used by Karim and Metwally [18] satisfactorily for modeling of the reforming of natural gas. A reaction scheme comprising 14 chemical species and 32 elemental reaction steps has been employed. The chemical species considered are six major gas components in the gasifier: $\mathrm{CH}_{4}, \mathrm{O}_{2}, \mathrm{CO}, \mathrm{H}_{2}, \mathrm{CO}_{2}$, and $\mathrm{H}_{2} \mathrm{O}$, and eight radicals: $\mathrm{OH}, \mathrm{CH}_{3}, \mathrm{H}, \mathrm{O}, \mathrm{HO}_{2}, \mathrm{H}_{2} \mathrm{O}_{2}, \mathrm{CH}_{2} \mathrm{O}$, and $\mathrm{CHO}$. Because reforming reactions without catalysts are not expected to occur even at the gasification temperature of $1000^{\circ} \mathrm{C}$, catalytic reaction kinetics was used in the model calculations.

The reaction rate for each species $R_{i}$ can be described as 


$$
R_{i}=\sum_{j=1}^{64} \alpha_{i j} K_{j} \prod_{l=1}\left(C_{l}\right)^{\alpha_{l j}}
$$

where $\alpha_{i j}$ is the stoichiometric coefficient of the $i$ th species appearing in the $j^{\text {th }}$ reaction with a positive sign for the product and a negative sign for the reactant, $K_{j}$ is the rate constant for the $j^{\text {th }}$ reaction, $C_{l}$ is the molar concentration of the species $l$, and $\prod_{l=1}\left(C_{l}\right)^{\alpha_{l j}}$ denotes multiplication of $\left(C_{l}\right)^{\alpha_{l j}}$ for species $l$ appearing in the reactants of the $j^{\text {th }}$ reaction. The detailed reaction steps and the rate constants can be found from reference [18]. Because both forward and backward reactions are considered, there are effectively 64 reaction steps altogether.

In a simplified form, the hydrogen flux can be expressed in the form of the Wagner equation $[19,20]$ :

$$
J_{H_{2}}=-\frac{R T}{4 F^{2} L} \frac{\left(\sigma_{H^{+}}\right)\left(\sigma_{e l}\right)}{\sigma_{H^{+}}+\sigma_{e l}}\left(\ln \left(p_{H_{2}}^{f}\right)-\ln \left(p_{H_{2}}^{p}\right)\right)
$$

where $\mathrm{R}$ is the gas constant, $\mathrm{F}$ is the Faraday constant, $\mathrm{L}$ is the membrane thickness, $\sigma_{H^{+}}$is the proton conductivity, $\sigma_{e l}$ is the electronic conductivity, $p_{\mathrm{H}_{2}}^{f}$ is the partial pressure of hydrogen in the feed side of the membrane and $p_{\mathrm{H}_{2}}^{p}$ is the partial pressure of hydrogen in the permeate side. The membrane ambipolar conductivity was determined from the hydrogen permeation data measured in this project. The ambipolar conductivity values calculated from Eq. (3) based on the hydrogen flux of the SCTm membrane are shown in Figure 29. Although the conductivities vary with the pressure, a constant value of $0.05 \mathrm{~S} / \mathrm{cm}$ was used for the calculation. The membrane thickness was assumed to be 25 micron, which is considered achievable with the current fabrication technologies.

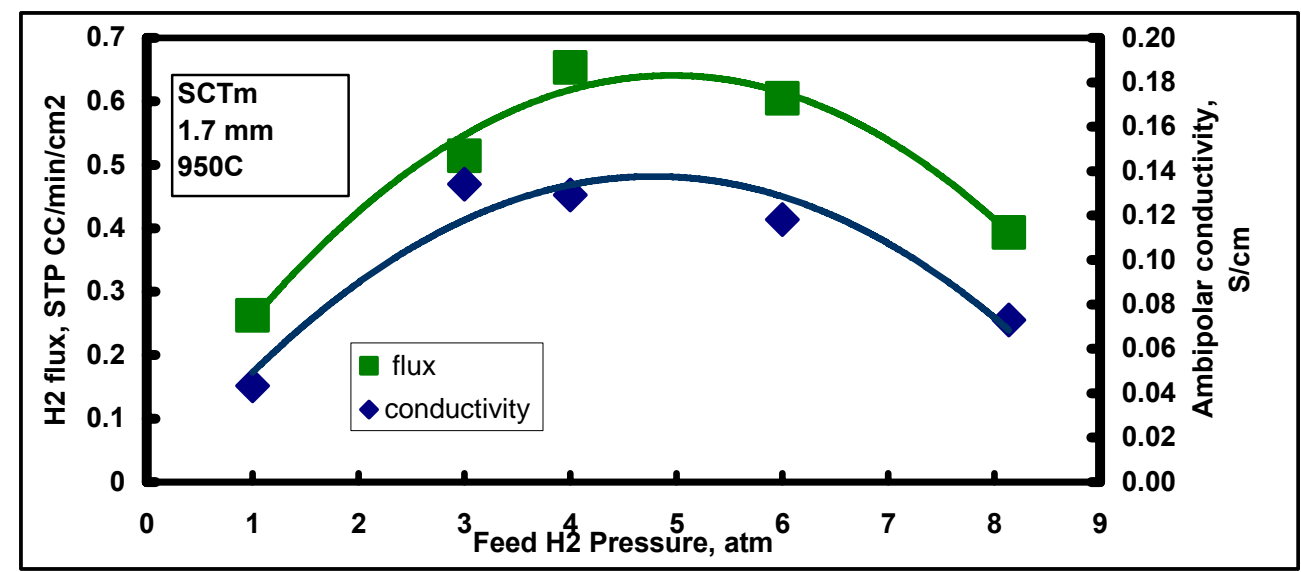

Figure 29. Hydrogen flux and calculated ambipolar conductivity for the SCTm membrane 
Equation (1) can be solved with the typical numerical techniques. The required boundary conditions are the flow rates and the compositions of the coal syngas entering the membrane tubes. A GTI gasification model U-GAS ${ }^{\circledR}$ was used to estimate the gas flow rates and the compositions from a fluidized bed gasifier, which are listed in Table 2 along with other operating conditions and parameters. The Illinois \#6 coal was used for this example.

In this design example, the membrane gasification reactor produces $44240 \mathrm{Nm}^{3} / \mathrm{hr}$ of hydrogen and $46610 \mathrm{Nm}^{3} / \mathrm{hr}$ of non-permeable syngas with the following compositions: $4 \% \mathrm{H}_{2}, 0.8 \% \mathrm{CH}_{4}, 39 \% \mathrm{CO}, 40 \% \mathrm{CO}_{2}$, and $16 \% \mathrm{H}_{2} \mathrm{O}$. Further optimization and process options for recovering more hydrogen from the non-permeable syngas stream will need to be developed. The performance of this membrane configuration will be used in the simulation for the overall coal to hydrogen processes employing the membrane reactor.

Table 2. Summary of design parameters for the conceptual membrane gasification reactor

\begin{tabular}{|c|c|c|c|}
\hline coal feed, TPD & 1000 & temperature, $\mathrm{C}$ & 1100 \\
\hline oxygen feed, TPD & 600 & pressure, atm & 60 \\
\hline steam feed to gasifer, TPD & 595 & gasifier diameter, cm & 330 \\
\hline steam feed to shift reactor,TPD & 270 & membrane tube diameter, $\mathrm{cm}$ & 1.25 \\
\hline coal syngas flow rates, $\mathrm{Nm} / \mathrm{hr}$ & 97125 & membrane thickness, cm & 0.0025 \\
\hline \multicolumn{2}{|l|}{ coal syngas composition } & membrane tube length, $\mathrm{cm}$ & 900 \\
\hline $\mathrm{H} 2$ & 0.280 & number of membrane tubes & 21300 \\
\hline $\mathrm{CH} 4$ & 0.042 & membrae area, m2 & 7550 \\
\hline $\mathrm{CO}$ & 0.297 & ambipolar conductivity, S/cm & 0.05 \\
\hline $\mathrm{CO} 2$ & 0.146 & gas residence time of mem., sec & 8 \\
\hline $\mathrm{H} 2 \mathrm{O}$ & 0.236 & enclosing filter tube diameter, cm & 1.87 \\
\hline
\end{tabular}

The gasifier diameter without the membrane module calculated from GTI's gasification model was about 2.5 meter. To accommodate the membrane unit, the upper section of the gasifier was increased to 3.3 meter in diameter. It appears that a membrane module can be configured within a fluidized bed gasifier without a substantial increase of the gasifier dimensions. If multi-train of gasifiers are used for the 1000 TPD coal to hydrogen plant, the gasifier diameter and the associated number of membrane tubes will be reduced.

\section{Task 3 - Process Evaluation and Flow Sheet Development}

Flowsheet simulation was performed to calculate material and energy balances based on four hydrogen production processes from coal using high temperature membrane reactor $\left(1000^{\circ} \mathrm{C}\right)$, low temperature membrane reactor $\left(250^{\circ} \mathrm{C}\right)$, or conventional technologies. The commercial HYSYS simulator was used for the task. As shown in Figure 30, Process A is the conventional coal to hydrogen process, where a Pressure Swing Adsorption unit is used for hydrogen separation unit. Process B combines the low temperature shift reaction and hydrogen separation into a single membrane shift reactor unit. Process $\mathrm{C}$ is 
one of the membrane gasification reactor concept, where hydrogen is directly extracted from the coal gasifier and the non-permeable gas, after clean up, is used for power generation. If the non-permeable gas stream is further processed by a low temperature membrane shift reactor to increase the overall hydrogen product, this option of the membrane gasification reactor concept is designated as Process D as shown in Figure 30.

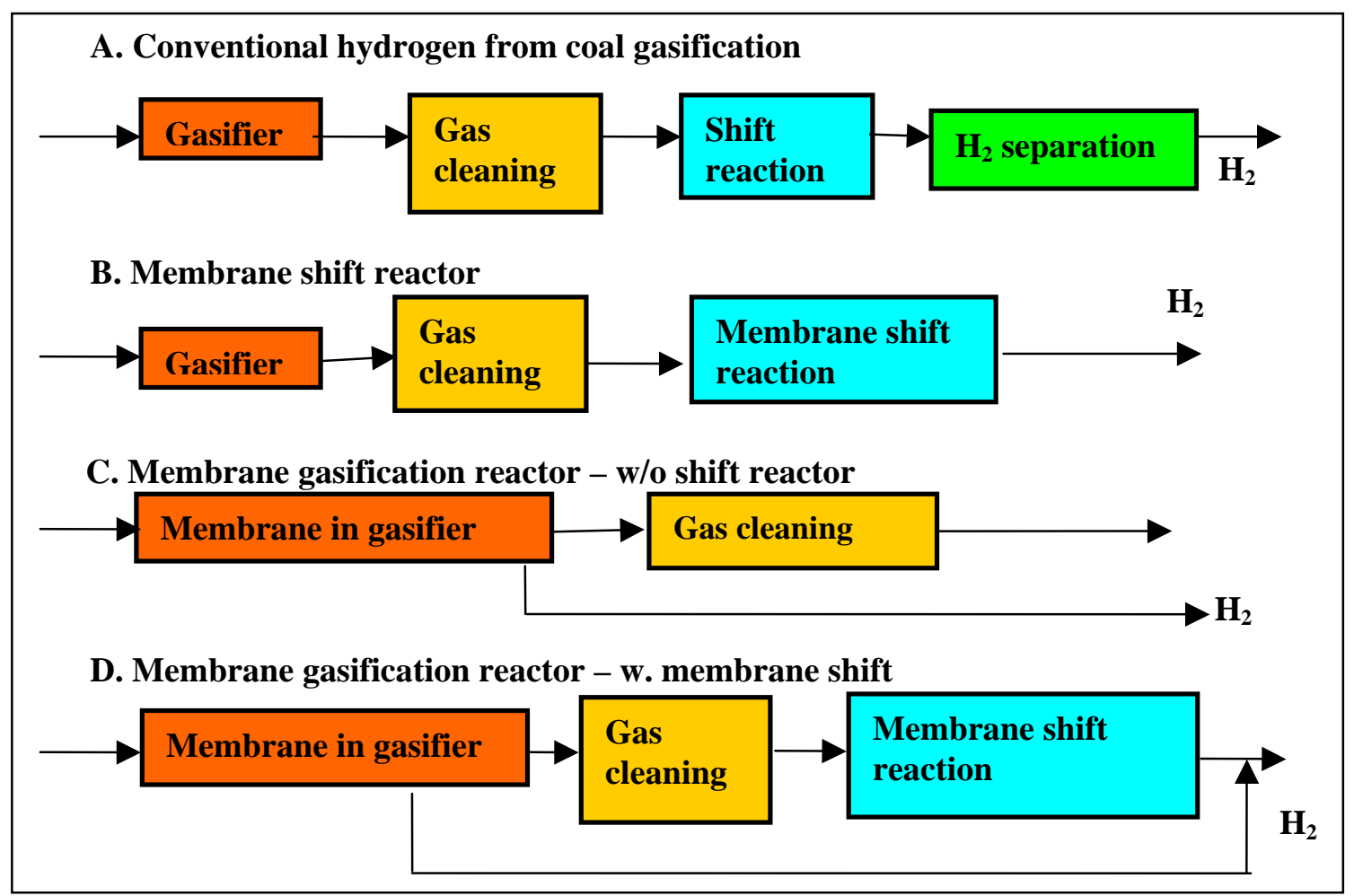

Figure 30. Comparison of Process Options for Hydrogen from Coal Gasification

\section{Design Basis}

The design was based on a coal feed of 1000 TPD (Tons per Day) using Illinois \#6 coal. GTI's U-GAS ${ }^{\circledR}$ fluidized bed was used for the gasifier, operating at 60 bars and $1100^{\circ} \mathrm{C}$. Oxygen, instead of air, was used for the gasifier oxidant. Air separation was based on the conventional cryogenic process. In addition to the gasifier, oxygen was also used for the combustion of the waste gas for steam or power generation. The simulation also focused on the heat recovery to generate additional power from the steam cycle. For the membrane processes, gas turbines were used to recover the heating value of the high pressure nonpermeate stream. For comparison purpose, the hydrogen product was generated at 50 bars, with the required hydrogen compression for the membrane processes. Hydrogen compression from the membrane unit can be eliminated if high pressure steam is used as a sweeping gas. However, this option is not considered in this work. Brief description of the four hydrogen from coal gasification processes examined in this task is given below 


\section{$\underline{\text { Process A }}$}

For the coal to hydrogen process using the conventional technologies, a block flow diagram is shown in Figure 31 with the calculated stream information listed in Table 1 of Appendix B. The hot syngas from the gasifier passes through a HRSG (Heat Recovery Steam Generation) unit to cool to below $300^{\circ} \mathrm{C}$. After the fine particulates are removed by a filter, the syngas stream is added with steam before entering the water-gas-shift reactor. Because the shift reactor is located upstream of the acid gas removal unit, a sulfur tolerant catalyst has to be used for the shift reactor unit. The shift reaction is assumed to reach equilibrium at the reactor adiabatic temperature, which results in a CO conversion greater than $80 \%$. Although the acid gas removal unit is not defined in this simulation, conventional process such as Selexol can be used in this low temperature range. All of the $\mathrm{H}_{2} \mathrm{~S}$ and $80 \%$ of $\mathrm{CO}_{2}$ are removed in the acid gas removal unit. The hydrogen recovery for the PSA unit is assumed to be $80 \%$. The PSA tail gas, which still contains $\mathrm{CH}_{4}, \mathrm{H}_{2}$ and $\mathrm{CO}$, is sent to a boiler for steam generation, which is then used for power generation in this case.

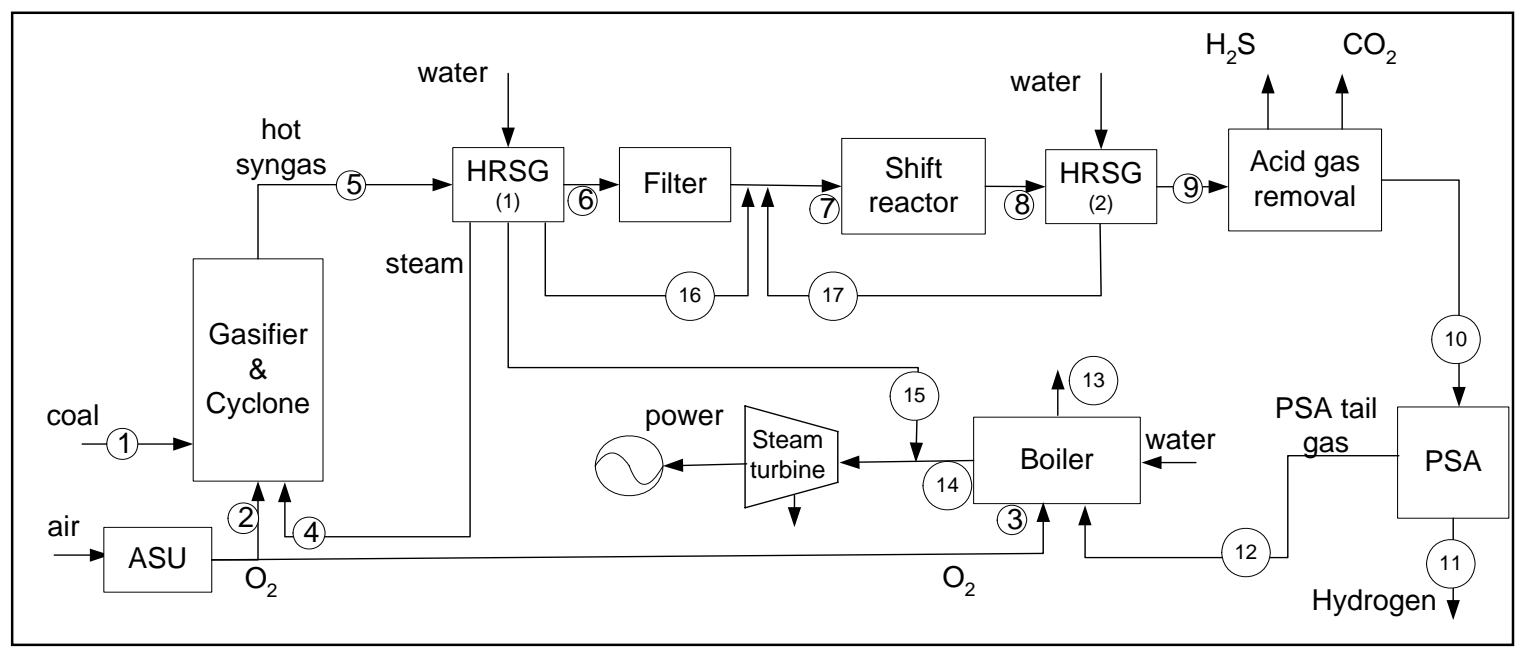

Figure 31. Block flow diagram for the coal to hydrogen process based on the conventional technologies, Process A

\section{Process B}

The block flow diagram for the Process B, which utilizes a low temperature $\left(<350^{\circ} \mathrm{C}\right)$ membrane shift reactor to replace the shift reactor and the PSA unit, is shown in Figure 32. The stream information is listed Table 2 of Appendix B.

The low temperature membrane shift reactor in process $\mathrm{B}$ is modeled as a shift reactor and a hydrogen separation unit with part of its non-permeate or retentate stream recycled to the shift reactor, as shown in Figure 33. The hydrogen recovery for the separation unit is assumed to be $80 \%$, and $70 \%$ of the retentate is recycled back to the shift reactor. The hydrogen partial pressure in the permeate side is maintained at about 2 bar. The final 
hydrogen product is compressed to 50 bars, which is at about the same pressure from the PSA unit of the Process A.

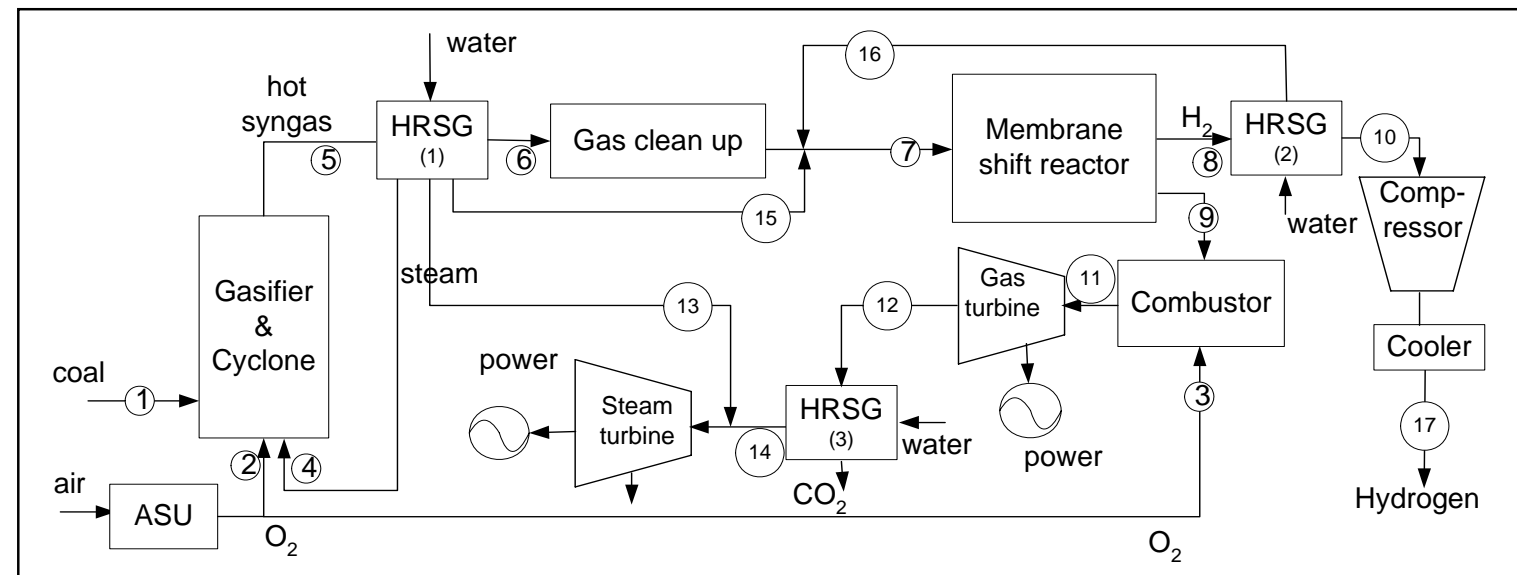

Figure 32. Block flow diagram for the coal to hydrogen process using a low temperature membrane shift reactor, Process $B$

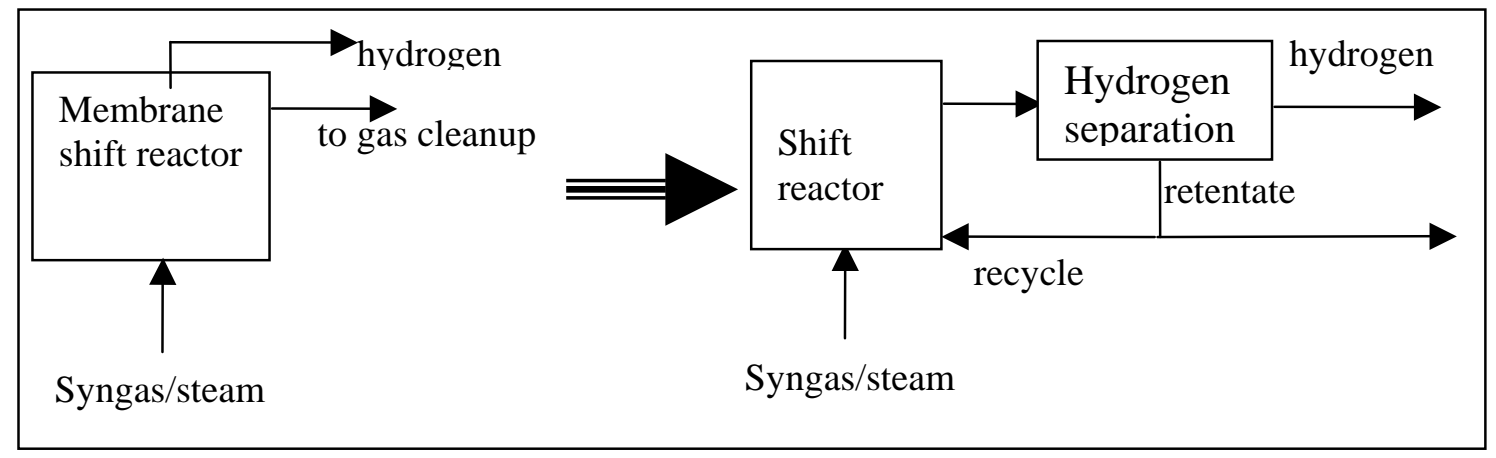

Figure 33. Modeling of membrane shift reactor

Because sulfur tolerance of the membrane material (such as palladium) has not been proven, a warm gas clean up unit is placed upstream the membrane shift reactor. This gas clean up unit is mainly for the $\mathrm{H}_{2} \mathrm{~S}$ removal.

The non-permeable gas from the membrane, which is at high pressure, 50 bar, is sent to a gas turbine for power generation. Oxygen combustion at the high pressure is used to facilitate the $\mathrm{CO}_{2}$ capture process. High pressure steam produced in the system is sent to a steam turbine for additional power generation.

\section{Process C}

Process $\mathrm{C}$ employs a high temperature $\mathrm{H}_{2}$-selective membrane such as the mixed protonic-electronic conducting membranes evaluated in this project. A block flow 
diagram of the Process $\mathrm{C}$ is shown in Figure 34 and the accompanied stream information is listed in Table B3.

The performance of the high temperature membrane reactor is based on the conceptual design and modeling of the tubular membranes, as reported in the Task 2 section.

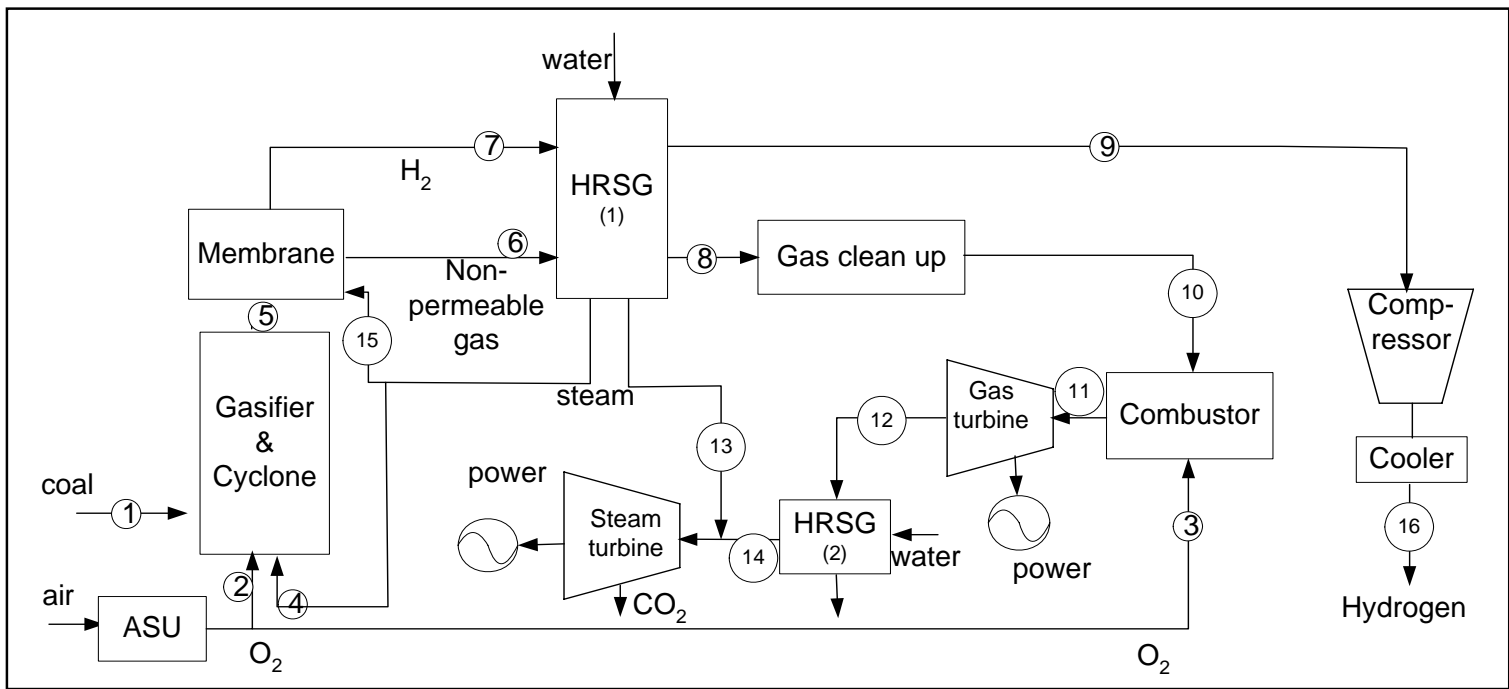

Figure 34. Block flow diagram for the coal to hydrogen process using a high temperature membrane reactor, Process $C$

Although the membrane module can be configured within the freeboard region of the fluidized bed gasifier, it can also be closely coupled with the gasifier, as shown in Figure 34. Because no low temperature shift reactor is used in this process option, additional steam is added to the membrane module to facilitate reforming and shift reactions in the membrane reactor. Similar to the low temperature membrane shift reactor case in Process $\mathrm{B}$, the hydrogen is produced at about 2 bars. Both hydrogen product and the nonpermeable gas streams go through a HRSG and are cooled to about $270^{\circ} \mathrm{C}$. After further cooling, the hydrogen product is compressed to about 50 bars.

The cooled non-permeable gas, after cleaned up for the removal of sulfur and other particulates, is sent to a combustor for power generation in a combined cycle, similar to the Process B.

\section{$\underline{\text { Process D }}$}

Process D combines the high temperature membrane reactor in Process $C$ and the low temperature membrane reactor in Process B to maximize the hydrogen production from coal gasification. The block flow diagram and the stream information are shown in Figure 35 and Table B4 respectively.

Again, the performance of the high temperature membrane reactor is based on the conceptual design as described in Task 2. The non-permeable gas from the high temperature membrane gasification reactor, after cooling and clean up is sent to a low 
temperature membrane reactor to further convert $\mathrm{CO}$ and separate $\mathrm{H}_{2}$. The nonpermeable gas from the low temperature membrane reactor is sent to a combustor for power generation in a combined cycle.

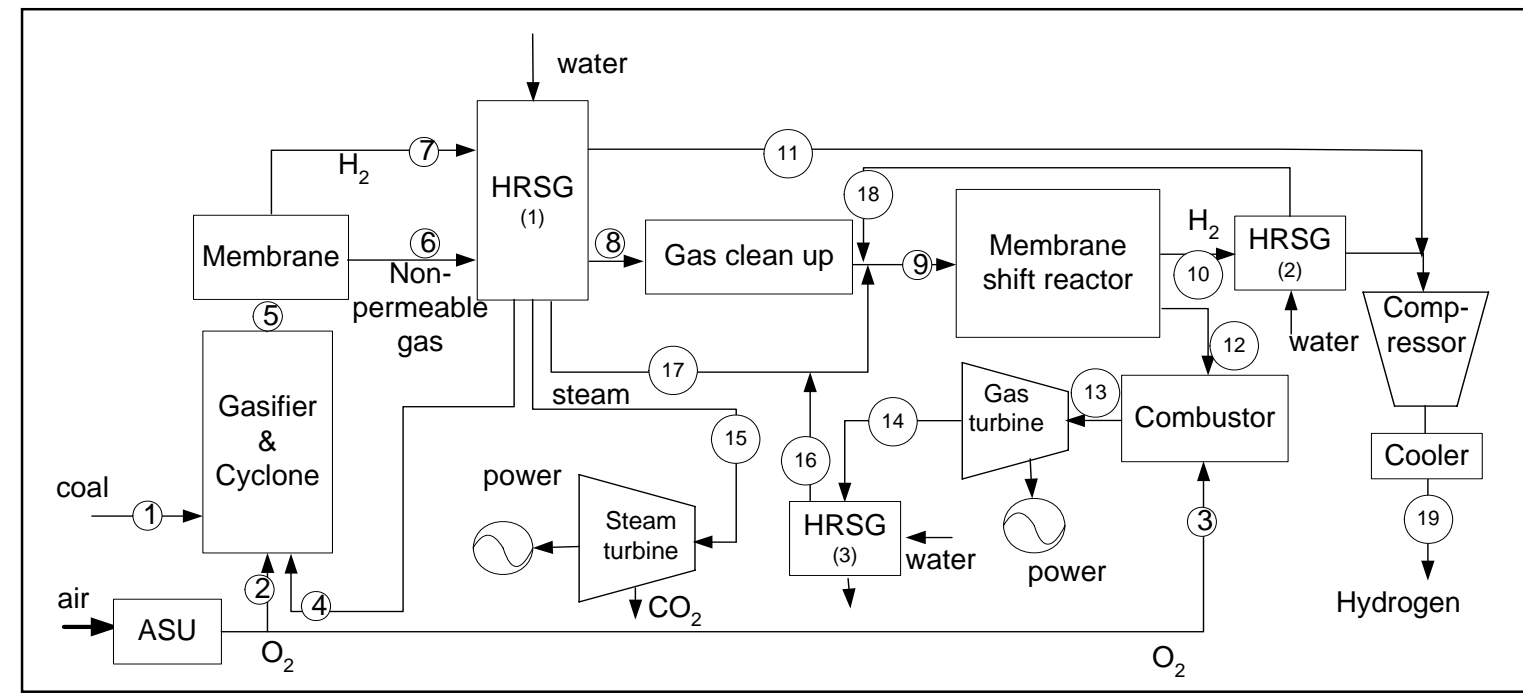

Figure 35. Block flow diagram for the coal to hydrogen process using a high temperature and a low temperature membrane reactors, Process $D$

For comparative purpose, the performances of the different coal to hydrogen processes are evaluated by the cold gas efficiency and the effective thermal efficiency, both of which are defined below:

Cold gas efficiency $=\underline{\text { hydrogen product heating value }(\mathrm{HHV})}$ coal heating value (HHV)

Effective thermal efficiency $=$ hydrogen product heating value + net power produced coal heating value

Table 3 summarized the amounts of hydrogen produced, power generated from the turbines, power consumption from the major equipment, the effective thermal efficiencies, the cold gas efficiencies and other parameters for the four processes evaluated in this work. In all four processes, $\mathrm{CO}_{2}$ can be readily captured due to the use of oxygen. However, compression of $\mathrm{CO}_{2}$ is excluded in the power calculation. Hydrogen product pressure is at 50 bars.

As can be seen, a less amount of oxygen would be required in the combustor to burn the waste gas when more hydrogen is produced in the process. Less power is produced when more hydrogen is generated. For the process employing both the high temperature and the low temperature membrane reactors (Process D), the hydrogen production can be increased by more than $50 \%$ relative to the conventional coal to hydrogen process (Process A), with a negative power output of $1 \mathrm{MW}$ for a $1000 \mathrm{TPD}$ plant. The 
conventional process has a net power output of $7 \mathrm{MW}$. For the process employing only the high temperature membrane reactor process (Process $\mathrm{C}$ ), the hydrogen production is increased by about $10 \%$ relative to the conventional process, with a net power output of $15 \mathrm{MW}$. For the process employing only the low temperature membrane reactor process (Process B), the hydrogen production is increased by about $20 \%$, with a net power output of $10 \mathrm{MW}$.

Process $\mathrm{C}$ or $\mathrm{D}$ also shows one advantage of the reduced syngas flows from the gasifier or from the high temperature membrane reactor to the syngas cooler, in comparison with Process A or Process B, which could potentially reduce the sizes of the downstream equipment such as gas clean up or shift reactor.

Apparently, the overall economics depends on the capital cost and the value of hydrogen versus the electrical power. Preliminary economic evaluation results are reported in the next section.

Table 3. Summary of performance for different coal to hydrogen processes

\begin{tabular}{|c|c|c|c|c|}
\hline Process & $\begin{array}{c}\text { A } \\
\text { conventiona } \\
l\end{array}$ & $\begin{array}{c}\text { B } \\
\text { Low temp } \\
\text { membrane }\end{array}$ & $\begin{array}{c}\mathrm{C} \\
\text { High- } \\
\text { temp } \\
\text { membrane }\end{array}$ & $\begin{array}{c}\text { D } \\
\text { Low-temp } \\
\text { \& high- } \\
\text { temp } \\
\text { membrane }\end{array}$ \\
\hline coal feed, TPD & 1000 & 1000 & 1000 & 1000 \\
\hline oxygen feed, kmole/hr & 1459 & 1279 & 1329 & 929 \\
\hline gasifier & 779 & 778.9 & 779 & 779 \\
\hline combustor & 680 & 500 & 550 & 150 \\
\hline hydrogen product, kmole/hr & 1826 & 2177 & 2070 & 2896 \\
\hline flow to syngas cooler, kmole/hr & 4270 & 4270 & 3156 & 2630 \\
\hline steam turbine power, MW & 22 & 12 & 20 & 7 \\
\hline gas turbine power, MW & & 21 & 19 & 14 \\
\hline oxygen compressor, MW & 3 & 5 & 5 & 4 \\
\hline ASU power, MW & 11 & 10 & 10 & 7 \\
\hline hydrogen compressor, MW & & 8 & 7 & 10 \\
\hline water pumps, MW & 0.5 & 0.4 & 0.4 & 0.2 \\
\hline net power, MW & 7 & 10 & 15 & -1 \\
\hline effective thermal efficiency, \% & 46.3 & 55.6 & 54.4 & 69.8 \\
\hline cold gas efficiency, \% & 44.1 & 52.6 & 50 & 69.9 \\
\hline
\end{tabular}

\section{Task 4 - Economic Evaluation for Overall $\mathrm{H}_{2}$ Production Process}

Economic analysis was performed to evaluate the hydrogen product costs from the above four coal to hydrogen processes. Cost estimates for hydrogen production from coal based 
on the conventional technologies have been studied by several groups [2,3,21-23]. Itemized capital costs used for the current study in this project are based on those reported in the literature. These include the major equipment such as gasifier, heat recovery system, air separation (ASU) plant, gas clean up unit, shift reactor, PSA, turbines, etc. and are listed in Table 4. Obviously, the cost of each processing unit depends on the size. The size of the unit is determined by the quantities of the material, coal or syngas, that each unit can process, which is listed in the third column of the Table 4. For the high temperature membrane reactor unit in Process $C$ or $D$, the membrane cost is assumed to meet the DOE's cost target of $\$ 100 / \mathrm{ft}^{2}$. Design study in Task 2 shows the required membrane area to be $7550 \mathrm{~m}^{2}$ (see Table 1), which results in a total membrane cost of $\$ 8124 \mathrm{~K}$. The membrane module is assumed to account for $40 \%$ of the membrane separation unit cost with the remaining $60 \%$ for the auxiliary equipment including hydrogen compressor. The total cost for the high temperature membrane unit is estimated to be $\$ 20,300 \mathrm{~K}$.

Table 4. Itemized capital cost and corresponding equipment size

\begin{tabular}{|l||c||c|}
\hline unit & Cost \$1000K & size \\
\hline coal preparation and handling & 32,000 & $2500 \mathrm{tpd}$ coal \\
\hline gasifier (fluidized bed) & 32,000 & $2500 \mathrm{tpd}$ coal \\
\hline Heat recovery steam generation & 7,400 & $259,000 \mathrm{Nm} / \mathrm{hr}$ syngas \\
\hline shift reactor & 19,000 & $259,000 \mathrm{Nm} / \mathrm{hr}$ syngas \\
\hline PSA & 34,000 & $259,000 \mathrm{Nm} / \mathrm{hr}$ syngas \\
\hline ASU +O2 compressor & 50,000 & $2000 \mathrm{tpd} \mathrm{O2}$ \\
\hline gas cleanup + sulfur recovery & 30,000 & $259,000 \mathrm{Nm} / \mathrm{hr}$ syngas \\
\hline gas turbine + combustor & 20,000 & $52 \mathrm{MW}$ \\
\hline steam turbine & 17,000 & $78 \mathrm{MW}$ \\
\hline balance of plant & 70,000 & $2500 \mathrm{tpd}$ coal \\
\hline low temp membrane + shift & 53,000 & $259,000 \mathrm{Nm} / \mathrm{hr}$ syngas \\
\hline high temp membrane & 20,300 & $97,125 \mathrm{Nm} / \mathrm{hr}$ syngas \\
\hline
\end{tabular}

Based on the flow rates of the material streams for the four processes shown in Figure 32, 33, 34 and 35, the cost of each piece of equipment can be calculated using the 0.6 scale factor. The numbers in Table 4 are used as the basis of the cost and the size of the equipment. For example, the gasifier cost for a 1000 TPD plant is \$32 million multiplied by $(1000 / 2500)^{0.6}$ or $\$ 18.5$ million. Instead of material flows, the power outputs are used to scale the costs of the turbines. The results for the capital cost of major equipment for the four processes are listed in Table 5.

The final hydrogen product cost is calculated using the IGCC Financial Model Version 4 developed by Nexant, Inc., which is available through DOE. The financial parameters used in the model are 30 years plant life, 95\% plant availability, 3 years construction period, $80 \%$ debt and 20\% equity, 39\% tax rate, and 18\% Internal Rate of Return (IRR). Other relevant cost parameters are cost of coal \$28/ton, cost of electricity \$30/MWh, and 
cost of annual operation 4\% of capital cost. The calculated hydrogen costs are listed at the bottom of Table 5.

Process D, despite its higher capital cost, shows about 30\% reduction in the hydrogen cost compared to Process A, because Process D produces more hydrogen for the given amount of coal feed. Process D has a lower ASU cost due to a smaller amount of waste gas to combust with $\mathrm{O}_{2}$. The cost of gas clean-up unit is also lower. However, the capital cost is increased by the additional membrane units. Process B, similar to Parson's study, shows a cost advantage over the conventional coal to hydrogen process. Process $C$, with an advantage of lower capital than Process B, also has an about 15\% cost saving from the conventional Process A.

Table 5. Summary of equipment size and capital cost for the four hydrogen production processes from coal gasification

\begin{tabular}{|c|c|c|c|c|c|c|c|c|c|}
\hline & \multicolumn{5}{|c|}{ Quantity of Material Processed } & \multicolumn{4}{|c|}{ Capital Cost, $\$ 1000$} \\
\hline unit & process & A & $\mathrm{B}$ & C & $\mathrm{D}$ & A & $\mathrm{B}$ & $\mathrm{C}$ & $\mathrm{D}$ \\
\hline \begin{tabular}{|l|} 
coal preparation \\
and handling \\
\end{tabular} & tpd coal & 1000 & 1000 & 1000 & 1000 & 18,470 & 18,470 & 18,470 & 18,470 \\
\hline $\begin{array}{l}\text { gasifier (fluidized } \\
\text { bed) } \\
\end{array}$ & tpd coal & 1000 & 1000 & 1000 & 1000 & 18,470 & 18,470 & 18,470 & 18,470 \\
\hline $\begin{array}{l}\text { Heat recovery } \\
\text { steam generation }\end{array}$ & $\begin{array}{l}\mathrm{Nm} / \mathrm{hr} \\
\text { syngas }\end{array}$ & 95648 & 95648 & 117062 & 103152 & 4,070 & 4,070 & 4,600 & 4,260 \\
\hline shift reactor & $\begin{array}{l}\mathrm{Nm} / \mathrm{hr} \\
\text { syngas }\end{array}$ & 116637 & 0 & 0 & 0 & 11,770 & 0 & 0 & 0 \\
\hline PSA & $\begin{array}{l}\mathrm{Nm} / \mathrm{hr} \\
\text { syngas }\end{array}$ & 63773 & 0 & 0 & 0 & 14,670 & 0 & 0 & 0 \\
\hline \begin{tabular}{|l|}
$\mathrm{ASU}+\mathrm{O} 2$ \\
compressor \\
\end{tabular} & tpd O2 & 1120 & 982 & 1020 & 710 & 35,320 & 32,630 & 33,390 & 26,860 \\
\hline $\begin{array}{l}\text { gas cleanup + } \\
\text { sulfur recovery }\end{array}$ & $\begin{array}{l}\mathrm{Nm} / \mathrm{hr} \\
\text { syngas }\end{array}$ & 95648 & 95648 & 70694 & 58912 & 16,500 & 16,500 & 13,770 & 12,340 \\
\hline $\begin{array}{l}\text { gas turbine + } \\
\text { combustor }\end{array}$ & MW & & 21 & 19 & 14 & 0 & 11,610 & 10,930 & 9,100 \\
\hline steam turbine & MW & 22 & 12 & 20 & 7 & 7,940 & 5,520 & 7,500 & 4,000 \\
\hline balance of plant & tpd coal & 1000 & 1000 & 1000 & 1000 & 40,400 & 40,400 & 40,400 & 40,400 \\
\hline $\begin{array}{l}\begin{array}{l}\text { low temp mem + } \\
\text { shift }\end{array} \\
\end{array}$ & $\begin{array}{l}\mathrm{Nm} / \mathrm{hr} \\
\text { syngas }\end{array}$ & & 112560 & & 74547 & 0 & 32,150 & & 25,100 \\
\hline high temp mem & $\begin{array}{l}\mathrm{Nm} / \mathrm{hr} \\
\text { syngas }\end{array}$ & & & 95648 & 95648 & 0 & 0 & 20,290 & 20,290 \\
\hline Total capital & & & & & & 167,600 & 179,800 & 167,800 & 179,300 \\
\hline$\$ / \mathrm{kg} \mathrm{H} 2$ & & & & & & 1.38 & 1.19 & 1.15 & 0.96 \\
\hline$\$$ /MBtu H2 & & & & & & 9.70 & 8.40 & 8.12 & 6.75 \\
\hline
\end{tabular}




\section{CONCLUSIONS AND RECOMMENDATIONS}

The major achievements from this project can be summarized as follows:

- Constructed and commissioned a new membrane permeation unit capable of operating at up to $1100^{\circ} \mathrm{C}$ and $60 \mathrm{bar}$, allowing screening and testing of hydrogen membranes under gasification conditions.

- The hydrogen flux measured for several proton-conducting perovskite membranes appeared to be adequate for the membrane module design. The highest hydrogen flux obtained was $1.0 \mathrm{STP} \mathrm{cc} / \mathrm{min} / \mathrm{cm}^{2}$ for the SCTm membrane at 3 bars and $1040^{\circ} \mathrm{C}$.

- Conceptual design of a membrane reactor for a plant of 1000 TPD coal showed that a membrane module could be configured within a fluidized bed gasifier without a substantial increase of the gasifier dimensions.

- Developed membrane reactor models for fluidized bed gasifier incorporating major gas phase reactions in the membrane gasifier and hydrogen permeation via mixed proton-electron conducting materials.

- Completed flowsheet simulation for hydrogen production based on the proposed membrane reactor processes and confirmed a more than $50 \%$ increase in hydrogen production efficiency compared to the conventional process.

- Identified the Zr-doped perovskite membrane as a leading material for further testing with respect to the chemical stability issues in the coal-derived syngas environment.

- The proposed membrane reactor process could potentially decrease the hydrogen cost by about 30\% from the conventional coal to hydrogen process, based on a preliminary economic analysis and the assumption of the membrane material meeting DOE's flux and cost targets.

GTI has developed a multi-year road map for moving this concept to commercial success. (Figure 36) The plan calls for development efforts in four major areas, membrane material development, membrane module development, membrane gasifier process development, and membrane gasifier scale-up. In the initial phase of the program, the membrane material development is the key effort, which is the focus of this project. The membrane material developed in the laboratory must be fabricated in a commercial scale, which also depends on a careful design of the membrane module, either tubular or planar form. Membrane process development and optimization is essential to realize the maximum performance from the selected membrane materials and achieve the overall cost effectiveness. The developed membrane gasifier technology will be validated through a series of bench, pilot and commercial demonstration units. Recommendations for future works include:

- Improve the hydrogen permeability by minimizing the membrane thickness and increasing the material conductivity.

- Improve the chemical and mechanical stability of the membrane materials.

- Conduct permeation testing with simulated syngas

- Conduct permeation testing with real syngas from a coal gasifier 
- Scale up the size of the membrane disks. Samples as large as 1.25” diameter disks have been routinely prepared in this program. Much bigger sizes will be needed for future commercial applications.

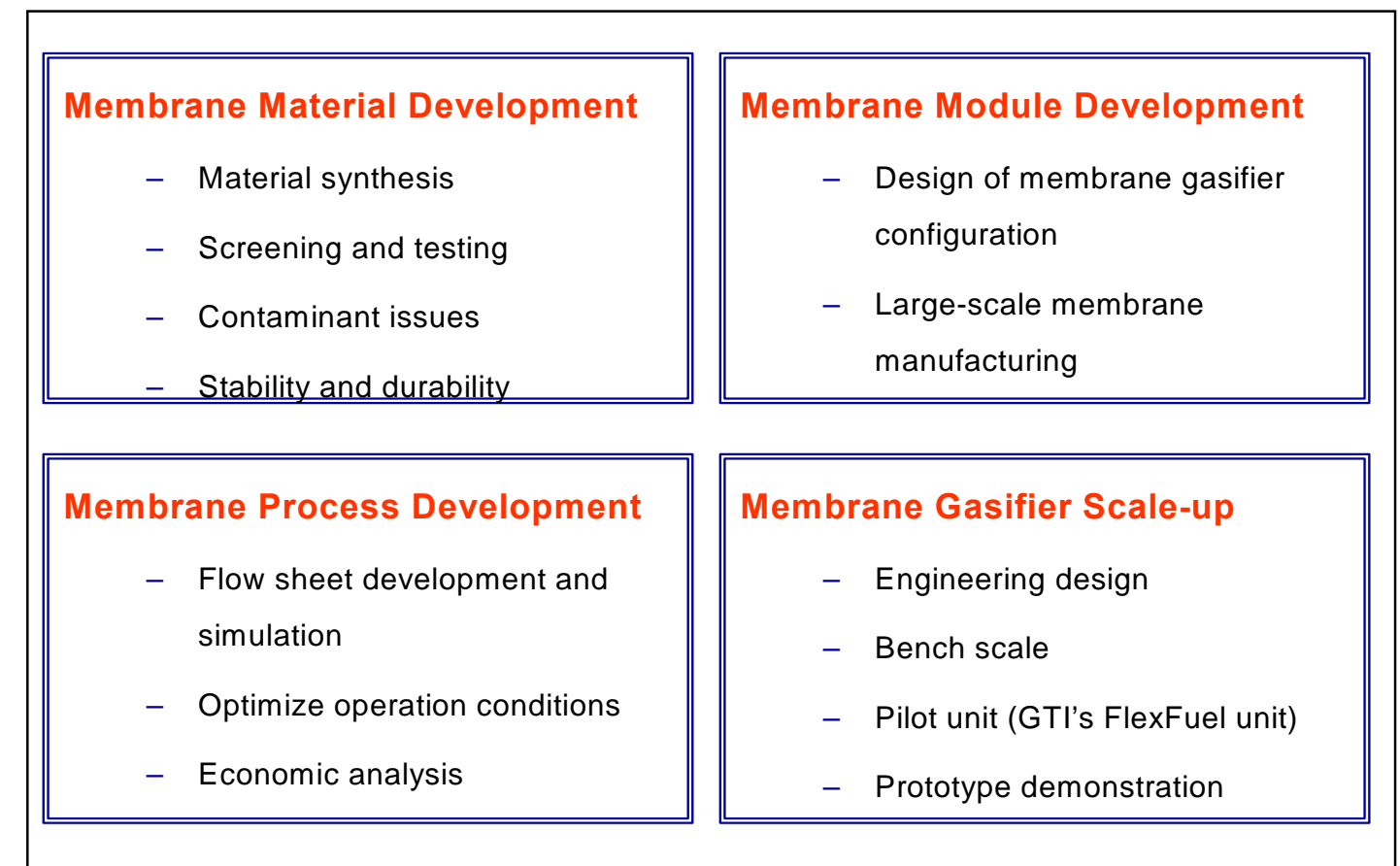

Figure 36. Roadmap for successful membrane reactor development 


\section{REFERENCES}

1. US Department of Energy “Office of Fossil Energy- Hydrogen Program Plan”, June 2003

2. Parsons Infrastructure and Technology Group, Inc., March 2002 "Hydrogen Production Facilities Plant Performance and Cost Comparisons”, Final Report DOE Contract DE-AM26-99FT40465.

3. Gary, D and G. Tomlinson, Mitretek, July 2002 "Hydrogen from Coal”, MTR 200231DOE Contract DE-AM26-99FT40465.

4. H. Iwahara, T. Esaka, H. Uchida, and N. Maeda, 1981. "Proton Conduction in Sintered Oxides and Its Application to Steam Electrolysis for Hydrogen Production" Solid State Ionics, 3/4, 359-363.

5. S. Doong, 2004 "Direct Hydrogen Production from Coal Using Novel Membrane Gasifier” ICCI project report 03-1/2.1A-2.

6. S.J. Doong, F. Lau and E. Ong, 2005 "Mixed Protonic-Electronic Conducting Membrane for Hydrogen Production from Solid Fuels" in "Advances in Membranes for Energy and Fuel Applications” ed. By A. Bose, ACS Book Series, in press.

7. J.F. Liu and A.S. Nowick, 1992 "The incorporation and migration of protons in Nddoped $\mathrm{BaCeO}_{3}$ ”, Solid State Ionics, 50, pp131.

8. X. Qi and Y.S. Lin, 2000, "Electrical Conduction and Hydrogen Permeation Through Mixed Proton-Electron Conducting Strontium Cerate Membranes" Solid State Ionics, 130, P149.

9. S. M. Haile, G. Staneff and K. H. Ryu, 2001 "Non-stoichiometry, Grain Boundary Transport and Chemical Stability of Proton Conducting Perovskites", J. of Materials Science, 36, p1149-1160.

10. K. H. Ryu and S.M. Haile, 1999, "Chemical Stability and Proton Conductivity of Doped $\mathrm{BaCeO}_{3}-\mathrm{BaZrO}_{3}$ Solid Solutions” Solid State Ionics, 125, P355-367.

11. K. Katahira, Y. Kohchi, T. Shimura and H. Iwahara, 2000, "Protonic Conduction in Zr-Substituted $\mathrm{BaCeO}_{3}$ " Solid State Ionics, 138, P91-98.

12. S-J Song, E.D. Wachsman, J. Rhodes, S.E. Dorris, U. Balachandran "Numerical modeling of hydrogen permeation in chemical potential gradients", Solid State Ionics, 164, pp107-116, 2003

13. T. Schober, W. Schilling and H. Wenzl "Defect model of proton insertion into oxides”, Solid State Ionics, 86-88, pp653-658, 1996

14. T. Schober, J. Friedrich, and J.B. Condon, "Effective hydrogen diffusivity in $\mathrm{SrCe}_{0.95} \mathrm{Yb}_{0.05} \mathrm{O}_{3-\mathrm{a}}$ and $\mathrm{SrZr}_{0.95} \mathrm{Yb}_{0.05 \mathrm{Y}} \mathrm{b} 0.05 \mathrm{O}_{3-\mathrm{a}}$ " Solid State Ionics, 77 pp175-179, 1995

15. X. Tan, S. Liu, K. Li and R. Hughs "Theoretical analysis of ion permeation through mixed conducting membranes and its application on dehydrogenation reactions", Solid State Ionics, 138, pp149-159, 2000

16. F. Krug, T. Schober and T. Springer "In situ measurements of the water uptake in $\mathrm{Yb}$ doped SrCeO3" Solid State Ionics, 81 pp111-118, 1995

17. J. Guan, S.E. Dorris, U. Balachandran and M. Liu, "Transport properties of SrCeYO3 and its applications for hydrogen separation” Solid State Ionics, 110, pp303-310, 1998 
18. G.A. Karim and M.M. Metwally, 1979. "A Kinetic Investigation of the Reforming of Natural Gas for the Production of Hydrogen”, Int. J. Hydrogen Energy, Vol. 5, P293.

19. H.J.M. Bouwmeester and A.J. Burggraaf, 1996. "Dense Ceramic Membranes for Oxygen Separation", in Fundamentals of Inorganic Membrane Science and Technology, Ed. By A.J. Burggraff and L. Cot, pp 435-528, Elsevier Science B.V.

20. T. Norby and Y. Larring, 2000. "Mixed Hydrogen Ion-Electronic Conductors for Hydrogen Permeable Membranes", Solid State Ionics, 136-137, pp139-148.

21. Nexant in association with GTI, March 2005, "Task 3 Gasification Alternatives for Industrial Applications” Final Report, DOE Contract No DE-AC26-99FT40342, Subtask 3.4 - Lignite Fueled IGCC Power Plant.

22. D. R. Simbeck and E. Chang, SFA Pacific, Inc., 2002, "Hydrogen Supply: Cost Estimates for Hydrogen Pathways - Scoping Analysis”, NREL Report, DOE Contract No. DE-AC36-99-GO10337.

23. M. Schwartz, ITN Energy Systems, Inc., 2004, "Novel Composite Membrane for Hydrogen Separation in Gasification Processes in Vision 21 Energy Plants", Final Report, DE-FC26-01NT40973.

24. L. Li and E. Iglesia, 2003, "Modeling and analysis of hydrogen permeation in mixed proton-electronic conductors”, Chem Engr Sci, 58, pp1977-1988 


\section{APPENDICES}

A. Transport Model for the Mixed Protonic-Electronic Conducting Membrane

In a MIEC membrane, the driving forces for the transport of charged species come from both chemical and electrical potential gradients. The flux of each species $\mathrm{k}, J_{k}$ can be described by a combination of Fick's law and the equation for ion migration:

$$
J_{k}=-\frac{\sigma_{k}}{z_{k}^{2} F^{2}}\left(\frac{\partial \mu_{k}}{\partial x}+z_{k} F \frac{\partial \phi}{\partial x}\right)
$$

where $\mu$ is the chemical potential, $\phi$ is the electrical potential, $\sigma$ is the conductivity, $z$ is the charge number and $\mathrm{F}$ is the Faraday constant.

When no external current is imposed on the membrane, the net flux from all the charged species is zero, i.e.

$I=\sum_{k=1}^{n} I_{k}=\sum_{k=1}^{n} z_{k} F J_{k}=0$

Combining Eqs.(A1) and (A2), a relationship between the electrical potential and the chemical potential can be obtained:

$$
\frac{\partial \phi}{\partial x}=-\sum_{k=1}^{n} \frac{t_{k}}{z_{k} F} \frac{\partial \mu_{k}}{\partial x}
$$

where $t_{k}$ is the transport number of species $\mathrm{k}$, which is a relative measure of conductivity of species $k$ to the total conductivity.

$$
t_{k}=\frac{\sigma_{k}}{\sum_{i=1}^{n} \sigma_{i}}
$$

The flux equation, Eq. (A1) now becomes

$$
J_{k}=-\frac{\sigma_{k}}{z_{k}^{2} F^{2}}\left(\frac{\partial \mu_{k}}{\partial x}-z_{k} \sum_{i=1}^{n} \frac{t_{i}}{z_{i}} \frac{\partial \mu_{i}}{\partial x}\right)
$$

Chemical potential $\mu$ is related to chemical activity $a_{i}$ by 
$\frac{\partial \mu_{k}}{\partial x}=R T \frac{\partial \ln a_{k}}{\partial x}$

Under ideal conditions, the activity $a$ can be substituted with the concentration C. Further, the conductivity of the defect species can be correlated with its concentration and diffusivity by the Nernst-Einstein equation:

$\sigma_{k}=\frac{z_{k}^{2} F^{2}}{R T} C_{k} D_{k}$

Substituting Eq.(A6) and (A7) into Eq.(A5), the following equation can be obtained:

$J_{k}=-C_{k} D_{k}\left[\frac{\left(1-t_{k}\right)}{C_{k}} \frac{\partial C_{k}}{\partial x}-\sum_{\substack{i=1 \\ i \neq k}}^{n} \frac{z_{k} t_{i}}{z_{i} C_{i}} \frac{\partial C_{i}}{\partial x}\right]$

Eq. (A8) relates the flux of each species to the concentrations and the diffusivities of all the species inside the MIEC membrane.

In proton-electron conductors, charged carriers are protons $\left(O H^{\bullet}\right)$, vacancies $\left(V_{\ddot{O}}\right)$, electrons $\left(e^{-}\right)$, and electron holes $\left(h^{\bullet}\right)$. The concentrations of the defect species in a typical proton conductor can be described by the following stoichiometric equations [24]:
$1 / 2 O_{2}+V_{\ddot{O}}=O_{O}^{x}+2 h^{\bullet}$$$
K_{1}=C_{h}^{2} /\left(C_{V} p_{O_{2}}^{1 / 2}\right)
$$$$
H_{2}+2 \mathrm{O}_{O}^{x}=2 O H^{\bullet}+2 e^{-}
$$$$
K_{2}=\left(C_{O H}^{2} C_{e}^{2}\right) / p_{\mathrm{H}_{2}}
$$$$
\mathrm{H}_{2}+1 / 2 \mathrm{O}_{2}=\mathrm{H}_{2} \mathrm{O}
$$$$
K_{3}=p_{w} /\left(p_{\mathrm{H}_{2}} p_{\mathrm{O}_{2}}^{1 / 2}\right)
$$

where $O_{O}^{x}$ denotes the lattice oxygen. Eqs.(A9) to (A11) establish the relationships between the concentrations of charged species inside the membrane to the gas partial pressures outside the membrane. The chemical potentials of each charged species can also be related to the chemical potentials of gases through the following equations corresponding to Eqs.(A9) to (A11):

$$
\begin{aligned}
& 1 / 2 \mu_{O_{2}}+\mu_{V}=2 \mu_{h} \\
& \mu_{H_{2}}=2 \mu_{O H}+2 \mu_{e}
\end{aligned}
$$


$\mu_{H_{2}}+1 / 2 \mu_{O_{2}}=\mu_{w}$

Also the electronic equilibrium requires

$e^{-}+h^{\bullet}=$ nil $\quad K_{e}=C_{e} C_{h}$

$\mu_{e}+\mu_{h}=0$

Therefore, Eq.(A8) for proton $\mathrm{OH}^{\bullet}$ and vacancy $V_{\ddot{O}}$, will become

$$
\begin{aligned}
& J_{O H}=-\frac{t_{O H} \sigma R T}{2 F^{2}}\left[\left(t_{h}+t_{e}\right) \frac{\partial \ln p_{H_{2}}}{\partial x}+4 t_{V} \sigma \frac{\partial \ln p_{w}}{\partial x}\right] \\
& J_{V}=-t_{V} \sigma \frac{R T}{F^{2}}\left[\left(t_{h}+t_{e}\right) \frac{\partial \ln p_{H_{2}}}{\partial \ln x}-\left(t_{h}+t_{e}+t_{O H}\right) \frac{\partial \ln p_{w}}{\partial x}\right]
\end{aligned}
$$

Eqs.(A17) and (A18) can not be integrated directly because the transport numbers, $t_{i}$ and the total conductivity $\sigma$ are functions of the membrane position $x$. However, at steady state, $J_{\mathrm{OH}}$ and $J_{V}$ are constant and independent of the membrane positions. The above equations can be rearranged to give

$$
\begin{aligned}
& \frac{R T}{F^{2}} \frac{\partial \ln p_{H_{2}}}{\partial x}=-\frac{4 J_{V}}{\sigma\left(t_{h}+t_{e}\right)}-\frac{2 J_{O H}\left(t_{h}+t_{e}+t_{O H}\right)}{\sigma t_{O H}\left(t_{h}+t_{e}\right)} \\
& \frac{R T}{F^{2}} \frac{\partial \ln p_{w}}{\partial x}=\frac{J_{V}}{\sigma t_{V}}-\frac{2 J_{O H}}{\sigma t_{O H}}
\end{aligned}
$$

Given the boundary conditions at both the feed side and the permeate side of the membrane, Eqs.(A19) and (A20) can be integrated with respect to $x$ to obtain the profiles of hydrogen and water partial pressures across the membrane. The concentration profiles of the four defect species, proton $\left(C_{O H}\right)$, vacancy $\left(C_{V}\right)$, electron $\left(C_{e}\right)$, and electron hole $\left(C_{h}\right)$ are related to the gas partial pressure through Eqs.(A9) to (A11). The required parameters for the membrane material are equilibrium constants, $K_{1}, K_{2}, K_{3}$, and $K_{e}$ as well as the diffusivity data for the four defect species.

\section{B. Major Gas Streams for Different Coal to Hydrogen Processes}


Table B1. Major gas streams of Process A, conventional coal to hydrogen process

\begin{tabular}{|c|c|c|c|c|c|c|c|c|c|}
\hline stream number & 1 & 2 & 3 & 4 & 5 & 6 & 7 & \multicolumn{1}{c|}{8} & 9 \\
\hline stream description & coal feed & $\begin{array}{l}\text { oxygen to } \\
\text { gasifier }\end{array}$ & $\begin{array}{l}\text { oxygen to } \\
\text { combustor }\end{array}$ & $\begin{array}{l}\text { steam to } \\
\text { gasifier }\end{array}$ & $\begin{array}{l}\text { hot } \\
\text { syngas }\end{array}$ & $\begin{array}{l}\text { cool } \\
\text { syngas }\end{array}$ & $\begin{array}{l}\text { syngas to } \\
\text { shft }\end{array}$ & $\begin{array}{l}\text { syngas } \\
\text { from shift }\end{array}$ & $\begin{array}{l}\text { cool shifted } \\
\text { gas }\end{array}$ \\
\hline stream composition, \% & & & & & & & & & \\
\hline CH4 & & & & & 4.13 & 4.13 & 3.39 & 3.39 & 3.39 \\
\hline CO & & & & & 29.72 & 29.72 & 24.37 & 3.48 & 3.48 \\
\hline CO2 & & & & & 14.55 & 14.55 & 11.93 & 32.82 & 32.82 \\
\hline H2 & & & & & 27.99 & 27.99 & 22.95 & 43.84 & 43.84 \\
\hline H2O & & & & 100 & 22.06 & 22.06 & 36.08 & 15.19 & 15.19 \\
\hline O2 & & 97.5 & 97.5 & & 0 & 0 & 0 & 0 & 0 \\
\hline N2 & & 2.5 & 2.5 & & 0.69 & 0.69 & 0.57 & 0.57 & 0.57 \\
\hline H2S & & & & & 0.86 & 0.86 & 0.71 & 0.71 & 0.71 \\
\hline total & & & & & 100 & 100 & 100.00 & 100.00 & 100.00 \\
\hline molar flow, kgmole/hr & & 779 & 680 & 1377 & 4270 & 4270 & 5207 & 5207 & 5207 \\
\hline mass flow, $\mathrm{kg} / \mathrm{hr}$ & 41667 & 24920 & 21760 & 24781 & 87170 & 87170 & 104000 & 104000 & 104000 \\
\hline pressure, atm & 60 & 60 & 1.7 & 60 & 58 & 54 & 53 & 52 & 51 \\
\hline temperature, C & 25 & 30 & 30 & 276 & 1040 & 270 & 266 & 331 & 265 \\
\hline
\end{tabular}

\begin{tabular}{|c|c|r|r|r|r|r|r|r|}
\hline stream number & 10 & 11 & 12 & 13 & 14 & 15 & 16 & 17 \\
\hline stream description & $\begin{array}{l}\text { syngas to } \\
\text { PSA }\end{array}$ & $\begin{array}{l}\text { hydrogen } \\
\text { product }\end{array}$ & $\begin{array}{l}\text { PSA tail } \\
\text { gas }\end{array}$ & $\begin{array}{l}\text { boiler flue } \\
\text { gas }\end{array}$ & $\begin{array}{l}\text { steam } \\
\text { from } \\
\text { boiler }\end{array}$ & $\begin{array}{l}\text { steam to } \\
\text { turbine } \\
\text { from } \\
\text { HRSG(1) }\end{array}$ & $\begin{array}{l}\text { steam to } \\
\text { shift from } \\
\text { HRSG(1) }\end{array}$ & $\begin{array}{l}\text { steam to } \\
\text { shift from } \\
\text { HRSG(2) }\end{array}$ \\
\hline stream composition, \% & & & & & & & & \\
\hline $\mathrm{CH} 4$ & 6.2 & 0 & 17.28 & 0 & 0 & 0 & 0 & 0 \\
\hline $\mathrm{CO}$ & 6.37 & 0 & 17.78 & 0 & 0 & 0 & 0 & 0 \\
\hline $\mathrm{CO} 2$ & 5.99 & 0 & 16.7 & 38.23 & 0 & 0 & 0 & 0 \\
\hline $\mathrm{H} 2$ & 80.18 & 100 & 44.73 & 0 & 0 & 0 & 0 & 0 \\
\hline $\mathrm{H} 2 \mathrm{O}$ & 0.23 & 0 & 0.63 & 59.04 & 100 & 100 & 100 & 100 \\
\hline $\mathrm{O} 2$ & 0 & 0 & 0 & 0.6 & 0 & 0 & 0 & 0 \\
\hline $\mathrm{N} 2$ & 1.03 & 0 & 2.88 & 2.13 & 0 & 0 & 0 & 0 \\
\hline $\mathrm{H} 2 \mathrm{~S}$ & 0 & 0 & 0 & 0 & 0 & 0 & 0 & 0 \\
\hline total & 100.00 & 100.00 & 100.00 & 100.00 & 100.00 & 100.00 & 100.00 & 100.00 \\
\hline molar flow, kgmole/hr & 2847 & 1826 & 1021 & 1383 & 5366 & 705 & 637 & 300 \\
\hline mass flow, $\mathrm{kg} / \mathrm{hr}$ & 20960 & 3682 & 17278 & 39033 & 96662 & 12700 & 11469 & 5340 \\
\hline pressure, atm & 50 & 50 & 1.7 & 1.6 & 87 & 87 & 51 & 51 \\
\hline temperature, C & 40 & 40 & 35 & 375 & 510 & 510 & 267 & 262 \\
\hline
\end{tabular}


Table B2. Major gas streams of Process B, low temperature membrane shift reactor

\begin{tabular}{|c|c|c|c|c|c|c|c|c|c|}
\hline stream number & 1 & 2 & 3 & 4 & 5 & 6 & 7 & 8 & 9 \\
\hline stream description & coal feed & $\begin{array}{l}\text { oxygen to } \\
\text { gasifier }\end{array}$ & $\begin{array}{l}\text { oxygen to } \\
\text { combustor }\end{array}$ & \begin{tabular}{|l} 
steam to \\
gasifier
\end{tabular} & $\begin{array}{l}\text { hot } \\
\text { syngas }\end{array}$ & $\begin{array}{l}\text { cooled } \\
\text { syngas }\end{array}$ & $\begin{array}{l}\text { syngas to } \\
\text { membran }\end{array}$ & $\begin{array}{l}\text { hydrogen } \\
\text { from mem }\end{array}$ & $\begin{array}{l}\text { syngas to } \\
\text { combustor }\end{array}$ \\
\hline \multicolumn{10}{|l|}{ stream composition, $\%$} \\
\hline $\mathrm{CH} 4$ & & & & & 4.13 & 4.13 & 3.54 & 0 & 6.28 \\
\hline $\mathrm{CO}$ & & & & & 29.72 & 29.72 & 25.44 & 0 & 4.29 \\
\hline $\mathrm{CO} 2$ & & & & & 14.55 & 14.55 & 12.46 & 0 & 62.95 \\
\hline $\mathrm{H} 2$ & & & & & 27.99 & 27.99 & 23.96 & 100 & 5.81 \\
\hline $\mathrm{H} 2 \mathrm{O}$ & & & & 100 & 22.06 & 22.06 & 34.01 & 0 & 19.62 \\
\hline $\mathrm{O} 2$ & & 97.5 & 97.5 & & 0 & 0 & 0 & 0 & 0 \\
\hline $\mathrm{N} 2$ & & 2.5 & 2.5 & & 0.69 & 0.69 & 0.59 & 0 & 1.05 \\
\hline $\mathrm{H} 2 \mathrm{~S}$ & & & & & 0.86 & 0.86 & 0 & 0 & 0 \\
\hline total & & & & & 100 & 100 & 100 & 100 & 100 \\
\hline molar flow, kgmole/hr & & 779 & 680 & 1377 & 4270 & 4270 & 115 & 0 & 2177 \\
\hline mass flow, kg/hr & 41667 & 24920 & 21760 & 24781 & 87170 & 86300 & 2066 & 0 & 4390 \\
\hline pressure, atm & 60 & 60 & 1.7 & 60 & 58 & 57 & 55 & 2 & 52 \\
\hline temperature, $\mathrm{C}$ & 25 & 30 & 30 & 276 & 1030 & 270 & 110 & 0 & 348 \\
\hline
\end{tabular}

\begin{tabular}{|c|c|c|c|c|c|c|c|c|}
\hline stream number & 10 & 11 & 12 & 13 & 14 & 15 & 16 & 17 \\
\hline stream description & $\begin{array}{l}\text { Cooled } \\
\text { hydrogen }\end{array}$ & $\begin{array}{l}\text { gas } \\
\text { turbine } \\
\text { inlet }\end{array}$ & $\begin{array}{l}\text { gas turbine } \\
\text { outlet }\end{array}$ & $\begin{array}{l}\text { steam } \\
\text { from } \\
\text { HRSG(1) }\end{array}$ & $\begin{array}{l}\text { steam } \\
\text { from } \\
\text { HRSG(3) }\end{array}$ & $\begin{array}{l}\text { steam to } \\
\text { shift from } \\
\text { HRSG(1) }\end{array}$ & $\begin{array}{l}\text { steam to } \\
\text { shift from } \\
\text { HRSG(2) }\end{array}$ & $\begin{array}{l}\text { compressed } \\
\text { hydrogen }\end{array}$ \\
\hline stream composition, \% & & & & & & & & \\
\hline $\mathrm{CH} 4$ & 0 & 0 & 0 & 0 & 0 & 0 & 0 & 0 \\
\hline $\mathrm{CO}$ & 0 & 0 & 0 & 0 & 0 & 0 & 0 & 0 \\
\hline $\mathrm{CO} 2$ & 0 & 65.22 & 65.22 & 0 & 0 & 0 & 0 & 0 \\
\hline $\mathrm{H} 2$ & 100 & 0 & 0 & 0 & 0 & 0 & 0 & 100 \\
\hline $\mathrm{H} 2 \mathrm{O}$ & 0 & 33.69 & 33.69 & 100 & 100 & 100 & 100 & 0 \\
\hline $\mathrm{O} 2$ & 0 & 0.16 & 0.16 & 0 & 0 & 0 & 0 & 0 \\
\hline $\mathrm{N} 2$ & 0 & 0.93 & 0.93 & 0 & 0 & 0 & 0 & 0 \\
\hline $\mathrm{H} 2 \mathrm{~S}$ & 0 & 0 & 0 & 0 & 0 & 0 & 0 & 0 \\
\hline total & 100 & 100 & 100 & 100 & 100 & 100 & 100 & 100 \\
\hline molar flow, kgmole/hr & 2177 & 3169 & 3169 & 706 & 2559 & 640 & 115 & 2177 \\
\hline mass flow, kg/hr & 4390 & 111171 & 111171 & 12723 & 46101 & 11526 & 2066 & 4390 \\
\hline pressure, atm & 1.8 & 52 & 1.4 & 87 & 87 & 57 & 57 & 50 \\
\hline temperature, C & 270 & 1053 & 573 & 510 & 510 & 277 & 277 & 40 \\
\hline
\end{tabular}


Table B3. Major gas streams of Process $C$, high temperature membrane shift reactor

\begin{tabular}{|c|c|c|c|c|c|c|c|c|}
\hline stream number & 1 & 2 & 3 & 4 & 5 & 6 & $\begin{array}{r}7 \\
\end{array}$ & 8 \\
\hline stream description & coal feed & $\begin{array}{l}\text { oxygen to } \\
\text { gasifier }\end{array}$ & $\begin{array}{l}\text { oxygen to } \\
\text { combustor }\end{array}$ & \begin{tabular}{|l} 
steam to \\
gasifier
\end{tabular} & $\begin{array}{l}\text { hot } \\
\text { syngas }\end{array}$ & $\begin{array}{l}\text { nonperme- } \\
\text { able syngas }\end{array}$ & \begin{tabular}{|l|} 
hydrogen \\
from HT mem
\end{tabular} & $\begin{array}{l}\text { cooled } \\
\text { syngas }\end{array}$ \\
\hline \multicolumn{9}{|l|}{ stream composition, \% } \\
\hline $\mathrm{CH} 4$ & & & & & 4.13 & 0.84 & 0 & 0.84 \\
\hline $\mathrm{CO}$ & & & & & 29.72 & 25.68 & 0 & 25.68 \\
\hline $\mathrm{CO} 2$ & & & & & 14.55 & 38.35 & 0 & 38.35 \\
\hline $\mathrm{H} 2$ & & & & & 27.99 & 5.35 & 100 & 5.35 \\
\hline $\mathrm{H} 2 \mathrm{O}$ & & & & 100 & 22.06 & 27.69 & 0 & 27.69 \\
\hline $\mathrm{O} 2$ & & 97.5 & 97.5 & & 0 & 0 & 0 & 0 \\
\hline $\mathrm{N} 2$ & & 2.5 & 2.5 & & 0.69 & 0.93 & 0 & 0.93 \\
\hline $\mathrm{H} 2 \mathrm{~S}$ & & & & & 0.86 & 1.16 & 0 & 1.16 \\
\hline total & & & & & 100 & 100 & 100 & 100 \\
\hline molar flow, kgmole/hr & & 779 & 550 & 1377 & 4270 & 3156 & 2070 & 3156 \\
\hline mass flow, kg/hr & 41667 & 24920 & 17600 & 24781 & 87170 & 94547 & 4173 & 94547 \\
\hline pressure, atm & 60 & 60 & 52 & 60 & 59 & 58 & 2 & 53 \\
\hline temperature, C & 25 & 30 & 30 & 276 & 1030 & 1030 & 1030 & 270 \\
\hline
\end{tabular}

\begin{tabular}{|c|c|c|c|c|c|c|c|c|}
\hline stream number & 9 & 10 & 11 & 12 & 13 & 14 & 15 & 16 \\
\hline stream description & $\begin{array}{l}\text { cooled } \\
\text { hydrogen }\end{array}$ & $\begin{array}{l}\text { syngas to } \\
\text { combustor }\end{array}$ & \begin{tabular}{|l|} 
gas turbine \\
inlet
\end{tabular} & $\begin{array}{l}\text { gas } \\
\text { turbine } \\
\text { outlet }\end{array}$ & $\begin{array}{l}\text { steam } \\
\text { from } \\
\text { HRSG(1) }\end{array}$ & $\begin{array}{l}\text { steam from } \\
\text { HRSG(2) }\end{array}$ & $\begin{array}{l}\text { steam to } \\
\text { membrane }\end{array}$ & $\begin{array}{l}\text { compressed } \\
\text { hydrogen }\end{array}$ \\
\hline \multicolumn{9}{|l|}{ stream composition, \% } \\
\hline $\mathrm{CH} 4$ & 0 & 0.85 & 0 & 0 & 0 & 0 & 0 & 0 \\
\hline $\mathrm{CO}$ & 0 & 25.98 & 0 & 0 & 0 & 0 & 0 & 0 \\
\hline $\mathrm{CO} 2$ & 0 & 38.8 & 64.39 & 64.39 & 0 & 0 & 0 & 0 \\
\hline $\mathrm{H} 2$ & 100 & 5.41 & 0 & 0 & 0 & 0 & 0 & 100 \\
\hline $\mathrm{H} 2 \mathrm{O}$ & 0 & 28.02 & 34.46 & 34.46 & 100 & 100 & 100 & 0 \\
\hline $\mathrm{O} 2$ & 0 & 0 & 0.23 & 0.23 & 0 & 0 & 0 & 0 \\
\hline N2 & 0 & 0.94 & 0.92 & 0.92 & 0 & 0 & 0 & 0 \\
\hline $\mathrm{H} 2 \mathrm{~S}$ & 0 & 0 & 0 & 0 & 0 & 0 & 0 & 0 \\
\hline total & 100 & 100 & 100 & 100 & 100 & 100 & 100 & 100 \\
\hline molar flow, kgmole/hr & 2070 & 3119 & 3180 & 3180 & 1256 & 4060 & 642 & 2070 \\
\hline mass flow, kg/hr & 4173 & 93299 & 110898 & 110898 & 22624 & 73140 & 11550 & 4173 \\
\hline pressure, atm & 2 & 52 & 52 & 1.4 & 87.5 & 87.5 & 60 & 50 \\
\hline temperature, $\mathrm{C}$ & 262 & 190 & 911 & 469 & 510 & 510 & 277 & 40 \\
\hline
\end{tabular}


Table B4. Major gas streams of Process D, with a high temperature and a low temperature membrane reactors

\begin{tabular}{|c|c|c|c|c|c|c|c|c|c|c|}
\hline stream number & 1 & 2 & 3 & 4 & 5 & 6 & 7 & 8 & 9 & 10 \\
\hline stream description & coal feed & $\begin{array}{l}\text { oxygen to } \\
\text { gasifier }\end{array}$ & $\begin{array}{l}\text { oxygen to } \\
\text { combustor }\end{array}$ & $\begin{array}{l}\text { steam to } \\
\text { gasifier }\end{array}$ & \begin{tabular}{|l} 
hot \\
syngas
\end{tabular} & $\begin{array}{l}\text { nonperme- } \\
\text { able syngas }\end{array}$ & $\begin{array}{l}\text { hydrogen } \\
\text { from HT mem }\end{array}$ & $\begin{array}{l}\text { cooled } \\
\text { syngas }\end{array}$ & $\begin{array}{l}\text { syngas to LT } \\
\text { membrane }\end{array}$ & $\begin{array}{l}\text { hydrogen } \\
\text { from LT mem }\end{array}$ \\
\hline \multicolumn{11}{|l|}{ stream composition, \% } \\
\hline $\mathrm{CH} 4$ & & & & & 4.13 & 0.71 & 0 & 0.71 & 0.56 & 0.00 \\
\hline $\mathrm{CO}$ & & & & & 29.72 & 38.27 & 0 & 38.27 & 30.24 & 0.00 \\
\hline $\mathrm{CO} 2$ & & & & & 14.55 & 38.76 & 0 & 38.76 & 30.63 & 0.00 \\
\hline $\mathrm{H} 2$ & & & & & 27.99 & 3.74 & 100 & 3.74 & 2.96 & 100.00 \\
\hline $\mathrm{H} 2 \mathrm{O}$ & & & & 100 & 22.06 & 16.05 & 0 & 16.05 & 34.74 & 0.00 \\
\hline $\mathrm{O} 2$ & & 97.5 & 97.5 & & 0 & 0 & 0 & 0 & 0 & 0.00 \\
\hline N2 & & 2.5 & 2.5 & & 0.69 & 1.1 & 0 & 1.1 & 0.87 & 0.00 \\
\hline $\mathrm{H} 2 \mathrm{~S}$ & & & & & 0.86 & 1.37 & 0 & 1.37 & 0 & 0.00 \\
\hline total & & & & & 100 & 100 & 100 & 100 & 100 & 100.00 \\
\hline molar flow, kgmole/hr & & 779 & 150 & 1377 & 4270 & 2630 & 1975 & 2630 & 3328 & 921.00 \\
\hline mass flow, $\mathrm{kg} / \mathrm{hr}$ & 41667 & 24920 & 4800 & 24781 & 87170 & 83188 & 3982 & 83188 & 95180 & 1857.00 \\
\hline pressure, atm & 60 & 60 & 1.7 & 60 & 59 & 58 & 2 & 54 & 53 & 2 \\
\hline temperature, C & 25 & 30 & 30 & 276 & 1030 & 1030 & 1030 & 270 & 203 & 348 \\
\hline
\end{tabular}

\begin{tabular}{|c|c|c|c|c|c|c|c|c|c|}
\hline stream number & 11 & 12 & 13 & 14 & 15 & 16 & 17 & 18 & 19 \\
\hline stream description & $\begin{array}{l}\text { hydrogen } \\
\text { from } \\
\text { HRSG(1) }\end{array}$ & $\begin{array}{l}\text { syngas to } \\
\text { combustor }\end{array}$ & \begin{tabular}{|l} 
gas \\
turbine \\
inlet
\end{tabular} & \begin{tabular}{|l} 
gas \\
turbine \\
outlet
\end{tabular} & $\begin{array}{l}\text { steam to } \\
\text { turbine } \\
\text { from } \\
\text { HRSG(1) }\end{array}$ & $\begin{array}{l}\text { steam to } \\
\text { shift from } \\
\text { HRSG(3) }\end{array}$ & $\begin{array}{l}\text { steam to shift } \\
\text { from } \\
\text { HRSG(1) }\end{array}$ & $\begin{array}{l}\text { steam to } \\
\text { shift from } \\
\text { HRSG(2) }\end{array}$ & $\begin{array}{l}\text { compressed } \\
\text { hydrogen }\end{array}$ \\
\hline \multicolumn{10}{|l|}{ stream composition, $\%$} \\
\hline $\mathrm{CH} 4$ & 0 & 0.78 & 0 & 0 & 0 & 0 & 0 & 0 & 0 \\
\hline $\mathrm{CO}$ & 0 & 4.75 & 0 & 0 & 0 & 0 & 0 & 0 & 0 \\
\hline $\mathrm{CO} 2$ & 0 & 79.44 & 82.96 & 82.96 & 0 & 0 & 0 & 0 & 0 \\
\hline $\mathrm{H} 2$ & 100 & 2.87 & 0.00 & 0.00 & 0 & 0 & 0 & 0 & 100 \\
\hline $\mathrm{H} 2 \mathrm{O}$ & 0 & 10.96 & 15.02 & 15.02 & 100 & 100 & 100 & 100 & 0 \\
\hline $\mathrm{O} 2$ & 0 & 0.00 & 0.85 & 0.85 & 0 & 0 & 0 & 0 & 0 \\
\hline N2 & 0 & 1.20 & 1.17 & 1.17 & 0 & 0 & 0 & 0 & 0 \\
\hline $\mathrm{H} 2 \mathrm{~S}$ & 0 & 0 & 0 & 0 & 0 & 0 & 0 & 0 & 0 \\
\hline total & 100 & 100 & 100 & 100 & 100 & 100 & 100 & 100 & 100 \\
\hline molar flow, kgmole/hr & 1975 & 2406 & 2464 & 2464 & 1779 & 451 & 283 & 48 & 2896 \\
\hline mass flow, $\mathrm{kg} / \mathrm{hr}$ & 3982 & 93317 & 98117 & 98117 & 32043 & 8120 & 5101 & 866 & 5839 \\
\hline pressure, atm & 1.8 & 52 & 51.8 & 1.4 & 87.5 & 57 & 57 & 57 & 50 \\
\hline temperature, $\mathrm{C}$ & 260 & 349 & 853 & 445 & 510 & 277 & 275 & 275 & 40 \\
\hline
\end{tabular}

